\title{
Marine Cyanobacteria and Microalgae Metabolites-A Rich Source of Potential Anticancer Drugs
}

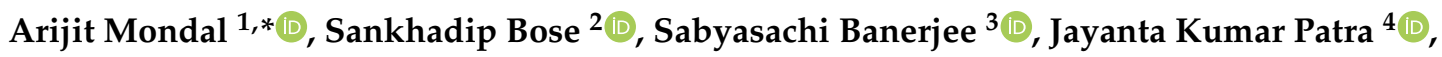 \\ Jai Malik ${ }^{5}{ }^{\circledR}$, Sudip Kumar Mandal ${ }^{6}$, Kaitlyn L. Kilpatrick ${ }^{7}$, Gitishree Das ${ }^{4}$, \\ Rout George Kerry ${ }^{8}\left(\right.$ ) , Carmela Fimognari ${ }^{9, *}$ (D) and Anupam Bishayee $7, *($ i) \\ 1 Department of Pharmaceutical Chemistry, Bengal College of Pharmaceutical Technology, Dubrajpur 731 123, \\ West Bengal, India \\ 2 Department of Pharmacognosy, Bengal School of Technology, Chuchura 712 102, West Bengal, India; \\ sankha.bose@gmail.com \\ 3 Department of Phytochemistry, Gupta College of Technological Sciences, Asansol 713 301, West Bengal, \\ India; sabyasachibanerjee04@gmail.com \\ 4 Research Institute of Biotechnology and Medical Converged Science, Dongguk University-Seoul, \\ Goyang-si 10326, Korea; jkpatra.cet@gmail.com (J.K.P.); gitishreedas@gmail.com (G.D.) \\ 5 Centre of Advanced Study, University Institute of Pharmaceutical Sciences, Punjab University, \\ Chandigarh 160 014, Punjab, India; jmalik_pu@hotmail.com \\ 6 Department of Pharmaceutical Chemistry, Dr. B.C. Roy College of Pharmacy and Allied Health Sciences, \\ Durgapur 713 206, West Bengal, India; gotosudip79@gmail.com \\ 7 Lake Erie College of Osteopathic Medicine, Bradenton, FL 34211, USA; kilpatrickkaitlyn@gmail.com \\ 8 Post Graduate Department of Biotechnology, Utkal University, Bhubaneswar 751 004, Odisha, India; \\ routgeorgekerry3@gmail.com \\ 9 Department for Life Quality Studies, Alma Mater Studiorum-Università di Bologna, 47921 Rimini, Italy \\ * Correspondence: juarijitmondal@gmail.com (A.M.); carmela.fimognari@unibo.it (C.F.); \\ abishayee@lecom.edu or abishayee@gmail.com (A.B.); Tel.: +91-967-412-4916 (A.M.); +39-0541-434658 (C.F.); \\ $+1-941-782-5729$ (A.B.)
}

Received: 25 July 2020; Accepted: 16 September 2020; Published: 19 September 2020

check for updates

\begin{abstract}
Cancer is at present one of the utmost deadly diseases worldwide. Past efforts in cancer research have focused on natural medicinal products. Over the past decades, a great deal of initiatives was invested towards isolating and identifying new marine metabolites via pharmaceutical companies, and research institutions in general. Secondary marine metabolites are looked at as a favorable source of potentially new pharmaceutically active compounds, having a vast structural diversity and diverse biological activities; therefore, this is an astonishing source of potentially new anticancer therapy. This review contains an extensive critical discussion on the potential of marine microbial compounds and marine microalgae metabolites as anticancer drugs, highlighting their chemical structure and exploring the underlying mechanisms of action. Current limitation, challenges, and future research pathways were also presented.
\end{abstract}

Keywords: marine; microbes; microalgae; cancer; prevention; therapy; in vitro; in vivo; clinical studies

\section{Introduction}

According to a World Health Organization (WHO) report, by 2030 there will be 21 million new cases of cancer and 13 million deaths due to this disease [1]. Currently, 13\% of all deaths worldwide are induced by cancer, and it is estimated that $30 \%$ of such deaths can be avoided by 
modifying or preventing the major risk factors, such as tobacco smoking, radiation exposure, alcohol, and infections [2]. Nearly all anticancer medications currently on the market have serious adverse effects, and therefore, new and safer anticancer drugs are desirable. Although there has been a decline in the interest of the pharma industry in natural products in the recent past, they are still the best platform for providing novel, effective, and unique chemical structures that may have considerable potential to treat or prevent cancer or serve as scaffolds or lead molecules for more effective anticancer drugs. From 1981 to 2010, approximately 1355 drugs were approved for therapeutic application, and among these, 128 were anticancer drugs with approximately $35 \%$ of them from either natural products or compounds extracted from natural products [3].

More than $70 \%$ of medicinal products for clinical use are derived from natural products, and this also extends into cancer chemotherapy, in which natural products make up most of the current chemotherapy medications [4]. Nature remains a rich resource of bioactive and varied chemotypes, and while comparatively very few of the extracted natural products are developed into clinically useful drugs by themselves, these specific molecules also act as preparatory models for more efficacious analogues and prodrugs through the implementation of chemical methodology. The main priority of natural products for the identification and development of new anticarcinogenic pharmaceutical drugs and the value of cross-disciplinary collaboration in the extraction of novel molecular functionalities from natural product resources have been extensively investigated [5].

However, the ocean holds a broad reservoir of marine species full of natural pharmaceutical components of potential significance. Marine bioprospecting is a recent phenomenon; thus, aquatic life is a largely unexplored field of research [6-9]. Terrestrial life is the source of most pharmaceutically effective natural products [10]. For centuries, marine flora has been exploited for their potential medicinal applications throughout the world [11]. Among the marine organisms, bacteria, fungi, actinobacteria, seaweeds, and sponges have been utilized for cancer treatment [12-16].The most effective anti-cancer drugs are natural products. However, the natural product research and innovation phases are expensive, tedious, and time-consuming [17,18].

Few marine pharmaceutical products for marketing have been licensed and some molecules are being clinically trialed within Phases I and III, along with preclinical studies. It is notable that among the scientifically developed marine compounds, four compounds are used in cancer treatment, such as cytarabine (Cytosar), trabectedin (Yondelis), eribulin mesylate (Halaven) and the conjugated antibody brentuximab vedotin (Acentris).

The dynamic and extremely sensitive global marine ecosystem covers about 70.8\% of Earth [19]. This extreme biodiversity encompasses a heterogeneous array of micro- and macro-organisms. Among them, microorganisms like marine bacteria, fungi, and micro-algae orchestrate a pivotal role in restoring the balance within the aquatic environment by being both a producer and decomposer [20]. Marine microalgae are essential ecologically which are used as food and medicinal products from ancient times. Marine microalgae are eukaryotic plants that contribute to drug discovery by their metabolicplasticity, which can trigger the production of several compounds with possible applications in combating various diseases, such as cancer [21]. Presently, these aquatic species have gained increasing acclaim for their bioactive metabolites, which provides an unparalleled potential for a range of pharmaceutical activity. The distribution of marine species differs depending on the type of open sea ecosystem, such as pelagic environment, epipelagic environment, mesopelagic zone, bathypelagic zone, abyssopelagic zone, and benthic environment. These diversified divisions of the aquatic world harbors heterogeneous species of marine microflora and microalgae. Therefore, summing all the types of microflora and microalgae, and their extracted bioactive chemical metabolites, would be too tedious to elaborate in a single article. Thus, only certain specific microflora including bacteria, fungus, and microalgae (cyanobacteria), along with their potent bioactive metabolites displaying anticancer activity are emphasized. The most common bioactive compounds having anticancer activity from these marine sources are alkaloids (staurosporine, ambigols, amycolactam, and marinoquinoline A), polyketides (chromone, engyodontiumones $\mathrm{H}$, pestalpolyol I, hytidchromone A, B, C, and E), 
terpenes (meroterpenes, diterpene, and scopararane I), peptides (beauvericin, polymyxin B and other non-ribosomal peptides), nucleosides (cytarabine, gemcitabine and other nucleoside analogues) and carbohydrates (laminaran, alginic acid, and other sulfated polysaccarides) [22-24].

Microflora and, up to certain extent, microalgae could be regarded as chief drivers of nutrient transformations in a marine ecosystem. Shift in abiotic factors of marine ecosystem, such as temperature, salinity, nutrients, oxygen, solar energy, water clarity, tides, waves, aerial exposure and current has immensely influenced the production and secretion of marine metabolites/ bioactive chemical compounds from these organisms. To survive under these harsh abiotic factors, the marine microflora tends to form a symbiotic relationship with other marine microorganisms. These synergetic relationships enable them to endure and secrete a number of exotic secondary metabolites/bioactive compounds which they would not do under natural circumstances [25]. Over the last two decades, natural product research has observed a paradigm shift from terrestrial areas to oceans. Approximately 15,000 marine-origin metabolites, which have demonstrated cytotoxicity in cancer models, have been identified during the past three decades and from these, 28 agents are under clinical trials for their anticancer properties [26]. There is myriad of structural motifs undiscovered from the marine ecosystem and these metabolites can serve as new potent anticancer agents.

There are only a few previous reviews that present an in-depth overview of this important field of research. Many of the preceding publications focus exclusively on the compilation of marine secondary metabolites for study on natural products [27-31]. This review looks at the pharmacology of marine species with respect to anticancer drug molecules which have shown significant bioactivity to become drug or is in queue to enter clinical trials. The data procured covers published preclinical study, research papers and review of marine molecules isolated from a diverse group of marine algae, and cyanobacteria. This review evaluates the anticancer effects of numerous marine cyanobacterium and microalgae secondary metabolites, emphasizing on their chemical structures and highlighting the mechanisms of action that underlie their pharmacological activities.

\section{Literature Search Methodology}

In vitro, in vivo and clinical research investigating the anticancer potential of secondary secreted metabolites of marine species by modulating various pathways were screened utilizing credible repositories which include PubMed, ScienceDirect, Web of Science, SpringerLink, Scopus, and Google Scholar. Comprehensive papers released in peer-reviewed publications up to April 2020 have been included. There was no time restrainst on publication year. Only publications written in English have been listed and used in this article. The exclusion criteria for not setecting articles included non-English language publications, letters to editors, conference abstracts, and unpublisged reports. The keywords included within the literature quest are cancer, tumor, proliferation, cytotoxicity, apoptosis, marine, microbes, microalgae, cyanobacteria, prevention, therapy, In vitro, in vivo, and clinical trials. The bibliography of selected primary literature was also searched for additional relevant papers.

\section{Various Classes of Secondary Metabolites of Marine Cyanobacterium and Microalgae}

\subsection{Alkaloids}

Alkaloids are naturally occurring/synthetic organic compounds collectively used to describe the diverse groups of heterocyclic compounds having alkali-like properties and having at least one single nitrogen atom within its structure [32,33]. Presently, these nitrogen atoms containing heterocyclic compounds could be classified based on the basis of carbon skeleton resemblance contained in biochemical precursors such as ornithine, lysine, tyrosine, and tryptophan, having either indole and isoquinoline, or pyridine moieties [34]. Marine alkaloids could also be grouped into indoles, halogenated indoles, and phenylethylamines [35]. Marinoquinoline A is an anticancer alkaloid produced by Catalinimonas alkaloidigena, a marine bacterium [36] along with 13 other alkaloid metabolites. Pseudoalteromonas tunicata and P. citrea are two marine bacteria that secrete a 
yellow-pigmented alkaloid that belongs to a group called tambjamines, and this showed anti-tumor activity along with antimicrobial, antifungal, and antimalarial activity [37,38]. Calothrixins A and $\mathrm{B}$ are alkaloids containing a phenanthridine moiety that are isolated from Calothrix sp. Both the alkaloids showed significant cytotoxicity to human cervical carcinoma cells (HeLa) [39]. Demay et al. [40] have comprehensively reviewed a variety of bioactive metabolites of cyanobacteria, such as Hapalosiphon fontinalis, Fischerella musicola, F. ambigua, H. welwitschii, and Westiella intricate, as among which hapalindole-like alkaloid, and ambigols, possess cytotoxic activity.

\subsection{Polyketides}

Polyketides are a broad group of compounds which are biosynthesized as analogs generated by a sequence of modular enzymes act as biocatalysts from precursors which contain alternating carbonyl and methylene groups(-CO- $\left.\mathrm{CH}_{2}-\right)$ [41]. Then the compound undergoes decarboxylative condensation and modification of the acetate or the propionate chains primarily by reduction reaction, dehydration reaction, cyclization reaction, and aromatization reactions. Streptomyces koyangensis, a marine bacterium that produces two abyssomicins which have antitumor activity, but in-depth investigation is scanty [42]. Extracts of marine cyanobacteria like Nostoc spongiaeforme and N. linckia, contained a polyketide called borophycin that showed the strong anticancerous effect against human colon carcinoma cell lines (LoVo) [43].

\subsection{Terpenes}

Terpenes are the hydrocarbon compounds formed from 5-carbon isoprene units assembled to generate a vast range of skeletons, which are used by various enzymes to conjugate functionality and alter oxidation. These cyclic molecules can be categorized as monoterpenes, diterpenes, triterpenes (steroids), tetraterpenes (carotenoids), sesquiterpenes, and sesterterpenes based on the isoprene units it contains [44]. Presently it is acknowledged that marine microflora is an excellent source of these terpenes, and among which few terpenes exhibited their anticancer activity apart from other biological properties [22].

\subsection{Peptides}

Peptides are the definite protein fragments which provide optimistic impacts on human health [41-45]. Peptides are usually inert within the parent protein chain and may exhibit several physiological tasks upon proteolysis $[46,47]$. Enzymatic hydrolysis has played a significant role in the synthesis of peptide compounds in marine species $[48,49]$. Numerous prospective reports were documented about the utilization of marine peptides for pharmaceutical developments, including antitumor properties [50,51]. Cyclic and linear peptides have been established as potentially effective cytotoxic agents. These peptides possess cytotoxic, antimicrobial, specific ion channel-blocking, and other pharmacological activities with innovative chemical structures correlated with the actual mode of action [50].

A new peptide, polydiscamide A, and its analogs possess anti-tumor activity [50]. A certain number of marine peptides were successfully evaluated through clinical research and have now been available as formulated drugs in the market under various trade names.

A cyclic depsipeptide known as Apratoxin A exhibited effective cytotoxic potential against the human cervical carcinoma cells (HeLa) by triggering cell cycle arrest [52]. Peptides extracted from Lyngbya sp. and Nostoc sp., were reported to possess promising anticancer activity by the disruption of microfilaments, inhibition of secretory pathways, and influencing other intracellular pathways [26].

\subsection{Nucleosides}

Nucleosides belong to a class of organic compounds and are commonly known as the nitrogen glycosides of purines and pyrimidines; with their phosphate esters, they are called nucleotides $[53,54]$. These are the important constituents of all living cells and are associated with various fundamental 
physiological processes [53,54]. Marine microbes are skilled at manufacturing different nucleosides forms with unfamiliar structures and associated biological properties [53-57]. A few of these nucleosides with substantial pharmacological activities have been documented [56-58]. The potent biological properties of marine-derived nucleosides have stimulated the production of some analogs [59-61]. Marine nucleosides themselves have exhibited numerous bioactive potentials including the anticancer, antiviral, muscle relaxant, hypertensive and vasodilator activities [54].

\subsection{Carbohydrates}

Carbohydrates form the major component of aquatic organisms and are considered the significant food source of these organisms, particularly algae [62]. These compounds vary extremely in their molecular structure and resemble a pool of sulfated polysaccharides manufactured fixation of sulfur and carbon by the photosynthetic organisms [62]. Carbohydrates are classified by source in three groups: plant polysaccharides [63], animal polysaccharides [64], and microbial polysaccharides [65], which include both neutral and negatively charged saccharides with varying size [24]. Examples include either the nitrogen-linked or oxygen-linked oligosaccharides in glycoproteins, glycosaminoglycan in proteoglycans, glycolipids, sulfated fucans, and sulfated galactans [24,66]. However, their chemical compositions and arrangements are complex and heterogeneous in nature [67].

Marine carbohydrates are produced by a specific enzymatic hydrolysis process of polysaccharides [67]. The enzymatic breakdown of the sulfated polysaccharides involves a set of enzymes that can cleave the glycosidic bond and eliminate the sulfate groups from the carbohydrate backbone [62]. These marine-derived carbohydrates, including alginic acid, agar, carrageenan, chitin, cellulose, chitosan, fucan, glucan, glucosamine glycan, and laminaran; these possesses a wide number of substantial bioactive properties which includes the anticancer potentials $[11,67,68]$. These carbohydrate-based compounds exhibited anticancer effects against a number of carcinoma cells by modulating the innate immune system, which triggered the chemotactic response of macrophages and natural killer cells to the target location and have them produce their tumoricidal cytokines [12]. Fucoidan is a sulfated polysaccharide present as a metabolite in the brown algae cell wall and has been shown to inhibit atherosclerosis, angiogenesis, and metastasis [69] in the human lymphoma cell line (HS-Sultan) by subsequent activation of caspase-3, and downregulating kinase activity [12,70].

\section{Secondary Metabolites of Marine Cyanobacteria and Microalgae at Various Phases of Clinical Research}

Certain anticancer compounds from marine cyanobacteria and microalgae are currently undergoing clinical trials [12,22]. These natural bioactive compounds exhibited anticancer activity by regulating macromolecule expression induced in cancer cells via oncogenic signal transduction pathways [71].

Fewer than $10 \%$ of marine pharmacologically active compounds have been tested against diverse cancer types [60]. For example, the compounds dolastatin 10, ET-743, and bryostatin 1 are tested and analyzed in clinical research [12]. A variety of dolastatins and associated molecules were extracted from filamentous cyanobacteria of the genera Symploca and Lyngbya [72].These are small oligopeptides containing four unique non-protein amino acids-dolaphenine, dolaproline, dolaisoleucine, and dolavaline. Dolastatin 10 is a linear peptide while dolastatin 15 is a seven-unit depsipeptide agent, and both are potent cytostatic peptides that arrest cell division [59]. This was proven by studies that showed that dolastatins, especially dolastatin 10, attached to tubulin at the guanosine triphosphate position, leading to the disruption of its normal function and triggering metaphase cell cycle arrest [73]. Dolastatin 10 reached Phase I of clinical research in 1990s and has advanced to Phase II of clinical research [74]. However, because it developed peripheral neuropathy in over $40 \%$ of patients, it was discontinued [74]. Even so, it was the basis for more efficient derivatives to come into existence. One of its derivatives, the monoclonal antibody-drug conjugate Brentuximab vedotin (Adcetris) has been licensed for its anticancer activity against Hodgkin's lymphoma [75]. 
Various other derivatives as antibody-drug conjugates (Polatuzumab vedotin, Depatuxizumab vedotin) are under Phase III of clinical research; Enfortumab vedotin, Glembatumumab vedotin, Tisotumab vedotin, and others are under Phase II of clinical trials, whereas ABBV-085, ASG-15ME, and AGS-67E are under Phase I of clinical research for different types of cancers (www.clinicaltrials.gov). Soblidotin (TZT-1027) is a synthetic analog of dolastatin 10 that is more potent against cancer than its parent compound and other established anticancer medications such as podophyllotoxin and vincristine [76]. In addition to inhibiting tubulin function, TZT-1027, a vascular disrupting agent, causes a collapse in the vasculature of the tumor, causing cell death [77]. After completing Phase I and II trials, TZT-1027 is in the Phase III of clinical research under Aska Pharmaceuticals [78].

Synthadotin (ILX-651) is a synthetic pentapeptide derivative of dolastatin 15, is a potent antitumor agent in patients having metastatic melanoma in advanced stage [75]. It has been shown to inhibit microtubule nucleation [79]. Other dolastatins showed cardiovascular toxicity, but ILX-651 has not exhibited such toxicity [79]. It has successfully completed both Phase I and Phase II of clinical research and was found to be well tolerated and completely safe [80]. Another compound, bryostatin 1, has successfully completed Phase II of clinical research for the treatment of melanoma, non-Hodgkin's lymphoma, renal cancer, and colorectal cancer [12]. The marine bioactive compounds play a significant major role in the discovery of anticancer drugs, and these are classified as the antimigration, antimetastatic, anti-invasion, antitubulin agents and growth inhibitors, apoptosis inducers, autophagy, and antiangiogenic agents [22]. Also, because of their importance in signal transduction pathways, an additional family that includes proliferation inhibitors of mitogen-activated protein kinases have also been incorporated [22].

Salinosporamide Ais a cytotoxic bicyclic $\beta$-lactone- $\gamma$-lactam isolated from the Salinispora tropica, amarine actinobacterium [81]. It is an inhibitor of proteasome where the halogenation in its side chain containing ethyl functional group helps to irreversibly bind the 20S proteasome [81]. By binding to this enzyme, salinosporamide A triggers apoptosis of cancer cells [82]. Phase I and Phase II clinical research have been successfully completed for the treatment of solid tumors lymphoma and multiple myeloma [83]. The finding of the Phase 1 trial demonstrated good anticancer activity among multiple myeloma patients, with decent health and a non-cross-reactive toxicity profile [83]. Salinosporamide A did not induce peripheral neuropathy, thrombocytopenia, or myelosuppression, which were observed with other proteasome inhibitors [83]. Similarly, Phase II findings showed enhanced therapeutic function and increased duration of the inhibition of the proteasome [75]. Both the United States Food and Drug Administration (US-FDA) and European Medicines Agency (EMA) declared it to be an orphan medicine targeting multiple myeloma [75]. At present salinosporamide is undergoing Phase III studies for newly diagnosed cases of glioblastoma [75].

\section{Marine Cyanobacteria Metabolites with Anticancer Property}

Owing to their extraordinary abundance, marine cyanobacteria have drawn tremendous interest within the marine ecosystem. Some of the anticancer agents from marine cyanobacteria as shown in Table 1 are discussed below. 
Table 1. Anticancer effects and mechanisms of action of various secondary metabolites of marine cyanobacteria.

\begin{tabular}{|c|c|c|c|c|c|c|}
\hline Class & $\begin{array}{l}\text { Secondary } \\
\text { Metabolite }\end{array}$ & Biological Source & Cell Lines Used & Effects and Mechanisms & $\mathrm{IC}_{50}$ Values & References \\
\hline Anthracycline & Komodoquinone A(1) & Streptomyces sp. KS3 & Neuro 2A neuroblastoma cell & $\begin{array}{c}\text { Neuritogenic activity, } \uparrow \text { cell } \\
\text { differentiation }\end{array}$ & $1 \mu \mathrm{g} / \mathrm{mL}$ & [84] \\
\hline Phenoxazin-3-one & $\begin{array}{l}\text { Chandrananimycins } \\
\text { A, B, C (2,3,4) }\end{array}$ & Actinomadura sp. & $\begin{array}{l}\text { CCL HT29 (colon cancer); } \\
\text { MEXF 514L (melanoma); } \\
\text { LXFA 526L, LXFL 529L (lung } \\
\text { cancer); CNCL SF268, LCL } \\
\text { H460, MACL MCF-7 (breast } \\
\text { cancer); PRCL PC3M, RXF } \\
\text { 631L (kidney tumor cells) }\end{array}$ & Anti-tumor activity & $\sim 1.4 \mu \mathrm{g} / \mathrm{mL}$ & [85] \\
\hline $\begin{array}{l}\text { Glycosilated } \\
\text { polyketide }\end{array}$ & Ankaraholide A (5) & Geitlerinema sp. & $\begin{array}{l}\text { NCI-H460; Neuro-2a; } \\
\text { MDAMB- } \\
435 \text { cell lines }\end{array}$ & $\begin{array}{c}\perp \text { Proliferation; } \\
\uparrow \text { cytotoxicity }\end{array}$ & $119 ; 262 ; 8.9 \mathrm{nM}$ & [86] \\
\hline Polyketide & Swinholide A (6) & Symploca cf. sp. & Several cancer cell lines & $\begin{array}{l}\text { Antitumor activity; } \\
\perp \text { proliferation; } \\
\uparrow \text { cytotoxicity; } \\
\text { disruption of the actin } \\
\text { cytoskeleton }\end{array}$ & $0.37 \mathrm{nM}-1.0 \mu \mathrm{M}$ & [86] \\
\hline Pentapeptide & Symplostatin 1 (7) & Symploca hydnoides & $\begin{array}{l}\text { MDA-MB-435 (breast cancer } \\
\text { cell), SK-OV-3 (ovarian } \\
\text { cancer cell), NCI/ADR } \\
\text { (multidrug-resistance } \\
\text { ovarian cancer cell), A-10 } \\
\text { (smooth muscle cells), and } \\
\text { HUVEC (Human umbilical } \\
\text { vein endothelial cells); } \\
\text { in vivo study (murine colon } \\
38 \text { and murine mammary } \\
\text { 16/C carcinoma cells) }\end{array}$ & $\begin{array}{c}\text { Antitumor activity; } \\
\uparrow \text { phosphorylation of Bcl-2; } \\
\uparrow \text { micronuclei formation, } \\
\uparrow \text { caspase } 3, \uparrow \text { apoptosis, cell } \\
\text { cycle arrest at G2/M Phase, } \\
\perp_{\text {tubulin accumulation }}\end{array}$ & $\begin{array}{l}0.15 \pm 0.03 \mathrm{nM} \\
0.09 \pm 0.02 \mathrm{nM} \\
2.90 \pm 0.64 \mathrm{nM} \\
1.8 \pm 0.43 \mathrm{nM} \\
0.16 \pm 0.02 \mathrm{nM}\end{array}$ & {$[72,87]$} \\
\hline
\end{tabular}


Table 1. Cont

\begin{tabular}{|c|c|c|c|c|c|c|}
\hline Class & $\begin{array}{l}\text { Secondary } \\
\text { Metabolite }\end{array}$ & Biological Source & Cell Lines Used & Effects and Mechanisms & $\mathrm{IC}_{50}$ Values & References \\
\hline $\begin{array}{l}\text { Macrocyclic } \\
\text { depsipeptide }\end{array}$ & $\begin{array}{c}\text { Grassypeptolide, } \\
\text { Grassypeptolide A, B } \\
\text { and } C(\mathbf{8}, \mathbf{9}, \mathbf{1 0})\end{array}$ & Lyngbya confervoides & $\begin{array}{c}\text { human osteosarcoma (U2OS), } \\
\text { cervical carcinoma (HeLa), } \\
\text { colorectal adenocarcinoma } \\
\text { (HT29), and neuroblastoma } \\
\text { (IMR-32); }\end{array}$ & $\begin{array}{c}\text { Anticancer activity; } \\
\perp \text { proliferation; Cell cycle } \\
\text { arrest at G1 or G2/M Phase }\end{array}$ & $\begin{array}{c}1-4.2 \mu \mathrm{M} \text { for } \\
\text { grassypeptolide in all } \\
\text { cell lines. } \\
\text { Grassypeptolide A: } \\
1.22 \& 1.01 \mu \mathrm{M} \text { in } \\
\text { HT2 } 2 \text { and Hela. } \\
\text { Grassypeptolide B: } \\
4.07 \text { and } 2.93 \mu \mathrm{M} \text { in } \\
\text { HT29 and Hela. } \\
\text { Grassypeptolide C: } \\
76.7 \text { and } 44.6 \mathrm{nM} \\
\text { HT29 and Hela. }\end{array}$ & {$[88,89]$} \\
\hline ketopeptide & Curacin A (11) & Lyngbya majuscule & $\begin{array}{l}\text { Non-small cell lung cancer } \\
\text { cell line (A549) }\end{array}$ & $\begin{array}{c}\text { Anticancer activity; } \\
{ }^{\perp} \text { proliferation; } \uparrow \text { apoptosis; } \\
\text { cell cycle arrest at G2/M } \\
\text { Phase; binds to tubulin at } \\
\text { colchicines binding site }\end{array}$ & $0.72 \pm 0.02 \mu \mathrm{M}$ & [90-95] \\
\hline Linear peptide & Tasiamide B (12) & Symploca sp. & $\begin{array}{l}\text { kB oral epidermoid cancer; } \\
\text { human colon carcinoma } \\
\text { (LoVo) cells }\end{array}$ & $\begin{array}{l}\perp_{\text {Proliferation; }} \\
\uparrow \text { cytotoxicity }\end{array}$ & $0.48 ; 3.47 \mu \mathrm{g} / \mathrm{mL}$ & [96] \\
\hline \multirow{4}{*}{ Cyclic depsipeptide } & Apratoxin A (13) & Lyngbya majuscula & $\begin{array}{l}\text { U2OS osteosarcoma; } \\
\text { HeLa cervical carcinoma; in } \\
\text { LoVo colon carcinoma; } \mathrm{kB} \\
\text { carcinoma cancer cells }\end{array}$ & $\begin{array}{c}{ }^{\perp} \text { Secretory pathway; }{ }^{\perp} \text { cell } \\
\text { cycle at G1 Phase; } \\
\uparrow \text { cytotoxicity; } \\
{ }^{\perp} \text { translocation of protein } \\
\text { targeting Sec61 } \alpha\end{array}$ & $50 ; 2.2 ; 0.36 ; 0.52 \mathrm{nM}$ & {$[97,98]$} \\
\hline & Apratoxin B (14) & Lyngbya sp. & $\begin{array}{l}\mathrm{kB} \text { oral epidermoid cancer } \\
\text { and LoVo colon } \\
\text { cancer lines }\end{array}$ & $\uparrow$ Cytotoxicity & $21.3 ; 10.8 \mathrm{nM}$ & [97] \\
\hline & Apratoxin C (15) & Symploca cf. sp. & Several cancer cell lines & \multirow{2}{*}{$\uparrow$ Cytotoxicity } & $1.0 ; 0.73 \mathrm{nM}$ & [97] \\
\hline & Apratoxin D (16) & $\begin{array}{l}\text { Lyngbya majuscule; } \\
\text { Lyngbya sordida }\end{array}$ & H-460 lung cancer & & $2.6 \mathrm{nM}$ & [98] \\
\hline
\end{tabular}


Table 1. Cont

\begin{tabular}{|c|c|c|c|c|c|c|}
\hline Class & $\begin{array}{l}\text { Secondary } \\
\text { Metabolite }\end{array}$ & Biological Source & Cell Lines Used & Effects and Mechanisms & $\mathrm{IC}_{50}$ Values & References \\
\hline & Apratoxin E (17) & Lyngbya bouilloni & $\begin{array}{l}\text { U2OS osteosarcoma, HT29 } \\
\text { colon } \\
\text { adenocarcinoma and HeLa } \\
\text { epithelial carcinoma }\end{array}$ & $\uparrow$ Antiproliferative Activity & $59 ; 21 ; 72 \mathrm{nM}$ & [99] \\
\hline & Apratoxin F (18) & \multirow{2}{*}{ Lyngbya sp. } & \multirow{2}{*}{$\begin{array}{l}\text { H-460 lung cancer; HCT-116 } \\
\text { colorectal cancer cells }\end{array}$} & \multirow{2}{*}{$\uparrow$ Cytotoxicity } & $2 ; 36.7 \mathrm{nM}$ & \multirow{2}{*}{ [100] } \\
\hline & Apratoxin G (19) & & & & $14 \mathrm{nM}$; Not specified & \\
\hline & Aurilide B (20) & Lyngbya majuscula & $\begin{array}{c}\text { NCI-H460 } \\
\text { human lung tumor and } \\
\text { neuro-2a mouse } \\
\text { neuroblastoma cells }\end{array}$ & \multirow{2}{*}{$\begin{array}{c}\uparrow \text { Antiproliferative activity; } \\
\uparrow \text { OPA1 synthesis, } \\
\uparrow \text { apoptosis }\end{array}$} & $0.04 ; 0.01 \mu \mathrm{M}$ & \multirow{2}{*}[101,102]{} \\
\hline & Aurilide C (21) & Lyngbya majuscula & $\begin{array}{l}\text { U2OS osteosarcoma, HT29 } \\
\text { colon } \\
\text { adenocarcinoma and HeLa } \\
\text { epithelial carcinoma }\end{array}$ & & $0.13 ; 0.05 \mu \mathrm{M}$ & \\
\hline & \multirow{4}{*}{ Coibamide A (22) } & \multirow{4}{*}{ Leptolyngbya sp. } & $\begin{array}{l}\text { MDA-MB-231, melanoma } \\
\text { LOX IMVI, } \\
\text { leukemia HL-60 and } \\
\text { astrocytoma SNB75 }\end{array}$ & $\begin{array}{c}\uparrow \text { Cytotoxicity; }{ }^{{ }^{\perp}} \text { cell cycle at } \\
\text { G1 Phase }\end{array}$ & $\begin{array}{c}2.8 ; 7.4 ; 7.4 \text { and } 7.6 \\
\mathrm{nM}\end{array}$ & [103] \\
\hline & & & $\begin{array}{l}\text { glioblastoma cell lines } \\
\text { U87-MG and SF-295 }\end{array}$ & $\uparrow$ Cytotoxicity & $20 \mathrm{nM}$ & \multirow{2}{*}{ [104] } \\
\hline & & & $\begin{array}{l}\text { Normal human umbilical } \\
\text { vein endothelial cells } \\
\text { (HUVECs) }\end{array}$ & ${ }^{\perp}$ Proliferation; $\downarrow$ VEGFR2 & $0.3-3 \mathrm{nM}$ & \\
\hline & & & $\begin{array}{c}\text { Human U87-MG } \\
\text { glioblastoma cells and SF-295 } \\
\text { glioblastoma cells }\end{array}$ & $\uparrow$ Cytotoxicity; $\uparrow$ autophagy & $28.8,96.2 \mathrm{nM}$ & [105] \\
\hline
\end{tabular}


Table 1. Cont

\begin{tabular}{|c|c|c|c|c|c|c|}
\hline Class & $\begin{array}{l}\text { Secondary } \\
\text { Metabolite }\end{array}$ & Biological Source & Cell Lines Used & Effects and Mechanisms & IC $_{50}$ Values & References \\
\hline & Hoiamide A (23) & \multirow{2}{*}{$\begin{array}{l}\text { Lyngbya majuscule, } \\
\text { Phormidium gracile }\end{array}$} & \multirow{2}{*}{$\begin{array}{l}\mathrm{H}-460 \text { lung cancer and } \\
\text { neuro-2a mouse } \\
\text { neuroblastoma }\end{array}$} & \multirow{2}{*}{$\begin{array}{l}\uparrow \text { Cytotoxicity; } \\
\uparrow \text { neurotoxicity }\end{array}$} & $11.2 ; 2.1 \mu \mathrm{M}$ & \multirow{2}{*}{ [106] } \\
\hline & Hoiamide B (24) & & & & $\begin{array}{c}8.3 \mu \mathrm{M} ; \text { no effect on } \\
\text { neuro- } 2 \mathrm{a}\end{array}$ & \\
\hline & $\begin{array}{l}\text { Homodolastatin } 16 \\
\text { (25) }\end{array}$ & Lyngbya majuscule & $\begin{array}{l}\text { WHCO1 and WHCO6 } \\
\text { esophageal cancer; } \\
\text { ME180 cervical cancer }\end{array}$ & $\begin{array}{l}\uparrow \text { Apoptosis; }{ }^{\perp} \text { cell cycle at } \\
\text { G2/M Phase; } \uparrow \text { cytotoxicity }\end{array}$ & $\begin{array}{c}4.3 \text { and } 10.1 ; 8.3 \\
\mu \mathrm{g} / \mathrm{mL}\end{array}$ & [107] \\
\hline & Largazole (26) & Symploca sp. & $\begin{array}{l}\text { MDA-MB-23I breast cancer; } \\
\text { U2OS } \\
\text { osteosarcoma; colon HT29; } \\
\text { neuroblastoma IMR-32; } \\
\text { nontransformed } \\
\text { murine mammary epithelial } \\
\text { cells NMuMG; HCT-116 } \\
\text { colorectal carcinoma }\end{array}$ & $\begin{array}{c}\uparrow \text { Cytotoxicity; }{ }^{\perp} \text { tumor; cell } \\
\text { cycle arrest at G2/M Phase; } \\
{ }^{\perp} \text { HDAC }\end{array}$ & $\begin{array}{l}\text { 7.7; } 55 ; 12 ; 16 ; 122 \mathrm{nM} \\
\text { Not specified }\end{array}$ & {$[108,109]$} \\
\hline & Lyngbyabellin A (27) & Lyngbya majuscula & \multirow{2}{*}{$\begin{array}{c}\text { kB nasopharyngeal } \\
\text { carcinoma and LoVo colon } \\
\text { adenocarcinoma }\end{array}$} & \multirow{2}{*}{$\begin{array}{c}\uparrow \text { Cytotoxicity; }{ }^{\perp} \text { tumor; cell } \\
\text { cycle arrest at G2/M Phase; } \\
\uparrow \text { actin polymerization }\end{array}$} & $0.03 ; 0.05 \mu \mathrm{g} / \mathrm{mL}$ & [110] \\
\hline & Lyngbyabellin B (28) & Lyngbya majuscula & & & $0.10 ; 0.83 \mu \mathrm{g} / \mathrm{mL}$ & [110] \\
\hline & Lyngbyabellin E (29) & $\begin{array}{l}\text { Lyngbya majuscula } \\
\text { Symploca sp. }\end{array}$ & \multirow{5}{*}{$\begin{array}{l}\text { NCI-H460 human lung } \\
\text { tumor and neuro-2a mouse } \\
\text { neuroblastoma cells }\end{array}$} & $\begin{array}{l}\perp_{\text {Tumor growth; }}{ }^{\perp_{\text {cell }}} \\
\text { microfibrils network }\end{array}$ & $0.4 ; 1.2 \mu \mathrm{M}$ & \multirow{2}{*}{ [111] } \\
\hline & Lyngbyabellin F (30) & Lyngbya majuscula & & \multirow{4}{*}{$\uparrow$ Cytotoxicity } & $1 ; 1.8 \mu \mathrm{M}$ & \\
\hline & Lyngbyabellin G (31) & \multirow{2}{*}{ Lyngbya majuscula } & & & $2.2 ; 4.8 \mu \mathrm{M}$ & [111] \\
\hline & Lyngbyabellin H (32) & & & & $0.2 ; 1.4 \mu \mathrm{M}$ & [111] \\
\hline & Lyngbyabellin I (33) & Lyngbya majuscula & & & $1 ; 0.7 \mu \mathrm{M}$ & [111] \\
\hline & Lyngbyabellin N (34) & Moorea bouillonii & $\begin{array}{l}\text { HCT116 (colon cancer cell } \\
\text { line) }\end{array}$ & $\begin{array}{c}\text { Anticancer activity; } \\
\uparrow c y \text { totoxicity }\end{array}$ & $40.9 \pm 3.3 \mathrm{nM}$ & [112] \\
\hline & Majusculamide C (35) & Lyngbya majuscule & $\begin{array}{c}\text { Ovarian carcinoma } \\
\text { OVCAR-3, kidney cancer } \\
\text { A498, lung cancer NCI-H460, } \\
\text { colorectal cancer KM20L2; } \\
\text { glioblastoma SF-295 }\end{array}$ & $\begin{array}{c}\text { Anticancer activity; } \\
\uparrow c y \text { totoxicity }\end{array}$ & $\begin{array}{c}0.51 ; 0.058 ; 0.0032 \\
0.0013 ; 0.013 \mu \mathrm{g} / \mathrm{mL}\end{array}$ & {$[110,113]$} \\
\hline
\end{tabular}


Table 1. Cont

\begin{tabular}{|c|c|c|c|c|c|c|}
\hline Class & $\begin{array}{l}\text { Secondary } \\
\text { Metabolite }\end{array}$ & Biological Source & Cell Lines Used & Effects and Mechanisms & $\mathrm{IC}_{50}$ Values & References \\
\hline & \multicolumn{2}{|c|}{$\begin{array}{l}\text { Desmethoxymajusculamide } \\
\text { C (36) }\end{array}$} & $\begin{array}{l}\text { HCT-116 human colon } \\
\text { carcinoma cells }\end{array}$ & Selective antitumor activity & $20 \mathrm{nM}$ & [110] \\
\hline & Obyanamide (37) & Lyngbya confervoides & $\mathrm{kB}$ and LoVo cells & Anticancer activity & $0.58 ; 3.14 \mu \mathrm{g} / \mathrm{mL}$ & [114] \\
\hline & Palau'amide (38) & Lyngbya confervoides & $\begin{array}{l}\mathrm{kB} \text { oral epidermoid cancer } \\
\text { cells }\end{array}$ & Anticancer activity & $13 \mathrm{nM}$ & [115] \\
\hline & Palmyramide A (39) & Lyngbya majuscule & $\begin{array}{l}\text { Neuro2a cells and human } \\
\text { lung cell H-460 }\end{array}$ & $\begin{array}{c}\text { Anticancer activity; } \\
\uparrow \text { cytotoxicity; blocking the } \\
\text { voltage regulated sodium } \\
\text { channel }\end{array}$ & $17.2 ; 39.7 \mu \mathrm{M}$ & [116] \\
\hline & Pitipeptolide A (40) & Lyngbya majuscule & $\begin{array}{l}\text { HT29 colon adenocarcinoma } \\
\text { cancer cells, MCF-7 and LoVo } \\
\text { colon cancer }\end{array}$ & $\begin{array}{l}\text { Anticancer activity; } \\
\uparrow \text { cytotoxicity }\end{array}$ & $\begin{array}{c}13 ; 13 \mu \mathrm{M} \& 2.25 \\
\mu \mathrm{g} / \mathrm{mL}\end{array}$ & {$[117,118]$} \\
\hline & Pitipeptolide B(41) & Lyngbya majuscula & $\begin{array}{l}\text { HT29 colon adenocarcinoma } \\
\text { cancer cells, MCF-7 and LoVo } \\
\text { colon cancer }\end{array}$ & $\begin{array}{l}\text { Anticancer activity; } \\
\uparrow \text { cytotoxicity }\end{array}$ & $13 ; 11 \mu \mathrm{M} ; 1.95 \mu \mathrm{g} / \mathrm{mL}$ & {$[117,118]$} \\
\hline & Pitiprolamide (42) & Lyngbya majuscula & $\begin{array}{c}\text { HCT116 colorectal carcinoma } \\
\text { and MCF7 breast } \\
\text { adenocarcinoma }\end{array}$ & $\begin{array}{c}\text { Anticancer activity, } \\
\uparrow c y \text { totoxicity }\end{array}$ & $33 ; 33 \mu \mathrm{M}$ & [119] \\
\hline & Tasipeptins A (43) & Symploca sp. & $\mathrm{kB}$ oral epidermoid cancer & $\begin{array}{l}\text { Anticancer activity, } \\
\uparrow c y \text { totoxicity }\end{array}$ & $0.93 \mu \mathrm{M}$ & [120] \\
\hline & Tasipeptins B (44) & Symploca sp. & $\mathrm{kB}$ oral epidermoid & $\begin{array}{l}\text { Anticancer activity, } \\
\uparrow c y \text { totoxicity }\end{array}$ & $0.82 \mu \mathrm{M}$ & [120] \\
\hline & Ulongapeptin (45) & Lyngbya sp. & $\mathrm{kB}$ oral epidermoid cancer & $\begin{array}{l}\text { Anticancer activity; } \\
\uparrow \text { cytotoxicity }\end{array}$ & $0.63 \mu \mathrm{M}$ & [121] \\
\hline & $\begin{array}{l}\text { Veraguamide A-G } \\
\qquad(46-52)\end{array}$ & $\begin{array}{c}\text { Symploca cf. hydnoides, } \\
\text { Oscillatoria } \\
\text { margaritifera }\end{array}$ & $\begin{array}{l}\text { HT29 colon adenocarcinoma; } \\
\text { HeLa cervical carcinoma }\end{array}$ & $\begin{array}{c}\text { Anticancer activity; } \\
\uparrow c y \text { totoxicity }\end{array}$ & $\begin{array}{c}26 ; 2 \mu \mathrm{M} \& 141 \mathrm{nM} ; 30 \\
\& 17 \mu \mathrm{M} ; 5.8 \& 6.1 \\
\mu \mathrm{M} ; 0.84 \& 0.54 \mu \mathrm{M} ; \\
1.5 \& 0.83 \mu \mathrm{M} ; 49 \& 49 \\
\mu \mathrm{M} ; 2.7 \& 2.3 \mu \mathrm{M}\end{array}$ & {$[122,123]$} \\
\hline & $\begin{array}{l}\text { Wewakpeptins A-D } \\
\quad(53-56)\end{array}$ & Lyngbya semiplena & H-460 lung cancer & $\begin{array}{l}\text { Anticancer activity; } \\
\uparrow \text { cytotoxicity }\end{array}$ & $0.4 \mu \mathrm{M}$ & [124] \\
\hline
\end{tabular}


Table 1. Cont

\begin{tabular}{|c|c|c|c|c|c|c|}
\hline Class & $\begin{array}{l}\text { Secondary } \\
\text { Metabolite }\end{array}$ & Biological Source & Cell Lines Used & Effects and Mechanisms & $\mathrm{IC}_{50}$ Values & References \\
\hline Cyclic heptapeptides & $\begin{array}{c}\text { Nostocyclopeptide A1 } \\
\text { \& A2 }(57,58)\end{array}$ & Nostoc sp. & $\begin{array}{l}\mathrm{kB} \text { oral epidermoid cancer } \\
\text { and LoVo colon carcinoma } \\
\text { cell line }\end{array}$ & $\begin{array}{c}\text { Anticancer activity; } \\
\uparrow c y t o t o x i c i t y\end{array}$ & $1 \& 1 \mu \mathrm{M}$ for both & [125] \\
\hline Cyclopeptide & Symplocamide (59) & Symploca sp. & $\begin{array}{l}\text { Non-small cell lung cancer } \\
\text { cells H-460 and neuro-2a } \\
\text { neuroblastoma cells }\end{array}$ & $\begin{array}{c}\text { Anticancer activity; } \\
\uparrow \text { cytotoxicity }\end{array}$ & $40 ; 29 \mathrm{nM}$ & [110] \\
\hline Cyclicpeptide & Tasiamide (60) & Symploca sp. & $\begin{array}{l}\text { Human nasopharyngeal } \\
\text { carcinoma }(\mathrm{kB}) \text { and human } \\
\text { colon carcinoma (LoVo) cells }\end{array}$ & $\begin{array}{l}\text { Anticancer activity; } \\
\uparrow c y \text { totoxicity }\end{array}$ & $0.48 ; 3.47 \mu \mathrm{g} / \mathrm{mL}$ & [126] \\
\hline Linear tetrapeptide & Belamide A (61) & Symploca sp. & $\begin{array}{l}\text { MCF7 breast cancer cell; } \\
\text { HCT-116 colon cancer cell }\end{array}$ & $\begin{array}{c}\text { Anticancer activity; } \\
\uparrow \text { cytotoxicity; } \\
\text { depolymerizing effect on } \\
\text { microtubule in A-10 cells; } \\
\text { antimitotic activity }\end{array}$ & $1.6 \mu \mathrm{M} ; 0.74 \mu \mathrm{M}$ & [127] \\
\hline Peptide & Bisebromoamide (62) & Lyngbya sp. & $\begin{array}{l}\text { HeLa S3 cells; a panel of } 39 \\
\text { human cancer cell lines of the } \\
\text { Japanese Foundation for } \\
\text { Cancer Research (JFCR39) } \\
\text { Cancer Research }\end{array}$ & $\begin{array}{c}\uparrow \text { Cytotoxicity; } \\
\perp_{\text {protein kinases; }} \\
\perp_{\text {phosphorylation of ERK }}\end{array}$ & $\begin{array}{c}0.04 \mu \mathrm{g} / \mathrm{mL} \text {; average } \\
40 \mathrm{nM}\end{array}$ & {$[128,129]$} \\
\hline Lipopeptides & $\begin{array}{l}\text { Dragonamide, } \\
\text { Pseudodysidenin (63, } \\
64)\end{array}$ & Lyngbya majuscula & $\begin{array}{l}\text { P-388; A-549 lung epithelial } \\
\text { adenocarcinoma, HT-29 } \\
\text { colon adenocarcinoma; } \\
\text { MEL-28 melanoma }\end{array}$ & $\begin{array}{l}\text { Anticancer activity; } \\
\uparrow c y \text { totoxicity }\end{array}$ & $>1 \mu \mathrm{g} / \mathrm{mL}$ & [130] \\
\hline Lipopeptide & Kalkitoxin (65) & Phormidium sp. & $\begin{array}{l}\text { HCT-116 colon cancer cell; } \\
\text { T47D breast tumor cells }\end{array}$ & $\begin{array}{c}\text { Anticancer activity; } \\
\uparrow \text { cytotoxicity; } \\
\perp \text { hypoxia-induced } \\
\text { activation of HIF-1; } \\
\downarrow \text { mitochondrial oxygen } \\
\text { consumption at electron } \\
\text { transport chain (ETC) } \\
\text { complex I } \\
\text { (NADH-ubiquinone } \\
\text { oxidoreductase); blocking } \\
\text { of VEGF }\end{array}$ & $2.7 \mathrm{nM} ; 5.6 \mathrm{nM}$ & [131] \\
\hline
\end{tabular}


Table 1. Cont

\begin{tabular}{|c|c|c|c|c|c|c|}
\hline Class & $\begin{array}{l}\text { Secondary } \\
\text { Metabolite }\end{array}$ & Biological Source & Cell Lines Used & Effects and Mechanisms & $\mathrm{IC}_{50}$ Values & References \\
\hline Lipopeptide & $\begin{array}{l}\text { Somocystinamide A } \\
\text { (66) }\end{array}$ & Lyngbya majuscula & $\begin{array}{l}\text { Jurkat, CEM (leukemia), } \\
\text { A549 (lung carcinoma), Molt4 } \\
\text { (T cell leukemia), M21 } \\
\text { melanoma, and U266 } \\
\text { myeloma cell lines }\end{array}$ & $\begin{array}{c}\uparrow \text { Cytotoxicity; } \uparrow \text { apoptosis } \\
\text { via caspase } 8\end{array}$ & $\begin{array}{c}3 ; 14 ; 46 ; 60 \mathrm{nM} ; 1.3 ; \\
5.8 \mu \mathrm{M}\end{array}$ & [132] \\
\hline \multirow[b]{2}{*}{$\begin{array}{l}\text { Lipopeptide, Lyngbic } \\
\text { acid derivative }\end{array}$} & Malyngamide 2 (67) & Lyngbya sordida & H-460 lung cancer & $\uparrow$ Cytotoxicity & $27.3 \mu \mathrm{M}$ & [133] \\
\hline & $\begin{array}{l}\text { Malyngamide C, J, \& } \\
\quad \mathrm{K}(68,69,70)\end{array}$ & Lyngbya majuscula & $\begin{array}{c}\text { NCI-H460, Neuro-2a, and } \\
\text { HCT-116 }\end{array}$ & $\uparrow$ Cytotoxicity & $\begin{array}{c}1.4 ; 3.1 ; 0.2 \mu \mathrm{g} / \mathrm{mL} \\
10.8,4 \mu \mathrm{g} / \mathrm{mL}, \mathrm{nd} \\
1.1 ; 0.49 \mu \mathrm{g} / \mathrm{mL}, \text { nd }\end{array}$ & [134] \\
\hline Peptide ester & Malevamide D (71) & $\begin{array}{l}\text { Symploca hydnoides Kü } \\
\text { tzing ex Gomont }\end{array}$ & $\begin{array}{l}\text { P388, Lung cancer A-549, } \\
\text { colon cancer HT-29 } \\
\text { Melanoma MEL-28 }\end{array}$ & $\uparrow$ Cytotoxicity & $\begin{array}{l}0.3-0.7 \mathrm{nM} \\
0.7 \mathrm{nM}\end{array}$ & [135] \\
\hline Cyclodepside & $\begin{array}{l}\text { Malyngolide dimer } \\
\text { (72) }\end{array}$ & Lyngbya majuscule & $\begin{array}{l}\text { NCI H-460 human lung } \\
\text { tumor cell line }\end{array}$ & $\begin{array}{l}\text { Moderate cytotoxicity; } \\
\text { anticancer activity }\end{array}$ & Not specified & [136] \\
\hline \multirow{3}{*}{$\begin{array}{c}\text { Macrolide } \\
\text { depsipeptide }\end{array}$} & \multirow{3}{*}{ Cryptophycin 1 (73) } & \multirow{3}{*}{ Nostoc sp. } & L1210 murine leukemia cells & $\begin{array}{c}\text { Anticancer activity; } \\
\text { } \text { disruption of microtubule } \\
\text { assembly }\end{array}$ & Not specified & {$[137,138]$} \\
\hline & & & $\mathrm{kB}$ cells and LoVo cell & $\uparrow$ Apoptosis & $4.58,7.63 \mathrm{pM}$ & [139] \\
\hline & & & $\begin{array}{l}\text { MDA-MB-435 mammary } \\
\text { adenocarcinoma; SKOV3 } \\
\text { ovarian carcinoma cell lines }\end{array}$ & $\begin{array}{c}{ }^{\perp} \text { Proliferation; }{ }^{\perp} \text { cell cycle } \\
\text { at G2/M Phase }\end{array}$ & $50 \mathrm{pM}$ & {$[140,141]$} \\
\hline \multirow[t]{2}{*}{ Cyclic depsipeptide } & $\begin{array}{l}\text { Lagunamides A, B } \\
(\mathbf{7 5}, \mathbf{7 6})\end{array}$ & Lyngbya majuscule & $\begin{array}{l}\text { P388 (a murine leukemia cell } \\
\text { line) }\end{array}$ & $\uparrow$ Cytotoxicity & 6.4 and $20.5 \mathrm{nM}$ & [142] \\
\hline & Lagunamides C (77) & & $\begin{array}{l}\text { P388, A549, PC3, HCT8, and } \\
\text { SK-OV3carcinoma cell lines }\end{array}$ & & 2.1 to $24.4 \mathrm{nM}$ & [143] \\
\hline
\end{tabular}


Table 1. Cont

\begin{tabular}{|c|c|c|c|c|c|c|}
\hline Class & $\begin{array}{l}\text { Secondary } \\
\text { Metabolite }\end{array}$ & Biological Source & Cell Lines Used & Effects and Mechanisms & $\mathrm{IC}_{50}$ Values & References \\
\hline \multirow{3}{*}{ Macrolide glycoside } & Biselyngbyaside (78) & Lyngbya sp. & $\begin{array}{c}\text { HeLa }_{3} \text { epithelial carcinoma; } \\
\text { SNB-78 central nervous } \\
\text { system cancer; NCI H522 } \\
\text { lung cancer }\end{array}$ & $\begin{array}{l}{ }^{\perp} \text { Proliferation of cancer } \\
\text { cell; induced cytotoxicity }\end{array}$ & $\begin{array}{c}0.1 \mu \mathrm{g} / \mathrm{mL} ; 0.036 \\
0.067 \mu \mathrm{M}\end{array}$ & [144] \\
\hline & Biselyngbyasid B (79) & Symploca hydnoides & $\mathrm{HeLa} \mathrm{S}_{3}$ cells and HL60 cells & $\begin{array}{l}\perp \text { Proliferation of cancer } \\
\text { cell; induced cytotoxicity }\end{array}$ & $3.5 \& 0.82 \mu \mathrm{M}$ & [145] \\
\hline & $\begin{array}{c}\text { Biselyngbyasid E \& F } \\
(\mathbf{8 0}, \mathbf{8 1})\end{array}$ & Lyngbya sp. & HeLa and HL60 cells & $\begin{array}{l}{ }^{\perp} \text { Proliferation of cancer } \\
\text { cell; induced cytotoxicity }\end{array}$ & $\begin{array}{c}0.19 \& 0.071 \mu \mathrm{M} ; 3.1 \& \\
0.66 \mu \mathrm{M}\end{array}$ & [146] \\
\hline \multirow{3}{*}{ Glycomacrolide } & Lyngbyaloside B (82) & Lyngbya sp. & $\begin{array}{c}\text { kB nasopharyngeal } \\
\text { carcinoma and LoVo colon } \\
\text { adenocarcinoma }\end{array}$ & $\begin{array}{c}\uparrow \text { Cytotoxicity; } \\
\text { anticancer activity }\end{array}$ & $4.3 ; 15 \mu \mathrm{M}$ & [147] \\
\hline & $\begin{array}{l}\text { 2-epi-lyngbyalosid } \\
\text { (83) }\end{array}$ & Lyngbya bouillonii & $\begin{array}{c}\text { HT29 colorectal } \\
\text { adenocarcinoma and HeLa } \\
\text { cells }\end{array}$ & $\begin{array}{l}\text { Anticancer activity; } \\
\perp_{\text {proliferation }}\end{array}$ & 38 and $33 \mu \mathrm{M}$ & [148] \\
\hline & $\begin{array}{c}\text { 18E-lyngbyaloside C; } \\
\text { 18Z-lyngbyaloside C } \\
(\mathbf{8 4}, \mathbf{8 5})\end{array}$ & Lyngbya sp. & $\begin{array}{c}\text { HT29 colorectal } \\
\text { adenocarcinoma and HeLa } \\
\text { cells }\end{array}$ & $\begin{array}{l}\text { Anticancer activity; } \\
\perp_{\text {proliferation; }}\end{array}$ & $\begin{array}{c}13 \& 9.3 \mu \mathrm{M} ;>100 \mu \mathrm{M} \\
\& 53 \mu \mathrm{M}\end{array}$ & [148] \\
\hline Macrolide & $\begin{array}{c}\text { Biselyngbyolide A; } \\
\text { Biselyngbyolide B (86, } \\
\mathbf{8 7 )}\end{array}$ & Lyngbya sp. & HeLa $S_{3}$ cells and HL60 cells & Anticancer activity & $\begin{array}{c}0.22 \& 0.027 \mu \mathrm{M} ; 0.028 \\
\& 0.0027 \mu \mathrm{M}\end{array}$ & [149] \\
\hline Macrolide & $\begin{array}{c}\text { Koshikalide; } \\
\text { Acutiphycin and 20, } \\
\text { 21-didehydroacutiphycin } \\
(\mathbf{8 8}, \mathbf{8 9}, \mathbf{9 0})\end{array}$ & $\begin{array}{l}\text { Lyngbya sp., } \\
\text { Oscillatoria acutissima }\end{array}$ & $\begin{array}{c}\text { HeLa S3 cells; } \\
\text { KB and NIH/3T3 cells }\end{array}$ & $\begin{array}{l}\text { Anticancer activity; } \\
\uparrow c y \text { totoxicity }\end{array}$ & $\begin{array}{c}42 \mu \mathrm{g} / \mathrm{mL} \\
\text { Not specified for } \\
\text { Acutiphycin and 20, } \\
\text { 21-didehydroacutiphycin }\end{array}$ & {$[150,151]$} \\
\hline $\begin{array}{l}\text { Glycosylated } \\
\text { macrolide }\end{array}$ & Lyngbouilloside (91) & Lyngbya bouillonii & $\begin{array}{l}\text { Neuro-2a neuroblastoma } \\
\text { cells }\end{array}$ & $\begin{array}{c}\text { Anticancer activity; } \\
\uparrow c y \text { totoxicity }\end{array}$ & $17 \mu \mathrm{M}$ & [152] \\
\hline $\begin{array}{l}\text { Glycosylated } \\
\text { macrolide }\end{array}$ & $\begin{array}{l}\text { Polycavernoside D } \\
\text { (92) }\end{array}$ & Okeania sp. & $\begin{array}{l}\text { H-460 human lung cancer } \\
\text { cell line }\end{array}$ & ${ }^{\perp}$ Proliferation & $\mathrm{EC}_{50}=2.5 \mu \mathrm{M}$ & [153] \\
\hline
\end{tabular}


Table 1. Cont.

\begin{tabular}{|c|c|c|c|c|c|c|}
\hline Class & $\begin{array}{l}\text { Secondary } \\
\text { Metabolite }\end{array}$ & Biological Source & Cell Lines Used & Effects and Mechanisms & $\mathrm{IC}_{50}$ Values & References \\
\hline Macrocyclic lactone & $\begin{array}{c}\text { Tolytoxin }(93) \\
\text { 6-hydroxyscytophycin } \\
\text { B (95), } \\
\text { 19-O-demethylscytophy } \\
\text { C (96), and } \\
\text { 6-hydroxy-7-O-methylsc } \\
\text { E (98) }\end{array}$ & $\begin{array}{l}\text { Seytonema ocellaturn } \\
\text { inLyngbye ex Bornet } \\
\text { and Flahault } \\
\text { ytophycin }\end{array}$ & $\begin{array}{l}\text { L1210 (murine leukemia), } \\
\text { LoVo, kB, HEp-2 (human } \\
\text { epithelial type } 2 \text { cells), HL-60 } \\
\text { (Human promyelocytic } \\
\text { leukemia), HBL-100 (breast } \\
\text { cancer cell), T47-D (human } \\
\text { ductal carcinoma), COLO-201 } \\
\text { (colon adenocarcinom), } \\
\text { KATO-III (human gastric } \\
\text { carcinoma) } \\
\text { Nasopharynx cell (kB cells), } \\
\text { \&LoVo cells }\end{array}$ & $\begin{array}{l}\text { Anticancer activity; } \\
\uparrow \text { cytotoxicity; }\end{array}$ & $\begin{array}{c}3.9,8.4,5.3,2.3,4.8 \\
2.4,4.9,0.52, \text { and } 0.78 \\
\mathrm{nM} \\
>5 \mathrm{ng} / \mathrm{mL}\end{array}$ & {$[154,155]$} \\
\hline Macrolactone & $\begin{array}{l}\text { Caylobolide A (99), } \\
\text { Caylobolide B (100) }\end{array}$ & $\begin{array}{l}\text { Lyngbya majuscula } \\
\text { Phormidium sp. }\end{array}$ & $\begin{array}{c}\text { HCT-116 colon tumor } \\
\text { HT29 colorectal } \\
\text { adenocarcinoma, and HeLa } \\
\text { cervical carcinoma }\end{array}$ & $\begin{array}{c}\text { Anticancer activity; } \\
\uparrow c y \text { totoxicity }\end{array}$ & $\begin{array}{c}9.9 \mu \mathrm{M} \text { (same for both } \\
\text { caylobolide A \& B) } \\
4.5 ; 12.2 \mu \mathrm{M}\end{array}$ & {$[156,157]$} \\
\hline \multirow[t]{2}{*}{ Fatty acid amines } & $\begin{array}{l}\text { Isomalyngamide A } \\
\text { (101), and } \\
\text { Isomalyngamide A-1 } \\
\text { (102) }\end{array}$ & Lyngbya majuscula & $\begin{array}{c}\text { Breast cancer MCF-7 and } \\
\text { MDA-MB-231 }\end{array}$ & $\begin{array}{c}\perp_{\text {Proliferation; }} \perp_{\text {apoptosis; }} \\
\perp_{\text {cell migration; }} \\
\text { antimetastatic activity }\end{array}$ & $\begin{array}{c}4.6 \& 2.8 \mu \mathrm{M} \\
12.7 \mu \mathrm{M} \&>20 \mu \mathrm{M}\end{array}$ & [158] \\
\hline & $\begin{array}{c}\text { Jamaicamides A, B, \& } \\
\text { C }(\mathbf{1 0 3}, \mathbf{1 0 4}, \mathbf{1 0 5})\end{array}$ & Lyngbya majuscula & $\begin{array}{l}\mathrm{H}-460 \text { lung cancer and } \\
\text { Neuro-2a mouse neuro } \\
\text { blastoma cell lines }\end{array}$ & ${ }^{\perp}$ proliferation & $\mathrm{LC}_{50}: 15 \mu \mathrm{M}$ for all & [159] \\
\hline Pigment & Scytonemin (106) & Stigonema sp. & Jurkat T cells & $\begin{array}{c}\uparrow \text { Apoptosis; }{ }^{\perp} \text { formation of } \\
\text { mitotic spindle; }{ }^{\perp} \text { protein } \\
\text { serine/threonine kinase } \\
\text { activity }\end{array}$ & $7.8 \mu \mathrm{M}$ & {$[160,161]$} \\
\hline
\end{tabular}


Table 1. Cont

\begin{tabular}{|c|c|c|c|c|c|c|}
\hline Class & $\begin{array}{l}\text { Secondary } \\
\text { Metabolite }\end{array}$ & Biological Source & Cell Lines Used & Effects and Mechanisms & IC $_{50}$ Values & References \\
\hline $\begin{array}{l}\text { Boron containing } \\
\text { metabolite }\end{array}$ & Borophycin (107) & $\begin{array}{c}\text { Nostoc spongiaeforme, } \\
\text { N. linckia }\end{array}$ & $\begin{array}{l}\text { Human cancer cell lines kB } \\
\text { colorectal adenocarcinoma } \\
\text { and LoVo (human } \\
\text { epidermoid carcinoma) }\end{array}$ & $\begin{array}{c}{ }^{\perp} \text { Cancer; }{ }^{\perp} \text { cell cycle at } \\
\text { G2/M Phase }\end{array}$ & Not specified & {$[48,162]$} \\
\hline \multirow{2}{*}{$\begin{array}{l}\text { Phenanthridine } \\
\text { alkaloids }\end{array}$} & \multirow{2}{*}{$\begin{array}{c}\text { Calothrixins A and B } \\
(\mathbf{1 0 8}, \mathbf{1 0 9})\end{array}$} & \multirow[b]{2}{*}{ Calothrix sp. } & $\begin{array}{l}\text { Human carcinoma cell line } \\
\text { (HeLa) }\end{array}$ & $\uparrow$ Cytotoxicity ${ }^{\perp}$ proliferation & 40and $350 \mathrm{nM}$ & {$[163,164]$} \\
\hline & & & CEM leukemia cells & $\begin{array}{l}{ }^{\perp} \text { Proliferation; }{ }^{\perp} \text { cell cycle } \\
\text { at G1 and G2/M Phases }\end{array}$ & 0.20 to $5.13 \mu \mathrm{M}$ & [165] \\
\hline
\end{tabular}

Various symbols $\left(\uparrow, \downarrow\right.$ and $\left.{ }^{\perp}\right)$ indicate increase, decrease and inhibition in the obtained variables, respectively. 


\subsection{Anthracyclines}

Komodoquinone A (1) (Figure 1), produced by Streptomyces sp. KS3. This is a new anthracycline that caused neurotogenesis (process of forming new neurites) in the neuro 2A neuroblastoma cell line [84].

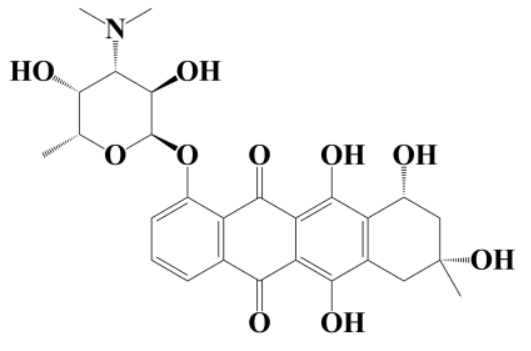

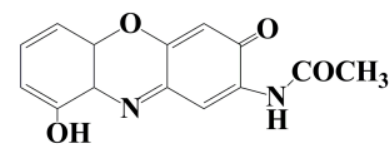

Chandrananimycin A (2)<smiles>O=C(O)NC1=CC2=NC3C=CC=CC3OC2=CC1=O</smiles>

Chandrananimycin B (3)

Komodoquinone A (1)<smiles>COC1CC(C)Nc2c1cc1c(cc2=O)Oc2cccc(O)c2N1</smiles>

Chandrananimycin C (4)

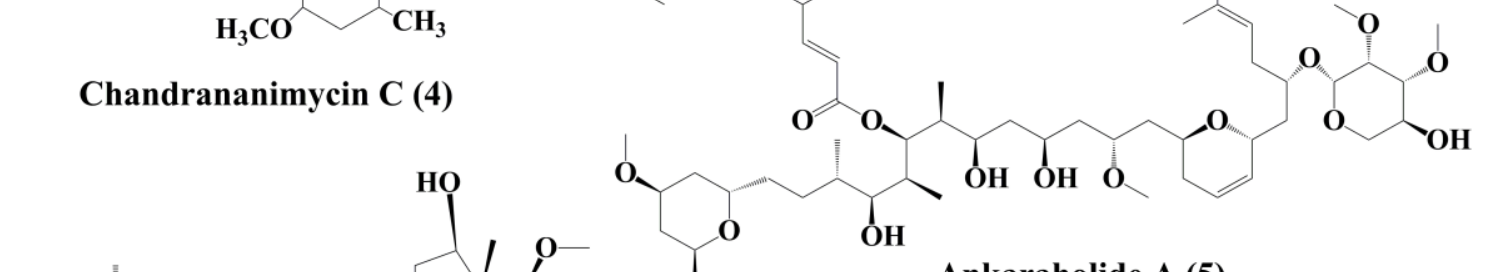

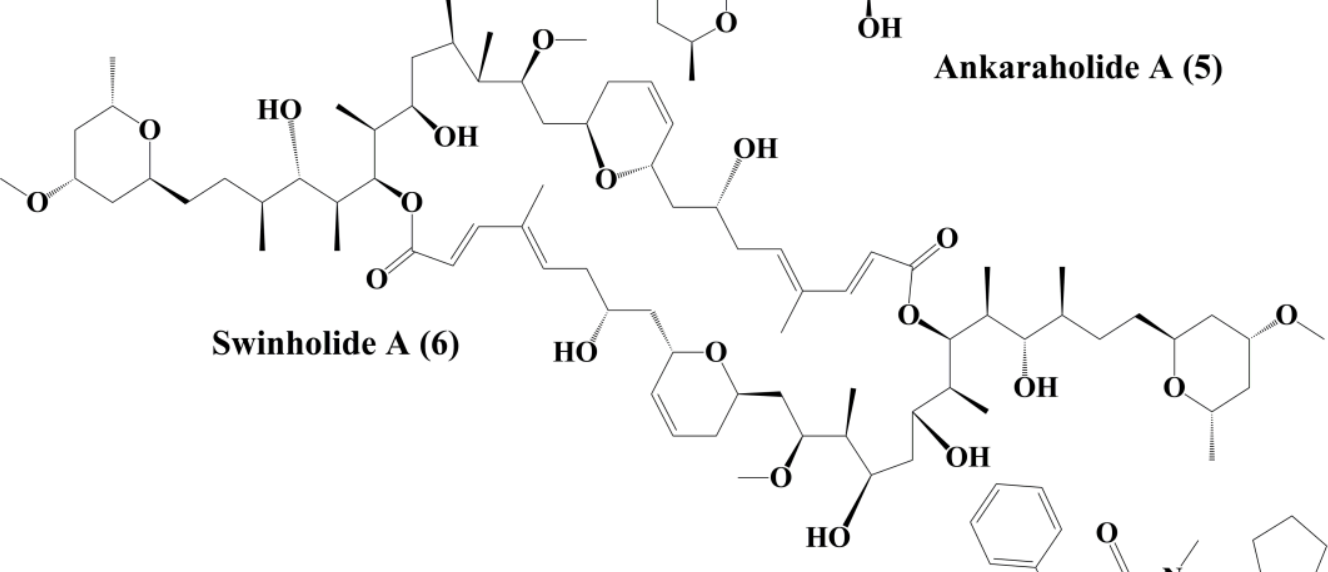<smiles>CCC(C)C(C(=O)NC(C(=O)N(C)C(C(C)CC)C(CC(=O)N1CCCC1C(OC)C(C)C(=O)NC(Cc1ccccc1)c1nccs1)OC)C(C)C)N(C)C</smiles>

Symplostatin 1 (7)

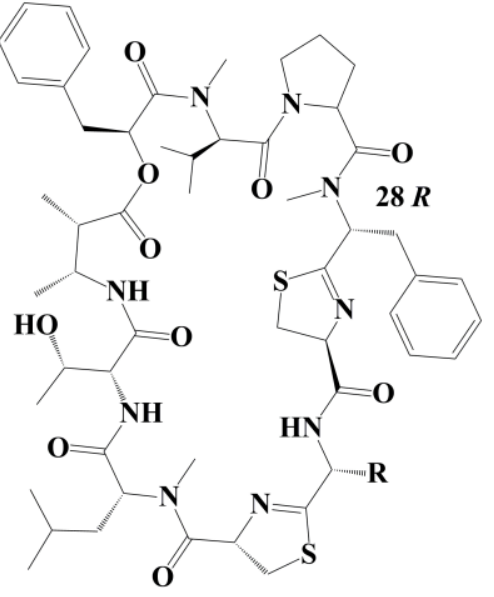

Grassypeptolide A: $\mathrm{R}=\mathrm{C}_{2} \mathrm{H}_{5}, 28 R$ (8)

Figure 1. Isolated marine cyanobacteria-derivedanthracyclines, phenoxazin-3-one compounds, polyketides and peptides (1-8). 


\subsection{Phenoxazin-3-One Compounds}

The novel anticancer antibiotics chandrananimycins A (2), B (3), and C (4) with phenoxazin-3-one moiety have been isolated from the marine Actinomadura sp. [85]. These compounds exhibited anticancer activity by inhibiting the proliferation of cancer cell lines such as, CCL HT29 (colon cancer cell), MEXF 514L (melanoma cells), LXFA 526L, LXFL 529L (lung cancer cells), CNCL SF268, LCL H460, MACL MCF-7 (breast cancer cells), and PRCL PC3M, RXF 631L (kidney tumor) [85].

\subsection{Polyketides}

Ankaraholide A (5) is a glycosylated swinholide compound, which is procured from Geitlerinema sp. [86]. It inhibited the proliferation of NCI-H460, Neuro-2a, and MDAMB-435 cells [96]. Swinholide A (6) was initially obtained from the marine sponge Theonella swinhoei. Later, it was also reported to be the metabolites of the marine cyanobacterium Symploca sp. It exhibited its antitumor activity by disruption of actin [86].

\subsection{Peptides}

Symplostatin 1 (7) (Figure 1) is an analogue of dolastatin 10, isolated from Symploca hydnoides, a marine bacterium. The antimitotic activity of symplostatin was shown against a panel of cancer cell lines, such as MDA-MB-435, SK-OV-3, NCI/ADR, A-10, and HUVEC [87].It also showed profound antitumor activity against murine colon 38 and murine mammary $16 / \mathrm{C}$ carcinoma cells. This metabolite triggered the phosphorylation of Bcl-2, micronuclei formation, caspase-3 activation, and induced apoptosis that led to cell cycle arrest at the G2/M Phase. It also prevented the accumulation of tubulin [87]. Grassypeptolideis a macrocyclic depsipeptide formed by the cynobacteria Lyngbya confervoides [88]. It showed cytotoxic antiproliferative activity against various cell lines, such as human osteosarcoma (U2OS), cervical carcinoma (HeLa), colorectal adenocarcinoma (HT29), and neuroblastoma (IMR-32) cell lines [88]. Grassypeptolide A (8) (Figure 1), B (9) and C (10) (Figure 2), significantly inhibited the proliferation of colorectal adenocarcinoma (HT29) cell lines and cervical carcinoma (HeLa) cell lines in a concentration-dependent manner by inducing cell cycle arrest at either G1 the Phase or G2/M Phase [89].

Curacin A (11) (Figure 2), a linear and complex hybrideketopeptide, was the first curacin that was isolated from extracts of the Caribbean cyanobacterium Lyngbya majuscule [90]. After curacin A, other curacin compounds, namely curacin B, C, and D, were also identified as the constituents of L. majuscule [91]. Amongst these, curacin A was the most active anticancer compound that inhibited the proliferation of non-small cell lung cancer cells (A549) by triggering apoptosis and causing cell cycle arrests in the G2-M Phase [92]. It acts by binding to tubulin at colchicine binding site and acting as a competitive antagonist, and tubulin polymerization inhibitor [93]. Its structural activity relationship (SAR) studies indicated that the existence of four double bonds, a conjugated diene, a readily oxidized thiazoline heterocycle, and high lipophilicity are the factors that govern the pharmacological function of curacin A [94]. Various analogues were prepared, but they exhibit activity, lower than that the parent compound [95]. 


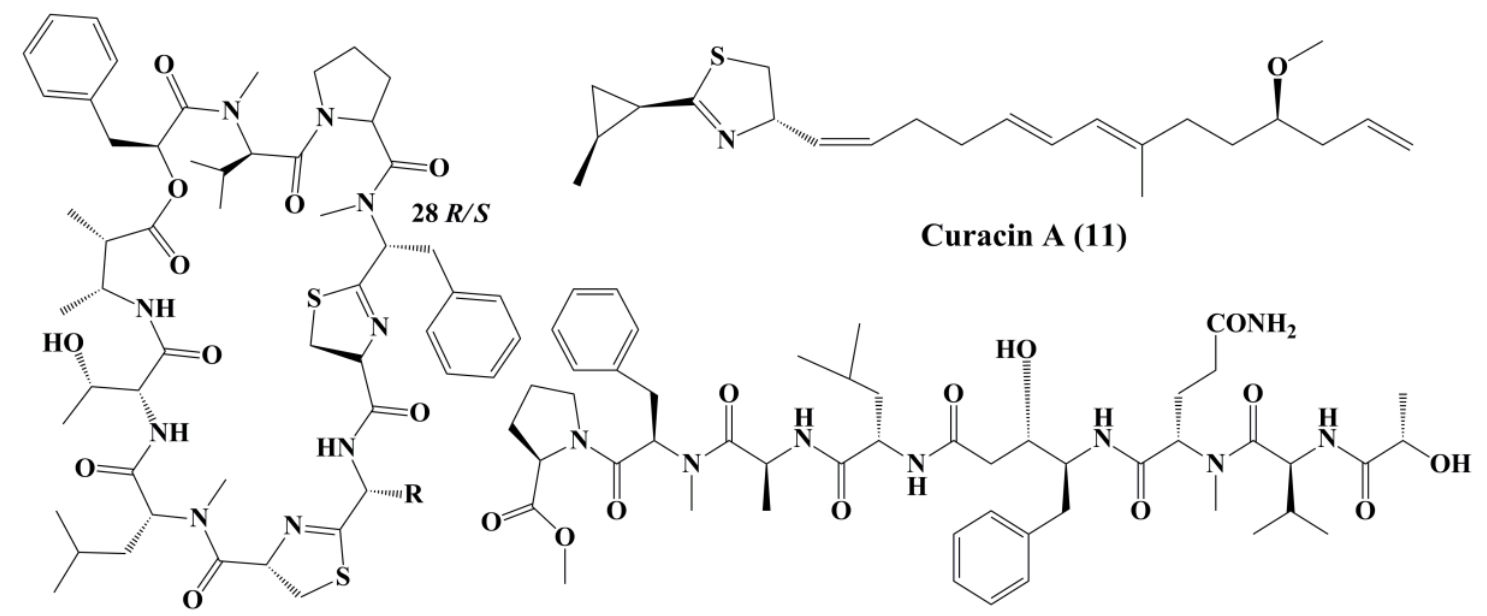

Grassypeptolide $\mathrm{B}: \mathrm{R}=\mathrm{CH}_{3}, 28 \mathrm{R}$ (9)

Grassypeptolide $\mathrm{C}: \mathrm{R}=\mathrm{C}_{2} \mathrm{H}_{5}, 28 S$ (10)

Tasiamide B (12)

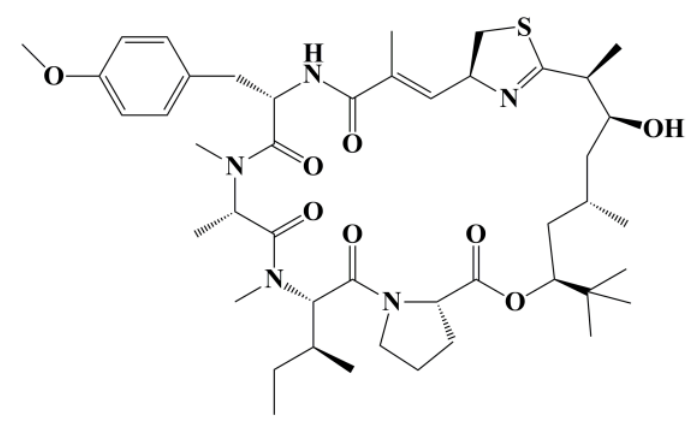

Apratoxin A (13)

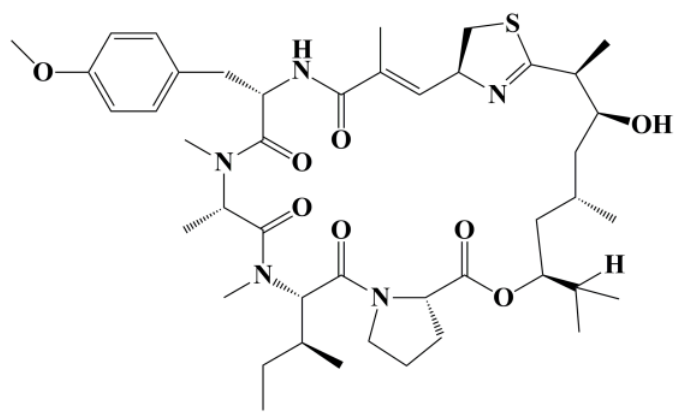

Apratoxin C (15)

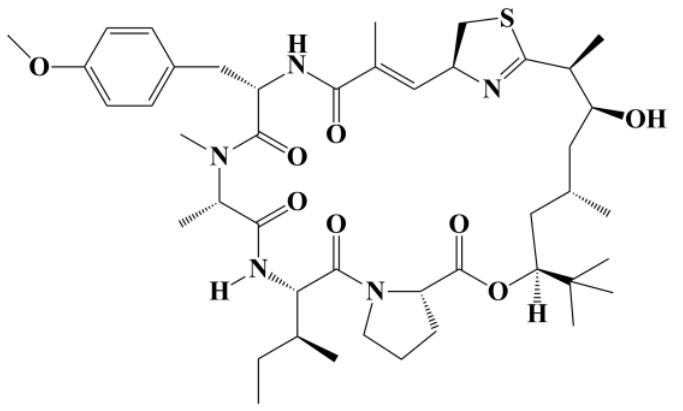

Apratoxin B (14)

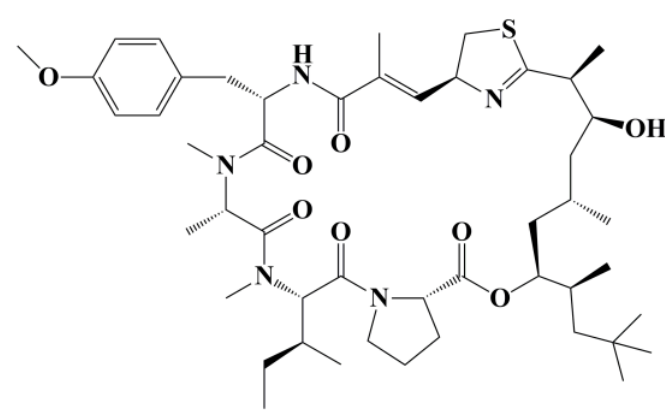

Apratoxin D (16)

Figure 2. Isolated marine cyanobacteria-derived peptides (9-16).

Tasiamide B (12) (Figure 2), a linear peptide extracted from cyanobacteria Symploca sp., demonstrated potent toxicity against human nasopharyngeal carcinoma $(\mathrm{kB})$ and LoVo cancer cells, respectively [96]. Apratoxins (Figure 2) are cytotoxic cyclic depsipeptides that have a novel polyketide and peptide fragmented structure [98]. Apratoxin A (13) (Figure 2) was found in an aquatic cyanobacteria Lyngbya majuscula. It disrupted the secretory pathway of U2OS osteosarcoma cells and even induced arrest at G1 Phase of the cell cycle in HeLa cervical carcinoma. It also demonstrated significant cytotoxic behavior in human tumor cell lines, such as LoVo cells and epidermal kB carcinoma cancer cells, respectively [97]. Apratoxin A inhibited the translocation of proteins by specifically attacking a central subunit of the protein translocation receptor, Sec61 $\alpha$ [99]. Apratoxin B (14) and C (15) (Figure 2), extracted from Lyngbya sp., has high cytotoxicity against $\mathrm{kB}$ oral epidermoid cancer cells and LoVo colon cancer cells [97]. Apratoxin D (16) (Figure 2), collected from Lyngbya majuscule 
and Lyngbya sordid, demonstrated significant cytotoxicity against the H-460 lung cancer cell line [98]. Apratoxin E (17) (Figure 3) extracted from Lyngbya bouilloni demonstrated strong antiproliferative action against diverse cancer cell lines, such as U2OS osteosarcoma, HT29 colon adenocarcinoma, and HeLa epithelial carcinoma [99].

Apratoxin F (18) and G (19) (Figure 3), containing N-methyl alanine in their composition, has been reported to be isolated from Lyngbya bouilloni and have strong cytotoxicity against H-460 lung cancer and HCT-116 colorectal cell lines [100]. Cyclic depsipeptidesaurilide B (20) and C (21) (Figure 3), isolated from Lyngbya majusculus, demonstrated cytotoxicity in human lung tumor cell line NCIH460 and neuro-2a mouse neuroblastoma cells [101]. Aurilides binds prohibitin 1 (PHB1) in the mitochondria, stimulates optic atrophy 1 (OPA1) proteolytic synthesis and contributes to mitochondrial apoptosis [102].Coibamade A (22) (Figure 3) is a cyclic depsipeptide extracted from marine cyanobacterium Leptolyngbya sp. It showed strong cytotoxic activity against a triple-negative breast cancer cell line (MDA-MB-231) [103]. The antiproliferative activity of the active metabolite is associated with the cell cycle arrest at the G1 Phase. Similar observations were reported, where glioblastoma cell lines, such as U87-MG and SF-295, were treated with coibamide A. It also inhibited the proliferation of HUVECs by inducing cell morphology change and reducing the expression level of vascular endothelial growth factor receptor 2 (VEGFR2) [104]. Cobamide A induced autophagy associated cell death of human U87-MG glioblastoma cells and SF-295 glioblastoma cells and mouse embryonic fibroblasts [105].

The structurally distinct cyclic depsipeptideshoiamide A (23) and B (24) (Figure 4), isolatedfrom Lyngbya majuscule and Phormidium gracile, exhibited strong cytotoxicity [106]. Hoiamide A displayed moderate cytotoxicity against mouse neuroblastoma (neuro-2a) cells and human lung adenocarcinoma (H460) cells, while hoiamide B exhibited weak cytotoxicity against H460 and no inhibition against neuro-2a cells [106].Homodolastatin 16 (25) (Figure 4), a cyclic marine depsipeptide isolated from Lyngbya majuscule, appears to have a modest cytotoxic effect against esophageal (WHCO1 and WHCO6) cell lines and cervical cell line (ME180), respectively [107]. Largazole (26) (Figure 4), a cyclodepsipeptide isolated from Symploca sp., has demonstrated a significant hindrance in the development of extremely invasive transformed human mammary epithelial cells (MDA-MB-231) in a concentration-dependent manner. The growth of HT29 colon and IMR-32 neuroblastoma cells has also been significantly inhibited. Similar pharmacological activity was observed towards transformed fibroblastic osteosarcoma (U2OS) cells [108]. It causes cell-cycle arrest colon cancer cell line HT29 at the G2/M Phase [110]. It is an inhibitor of histone deacetylase (HDAC) in vivo in the tumor xenograft model of HCT116 [109].

Lyngbyabellin A (27) and B (28) (Figure 4) are cyclic depsipeptides extracted from Lyngbya majusculus which possessed a strong actin polymerization mechanism with significant cytotoxicity against kB and LoVo cells [110]. Lyngbyabellin E-I (29-33) (Figure 5) demonstrated cytotoxicity to NCI-H460 human lung tumor and neuro-2a mouse neuroblastoma cells [110,111]. Lyngbyabellin N (34) (Figure 5) extracted from Moorea bouillonii demonstrated cytotoxicity in human lung carcinoma (H-460) and colon cancer cell lines (HCT116) [112]. Majusculamide C (35) and desmethoxymajusculamide C (36) (Figure 6) are cyclic depsipeptides derived from the Lyngbya majuscule, a marine cyanobacterium. Majusculamide $C$ was identified as cytotoxic and showed strong activity against several cancer cell lines, such as ovarian carcinoma (OVCAR-3), kidney cancer (A498), lung cancer (NCI-H460), colorectal cancer (KM20L2), and glioblastoma SF-295 cell lines [113]. Once screened against HCT-116 human colon carcinoma cells, desmethoxymajusculamide C has a good and a selective antitumor effect [110]. 


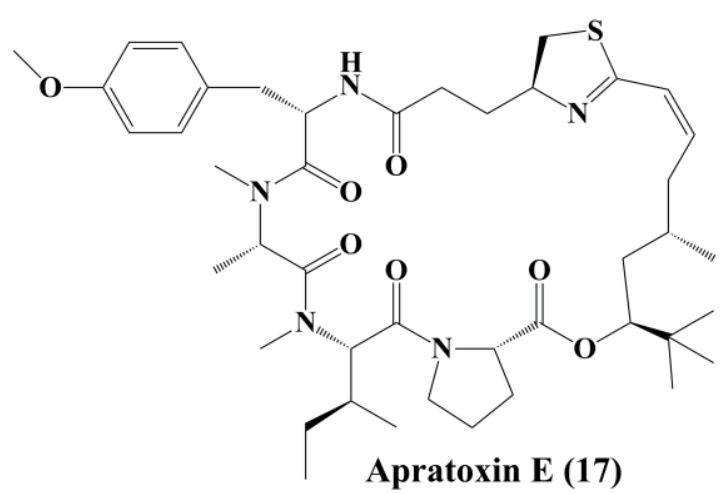

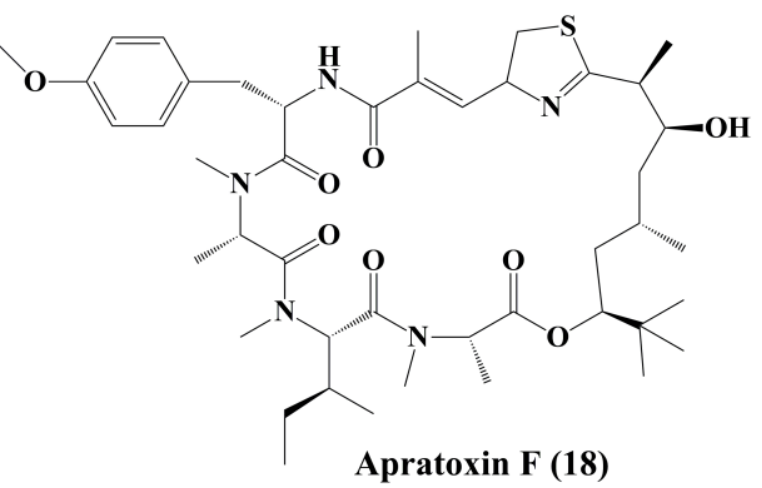<smiles>COc1ccc(C[C@H](NC(=O)/C(C)=C/C2CSC(N(C)C)C(C)C(O)CC(C)CC(OC(=O)C(C)N(C)C(=O)C(C(C)C)N(C)C(=O)C(C)N(C)C(=O)C(C)C)S2)C(C)(C)C)cc1</smiles><smiles>CC/C=C(\C)C(OC(=O)C(C)N(C)C(=O)C(NC(=O)CN(C)C(=O)C(C(C)CC)N(C)C(=O)C(NC(=O)C(OC(=O)/C(C)=C/C[C@@H](O)C(C)C)C(C)C)C(C)C)C(C)C)[C@@H](C)CC</smiles><smiles>CC/C=C(\C)C(OC(=O)C(C)N(C)C(=O)C(NC(=O)CN(C)C(=O)C(C(C)CC)N(C)C(=O)C(NC(=O)C(OC(=O)/C(C)=C/C[C@H](O)C(C)CC)C(C)C)[C@@H](C)CC)C(C)C)C(C)C</smiles>

Aurilide B (20)<smiles>COc1ccc(CC(NC(=O)C(CC(C)C)N(C)C(C)=O)C(=O)N(C)C(C)C(C)=O)cc1</smiles>

Aurilide C (21)<smiles>CCNC(=O)C(C(C)CC)N(C)C(=O)C(COC)N(C)C(=O)C(C(C)OC)N(C)C(=O)C(CC(C)C)N(C)C(=O)C(COC)N(C)C(=O)C(OC(=O)C(C(C)C)N(C)C)C(C)C</smiles>

Coibamide A (22)

Figure 3. Isolated cyanobacteria-derived peptides (17-22). 


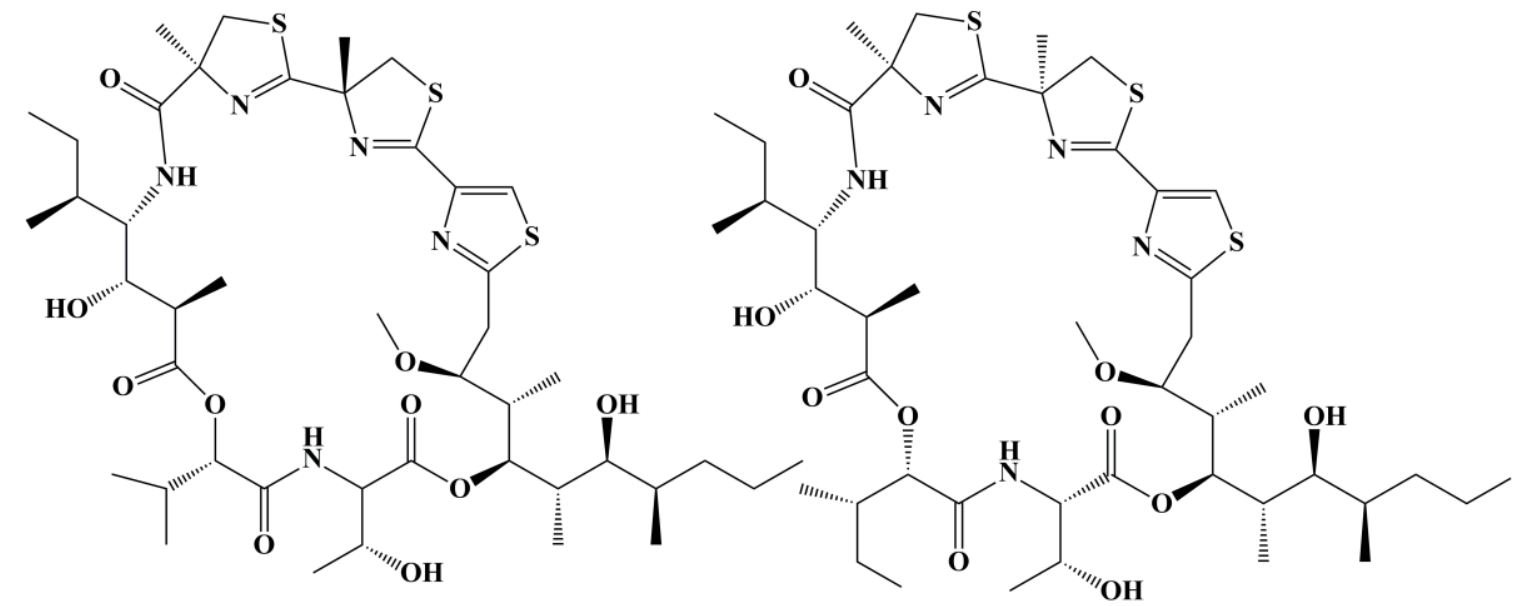

Hoiamide A (23)

Hoiamide B (24)<smiles>CC[C@H](C)C(=O)N1[C@H]([C@@H](C)CC)C(=O)N2CCC[C@H]2C(=O)NC(C(C)Cc2ccccc2)C(=O)N2CCC[C@H]2C(=O)NC(C(C)C)C(C)C(=O)OC(C)C(=O)N2CCC[C@H]2C(=O)O[C@@H](C(C)C)C(=O)N1CCCCCCCCC(C)=O</smiles>

Homodolastatin 16 (25)

Largazole (26)

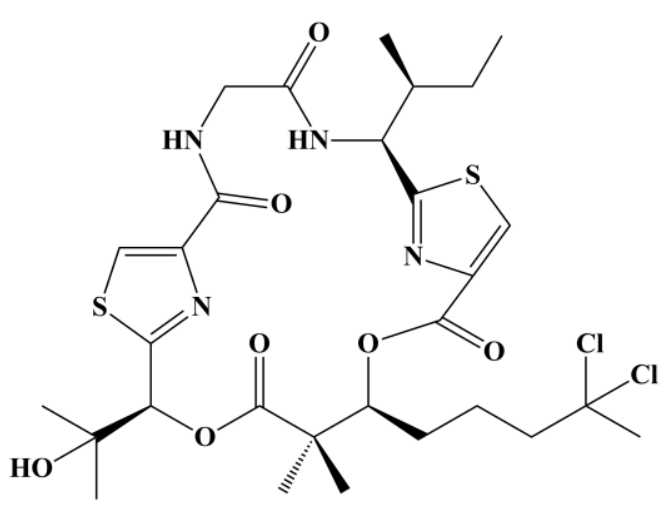

Lyngbyabellin A (27)

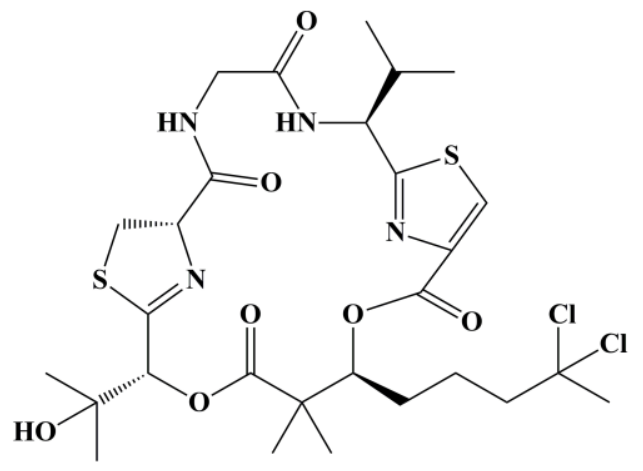

Lyngbyabellin B (28)

Figure 4. Isolated marine cyanobacteria-derived peptides (23-28). 


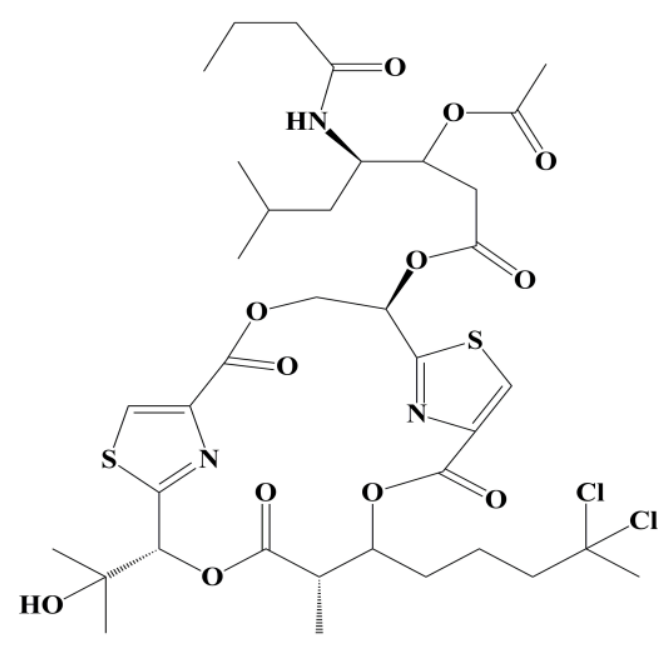

Lyngbyabellin E (29)<smiles>CC(C(=O)OC(c1nc(C(=O)OCC(O)c2nc(C(=O)OC(CCCC(C)(Cl)Cl)C(C)(C)O)cs2)cs1)C(C)(C)O)C(C)(C)O</smiles>

Lyngbyabellin G (31)<smiles>CCCC(=O)NC(CC(C)C)C(CC(=O)OCC(O)c1nc(C(=O)OC(CCCC(C)(Cl)Cl)C(C)C(=O)OC(c2nc(C(=O)OC)cs2)C(C)C)cs1)OC(C)=O</smiles>

Lyngbyabellin I (33)<smiles>CCCC(=O)NC(CC(C)C)C(CC(=O)OCC(O)c1nc(C(=O)O[C@@H](CCCC(C)(Cl)Cl)[C@@H](C)C(=O)OC(c2nc(C(=O)OC)cs2)C(C)(C)O)cs1)OC(C)=O</smiles>

Lyngbyabellin F (30)

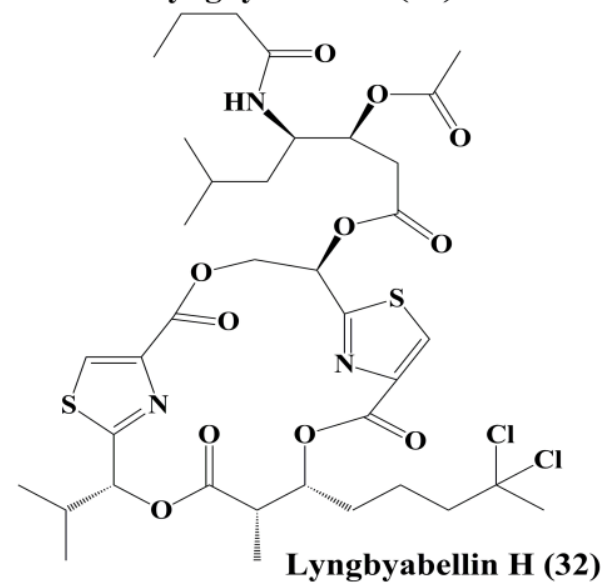

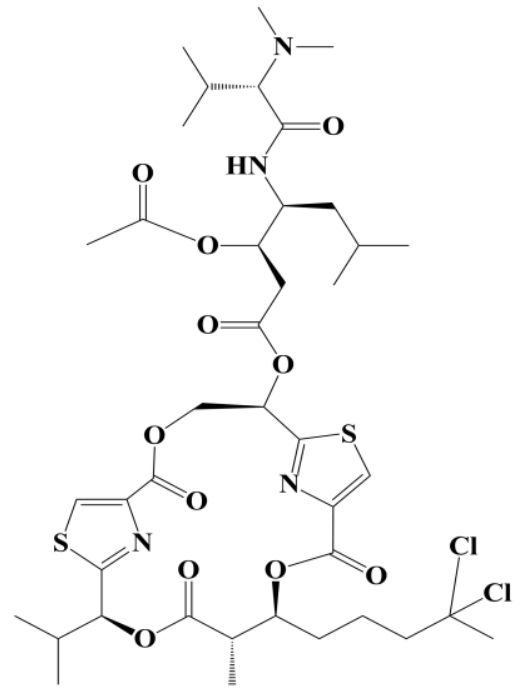

Lyngbyabellin N (34)

Figure 5. Isolated marine cyanobacteria-derived peptides (29-34).

Obyanamide (37) (Figure 6), a cyclic depsipeptide isolated from lyngbya confervoides, has demonstrated significant cytotoxicity to the kB and LoVo cells [114]. Palau'amide (38) (Figure 6) is a cyclical depsipeptide isolated from the same marine cyanobacteria Lyngbya sp., which has shown significant cytotoxicity to kB cells [115]. Palmyramide A (39) contributes to cytotoxicity in neuro-2a cells possibly through blocking the voltage regulated sodium channel. Palmyramide A has shown moderate 
cytotoxic effects on human lung cell line H-460 [116]. Pitipeptolides A (40), and B (41) (Figure 6), cyclic depsipeptides isolated from a marine cyanobacterium Lyngbya majuscule, were reported to possess cytotoxic action against HT29 colon adenocarcinoma cancer cells [117]. Apart from that pitipeptolide A and B also exhibit cytotoxicity against LoVo cells [118].

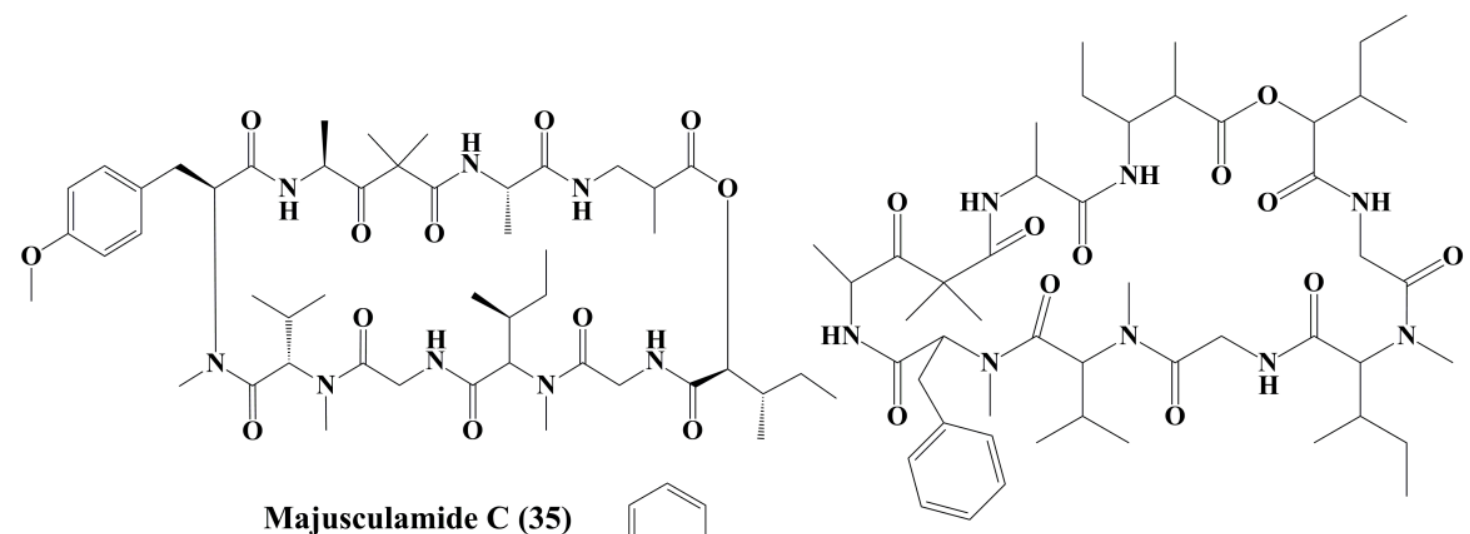

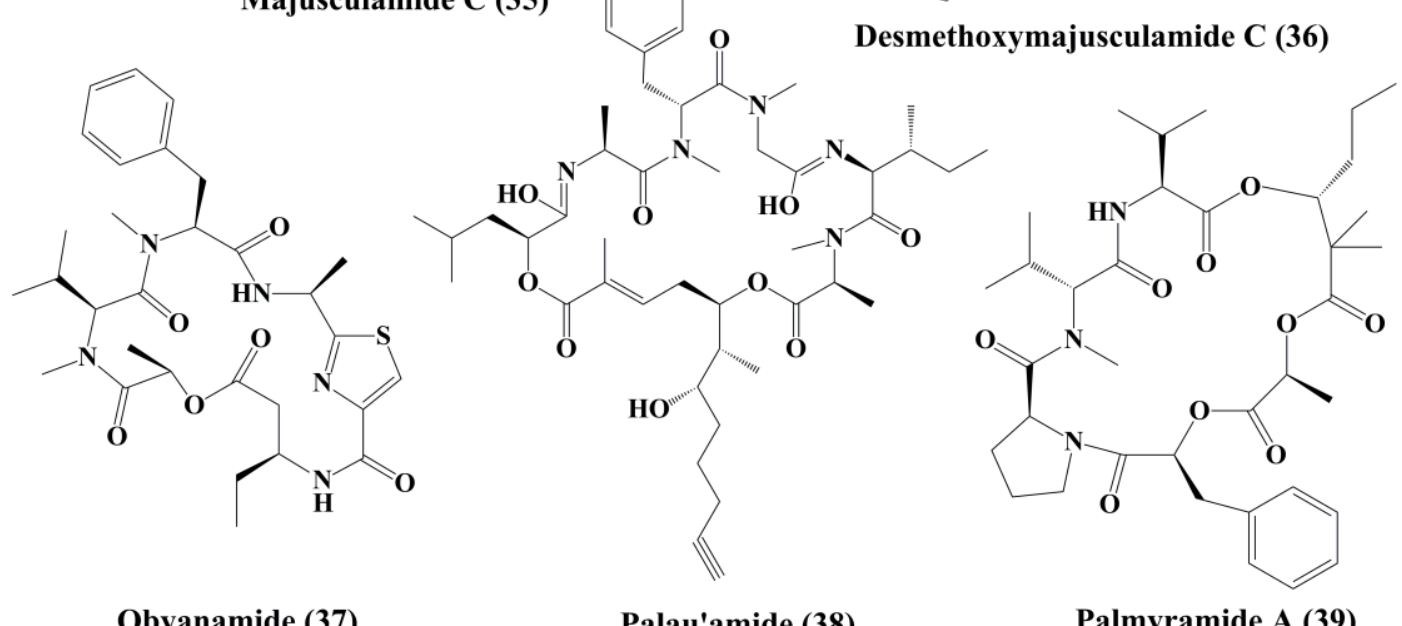

Obyanamide (37)

Palau'amide (38)

Palmyramide A (39)<smiles>C=CCCC(OC(=O)CNC(=O)[C@@H](NC(=O)C1CCCN1C(=O)C(OC(=O)C(Cc1ccccc1)N(C)C(=O)C(NC(=O)C(CC)C(C)C)C(C)CC)C(C)C)C(C)(C)C)C(=O)NC</smiles>

Pitipeptolide A (40)<smiles>C=CCCCC(OC(=O)CNC(=O)[C@@H](NC(=O)C1CCCN1C(=O)C(OC(=O)C(Cc1ccccc1)N(C)C(=O)C(NC(=O)C(CC)C(C)CC)C(C)CC)C(C)C)C(C)(C)C(=O)NC)C(C)CC</smiles>

Pitipeptolide B (41)

Figure 6. Isolated marine cyanobacteria peptides (35-41).

Pitiprolamide (42) (Figure 7) a cyclic depsipeptide obtained from Lyngbya majuscule, showed cytotoxicity against MCF7 breast adenocarcinoma and HCT116 colorectal carcinoma cell lines [119]. Tasipeptins A (43) and B (44) (Figure 7), cyclic depsipeptides derived from Symploca sp., 
exhibitedcytotoxicity against kB oral epidermoid cancer cells [120]. Ulongapeptin (45) (Figure 7), a cyclic depsipeptide obtained from Lyngbya sp., possessed cytotoxicity against $\mathrm{kB}$ oral epidermoid cancer cells [121]. Veraguamides A-G (46-52) (Figures 7 and 8) are cyclic hexadepsipeptide obtained from Symploca cf. hydnoides [120]. These metabolites demonstrated cytotoxic property against HT29 colon adenocarcinoma and HeLa cervical carcinoma cells [122]. In addition, it also possessed potent cytotoxicity against the H-460 human lung cancer cell line [123]. Wewakpeptins A-D (53-56) (Figures 8 and 9) are depsipeptides obtained from Lyngbya semiplena that have exhibited anticancer activity by inhibiting the proliferation of H-460 lung cancer cells [124].

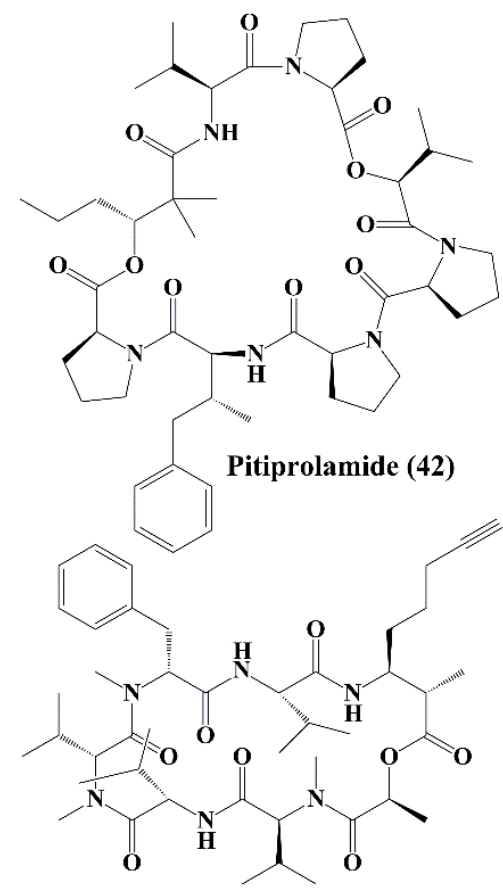

Ulongapeptin (45)

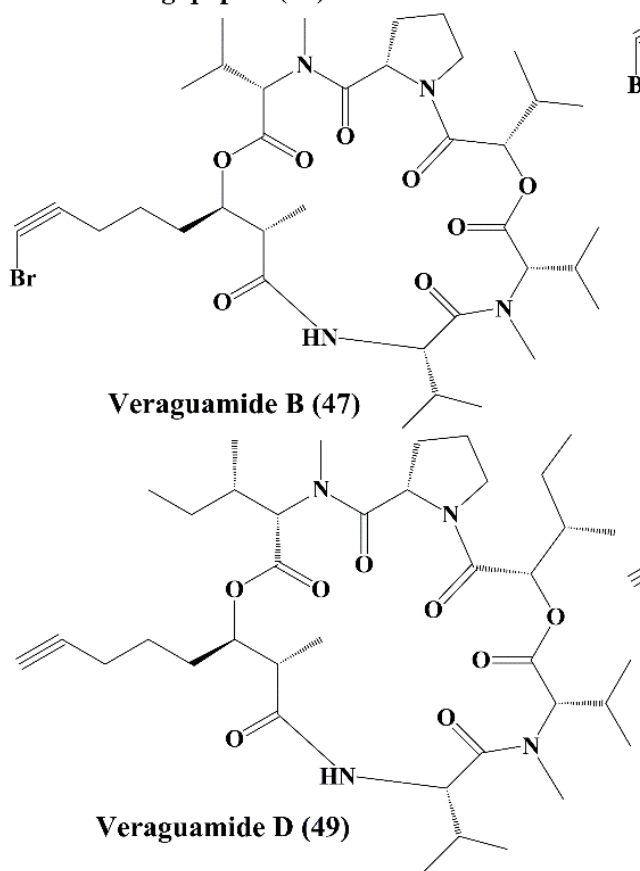

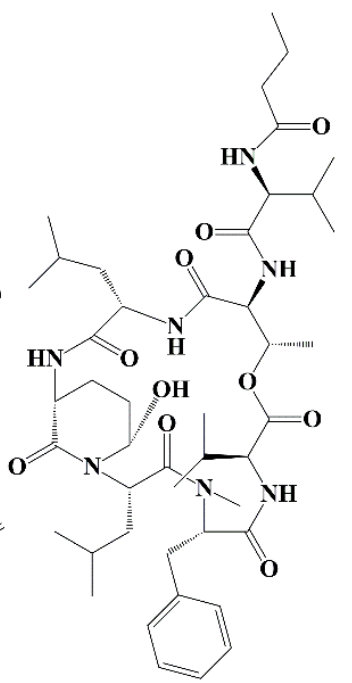

Tasipeptin A (43)

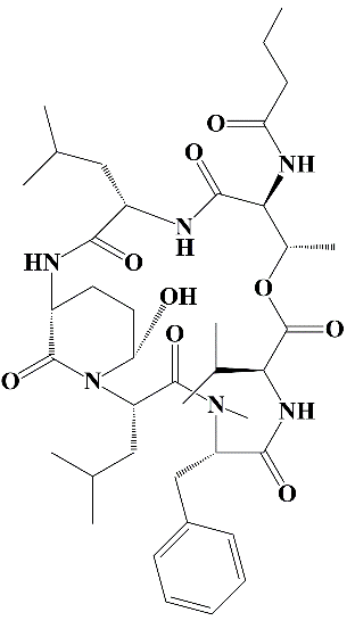

Tasipeptin B (44)<smiles>CCC(C)C(OC(=O)C(C(C)C)N(C)C(=O)C(C)C)C(=O)N1CCCC1C(=O)N(C)C(C(=O)OC(CCCC#CBr)C(C)C(=O)NCCCC#CBr)C(C)C</smiles>

Veraguamide A (46)<smiles>CCC(C)C(OC(=O)C(C(C)C)N(C)C(=O)C(CNC(=O)C(C)C(C)OC(=O)C(C(C)C)C(C)C)NC(=O)C1CCCN1C)C(=O)N1CCC1</smiles>

Veraguamide C (48)

Figure 7. Isolated marine cyanobacteria-derived peptides (42-49). 


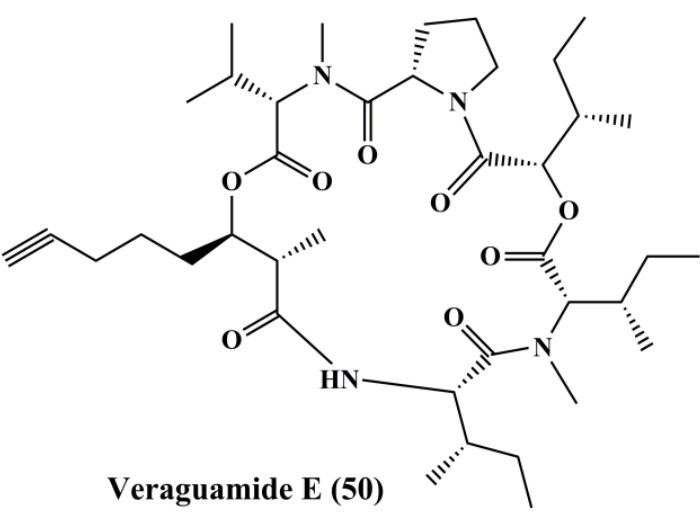

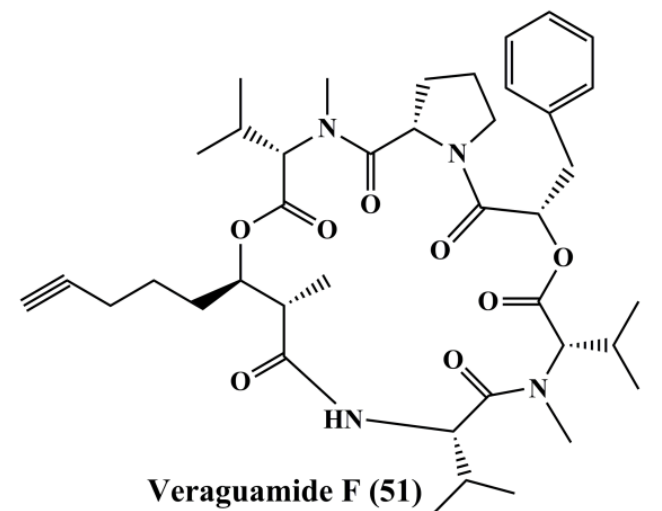

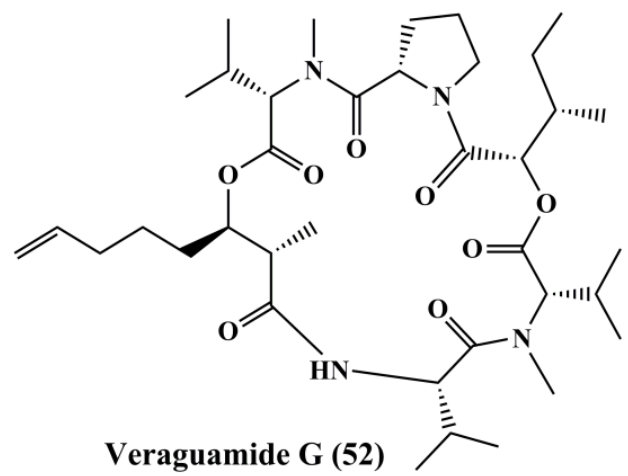

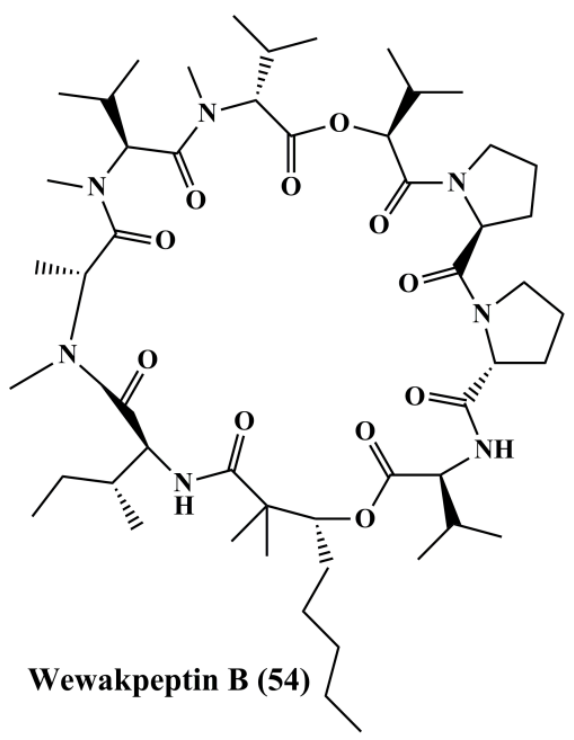

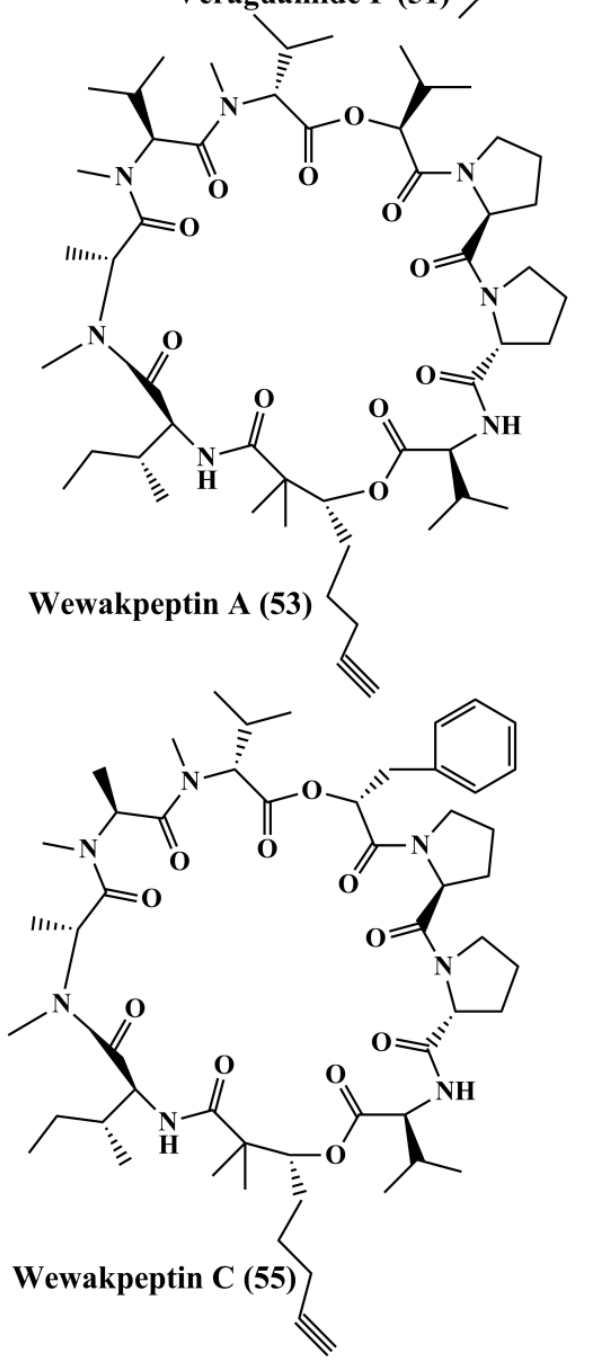

Figure 8. Isolated marine cyanobacteria peptides (50-55).

Nostocyclopeptide A1 (57) and A2 (58) (Figure 9), are cyclic heptapeptides isolated from Nostoc sp., displayed cytotoxicity against kB oral epidermoid cancer and LoVo colon cancer cells [125]. Symplocamide A (59), isolated from Symploca sp., is a cyclopeptide that showed potent cytotoxicity to H-460 non-small cell lung cancer cells and neuro-2a neuroblastoma cells [110]. Tasiamide (60) (Figure 9) is a cyclopeptide isolated from the cyanobacterium Symploca sp., which showed strong cytotoxicity against human nasopharyngeal carcinoma (kB) and LoVo cells [126]. Belamide A (61) (Figure 9) is categorized as a linear tetrapeptide with structural similarities to dolastatin 10 and dolastatin 15 that is isolated from cyanobacteria Symploca sp. It exhibited good cytotoxicity against HCT-116 colon cancer 
cell line [127]. This has been used to destabilize tubulin in vascular smooth muscle cells (A10) to induce antimitotic action [127].

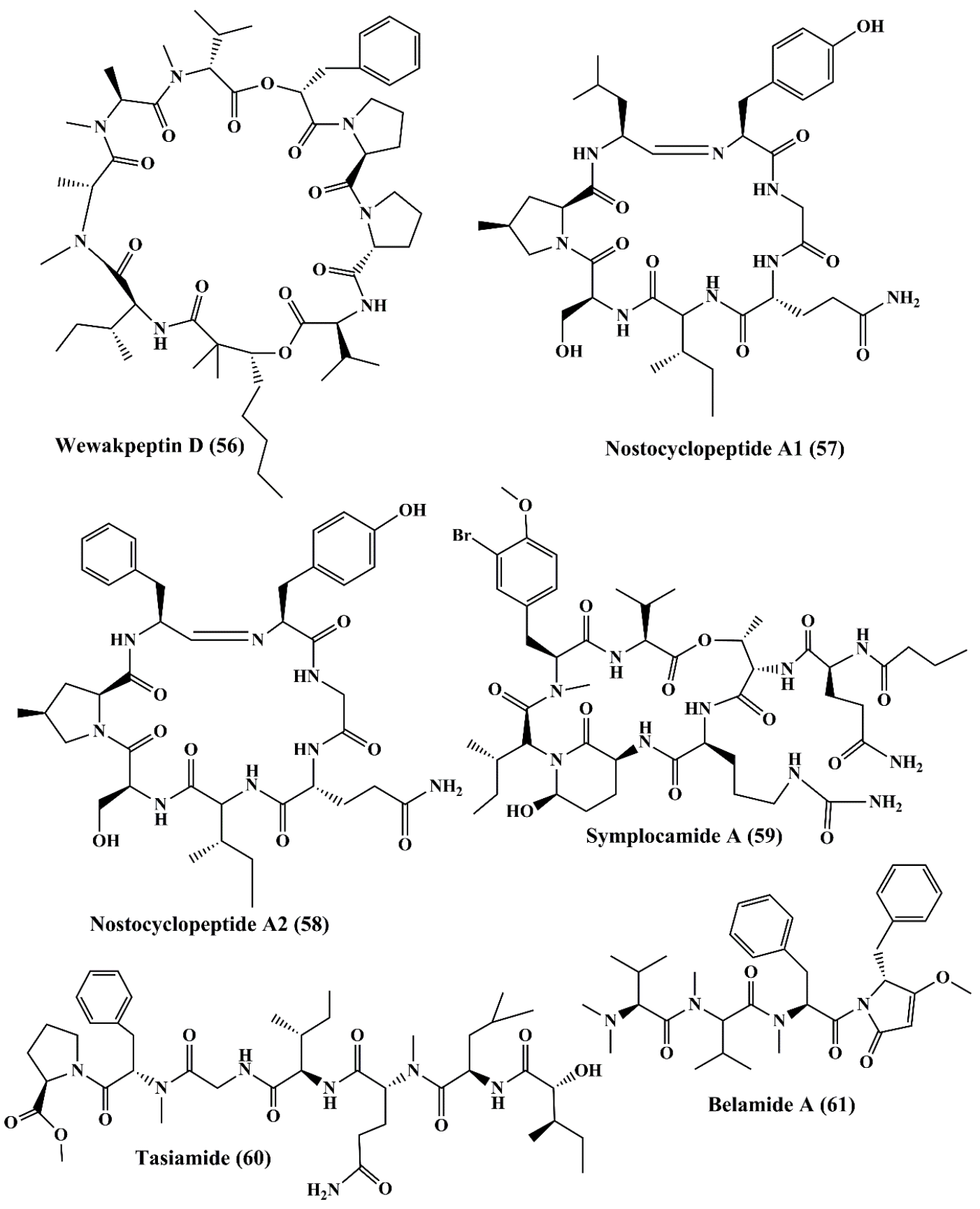

Figure 9. Isolated marine cyanobacteria peptides (56-61).

Bisebromoamide (62) (Figure 10) a peptide that is a marine toxic substance isolated from Lyngbya sp. $[128,129]$. It exhibited inhibition of the phosphorylation of extracellular signal-regulated kinases (ERK) in normal rat kidney epithelial (NRK) cells stimulated by platelet-derived growth factor [129]. Dragonamide (63) and pseudodysidenin (64) (Figure 10) are lipopeptides isolated from Lyngbya majuscule, and both exhibited cytotoxicity against P-388, A-549, HT-29, and MEL-28 carcinoma cells [130]. Kalkitoxin (65) (Figure 10), another lipopeptide is isolated from Lyngbya majuscule, was shown to decrease HCT116 colon cancer cell survival [131]. Somocystinamide A (66) (Figure 10), a lipopeptide obtained from the same cyanobacterium, exhibited antiproliferative activity against 
Jurkat (T cell leukemia), CEM leukemia, A549 lung carcinoma, Molt4T leukemia, M21 melanoma and U266 myeloma cells. It induced apoptosis via activation of caspase 8 [132].

Malyngamide 2 (67) (Figure 10), isolated from Lyngbya majuscule and Lyngbya sordid, displayed cytotoxicity against H-460 human lung carcinoma cells [133]. Malyngamide C (68), J (69), and K (70) (Figure 10) are documented to be the metabolites of Lyngbya majuscule, exhibited cytotoxicity against some cancer cell lines [134]. Malyngamide C showed cytotoxicity against NCI-H460, neuro-2a, and HCT-116 cancer cell lines [134]. Malyngamide J and K displayed cytotoxicity against NCI-H460 and neuro-2a cell lines [134].

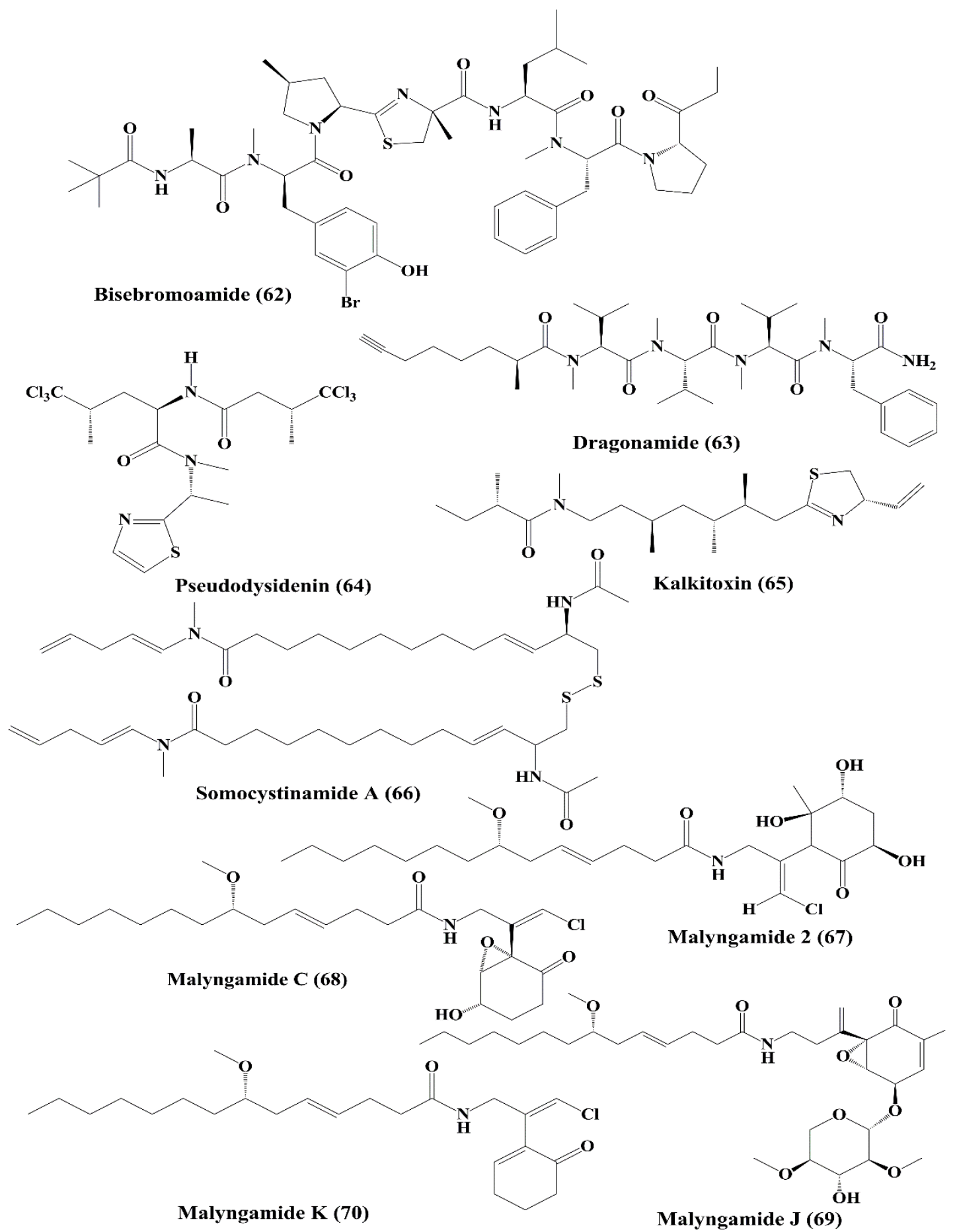

Figure 10. Isolated marine cyanobacteria-derived peptides (62-70). 
Malevamide D (71) (Figure 11), a peptide ester isolated from Symploca hydnoides, exhibited strong cytotoxicity against a panel of cancer cell line, such as P-388, human lung carcinoma (A-549), and human colon carcinoma (HT-29), and human melanoma (MEL-28) cells [135].Malyngolide dimer (72) (Figure 11) is a cyclodepsipeptide obtained from Lyngbya majuscule exhibited cytotoxicity when evaluated against the $\mathrm{H}-460$ human lung cell line [136].<smiles>CC[C@H](C)[C@H](C(=O)N[C@H](C(=O)N(C)C(C(C)C)C(C)C)[C@@H](CC(=O)N1CCC[C@H]1[C@H](OC)[C@@H](C)C(=O)O[C@H](CO)Cc1ccccc1)OC)N(C)C</smiles>

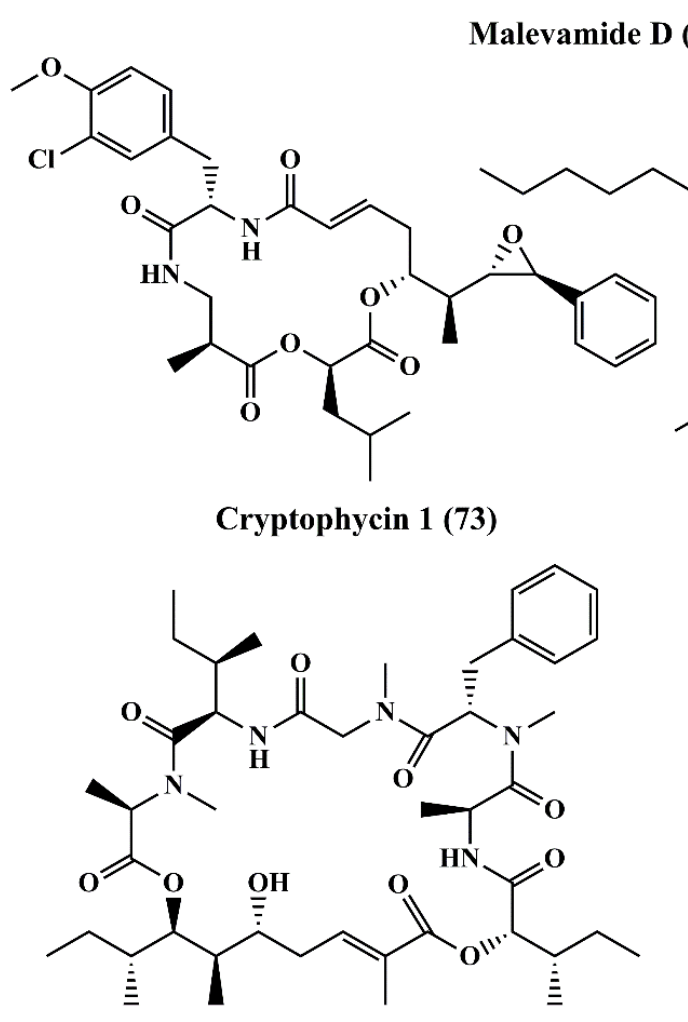

D (71)<smiles>C/C=C\C=C/[C@H]1O[C@@H]1[C@H](C)[C@@H](O)C/C=C\C(=O)N[C@H](Cc1ccc(OC)c(Cl)c1)C(=O)NCC</smiles>

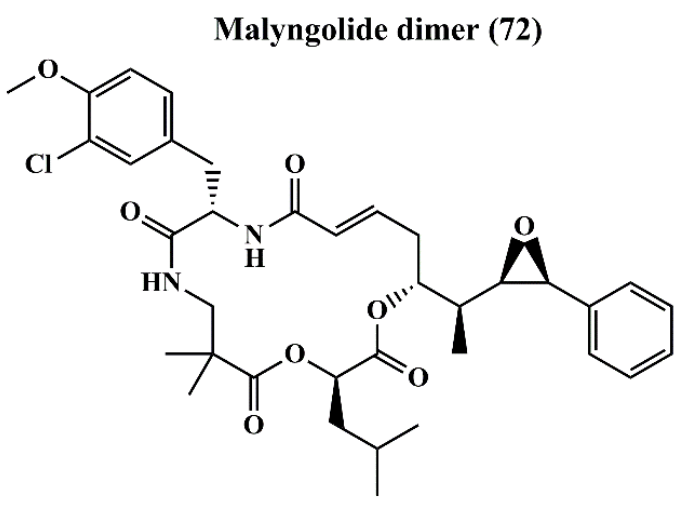

Cryptophycin 52 (74)

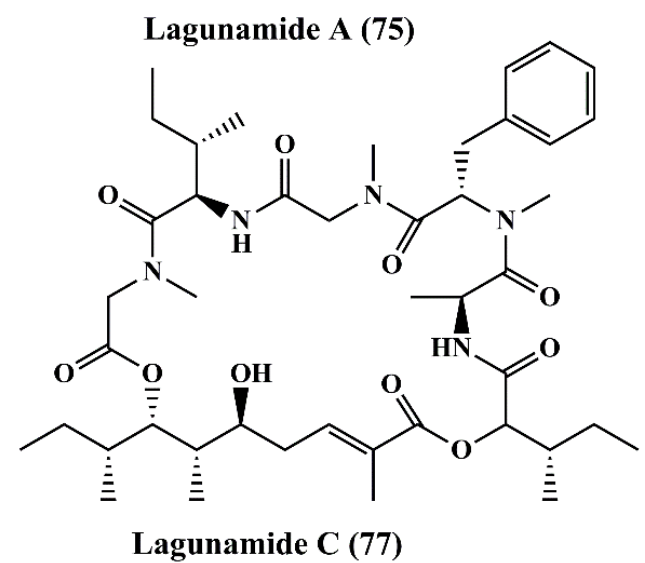

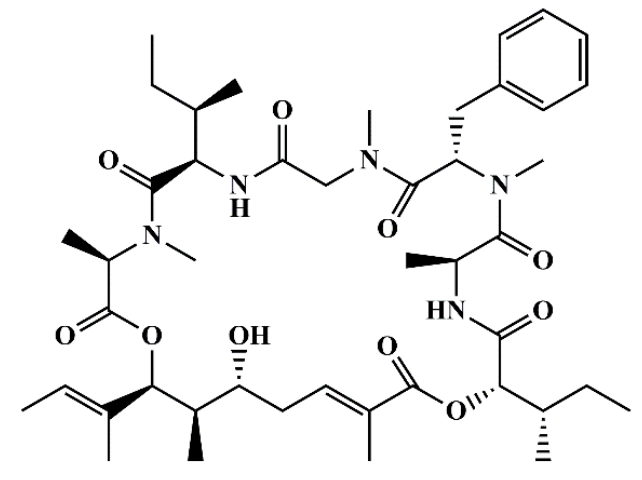

Lagunamide B (76)

Figure 11. Isolated marine cyanobacteria-derived peptides (71-77).

Cryptophycin 1 (73) and cryptophycin 52 (74) (Figure 11) are macrolide depsipeptides that are potent cytotoxic molecules. These are microtubule inhibitors bearing similar mechanism of action as that of Vinca alkaloids. Cryptophycin 1 is isolated from Nostoc sp., (blue green algae/cyanobacterium), 
showed anticancer activity against L1210 murine leukemia cells [137]. It binds with tubulin and triggers the disruption of microtubule assembly [138]. It exhibited cytotoxic function against KB cells and LoVo cell lines by inducing apoptosis [139]. It also displayed antiproliferative activity against MDA-MB-435 mammary adenocarcinoma and SKOV3 ovarian carcinoma cell lines by triggering cell cycle arrest at the G2/M Phase [140]. Cryptophycin 52 is a synthetic derivative of cryptophycin. Interestingly, even though it reached Phase II of the clinical trials, its development has been halted due to severe side effects [141]. Lagunamide A (75) and B (76) (Figure 11) are cyclic depsipeptides extracted from the marine cyanobacterium Lyngbya majuscule. Both the metabolites exhibited potent cytotoxicity against P388 (a murine leukemia cell line) [142]. Lagunamide C (77) (Figure 11) showed its cytotoxicity against carcinoma cell lines, such as P388, A549, PC3, HCT8, and SK-OV3 [143].

\subsection{Macrolides}

Biselyngbyaside (78) (Figure 12), obtained from the Lyngbya sp., is a secreted macrolide glycoside that induced apoptosis by nuclear condensation of mature osteoclasts [144]. Cytotoxicity has been demonstrated against HeLa S3, SNB-78 (central nervous system cancer) and NCI H522 (lung cancer) cells [144]. Biselyngbyasid B (79) (Figure 12), obtained from Lyngbya sp., showed cytotoxicity against HeLa S3 cells and HL60 cells [145]. Biselyngbyaside E (80) and F (81) (Figure 12) showed cytotoxic activity against HeLa and HL60 cells [146]. Lyngbyaloside B (82) (Figure 12), a macrolide glycoside isolated from Lyngbya sp., was shown to have a cytotoxic impact on $\mathrm{kB}$ cells and had a slightly reduced effect on LoVo cells [147]. Further, 2-epi-lyngbyalosid (83) (Figure 12), a macrolide glycoside extracted from Lyngbya bouillonii, demonstrated cytotoxic properties against HT29 colorectal adenocarcinoma and HeLa cells [148].

In addition, 18E-lyngbyaloside C (84) and 18Z-lyngbyaloside C (85) (Figure 13) also displayed potent cytotoxic property against HT29 colorectal adenocarcinoma and HeLa cells [148]. Biselyngbyolide A (86) and B (87) (Figure 13) are macrolide metabolites that have been isolated from the marine cyanobacterium Lyngbya sp., and have shown strong cytotoxicity against HeLa S3 cells and HL60 cells [149].Koshikalide (88) (Figure 13), a macrolide isolated from Lyngbya sp., displayed cytotoxic activity against $\mathrm{HeLa} \mathrm{S}_{3}$ cells [150]. Acutiphycin (89) and 20,21-didehydroacutiphycin (90) (Figure 13), both macrolides isolated from Oscillatoria acutissima, demonstrated cytotoxic activity against $\mathrm{kB}$ cells and NIH/3T3 cells [151]. Lyngbouilloside (91) (Figure 14), a macrolide glycoside isolated from cyanobacteria Lyngbya bouillonii showed cytotoxic effect against neuroblastoma cells [152]. Polycavernoside D (92) (Figure 14), another glycosidic macrolide isolated from cyanobacteria Okeania sp., exhibited cytotoxic effect against human lung cancer cells (H-460) [153]. 

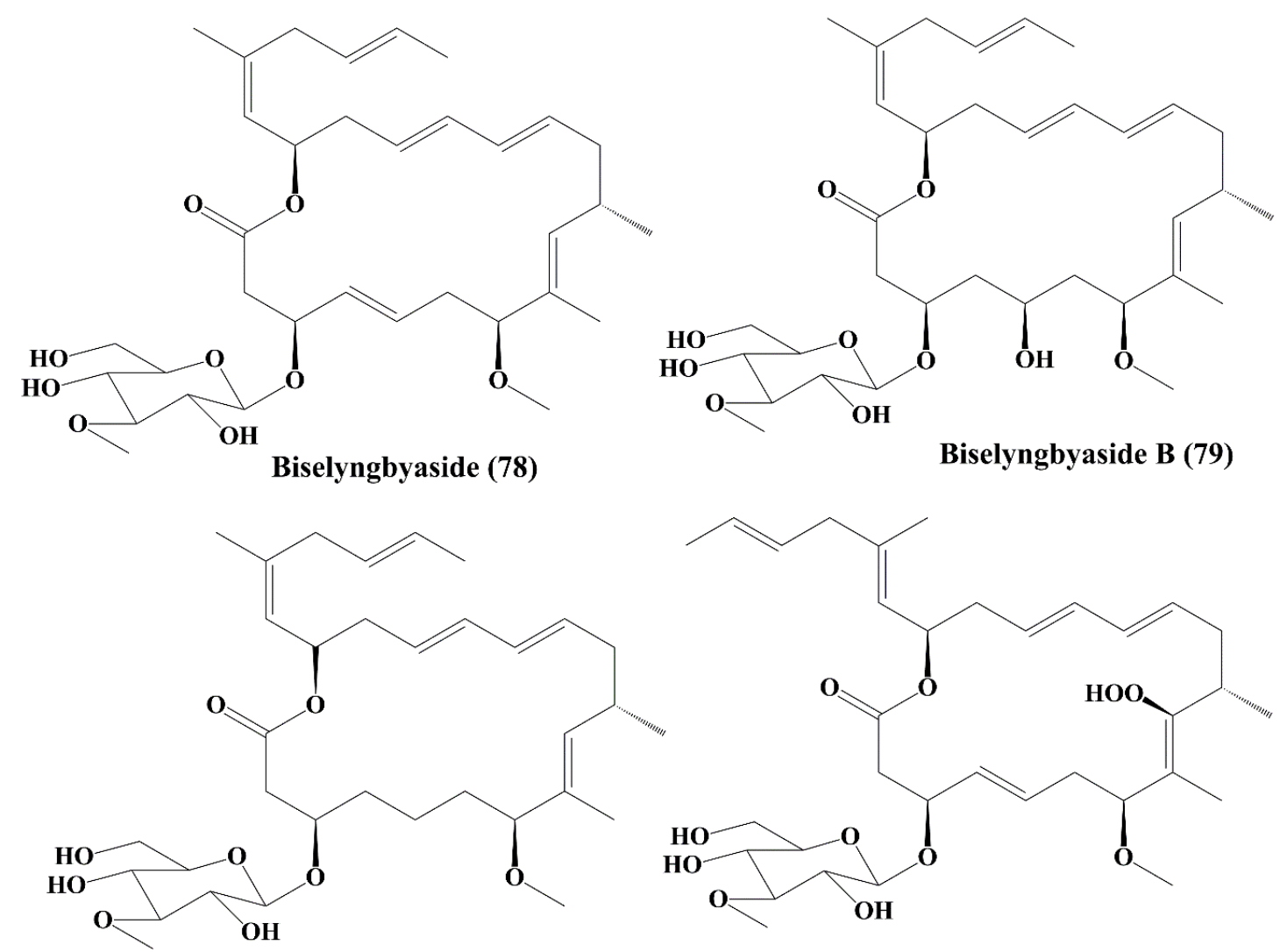

Biselyngbyaside E (80)

Biselyngbyaside F (81)

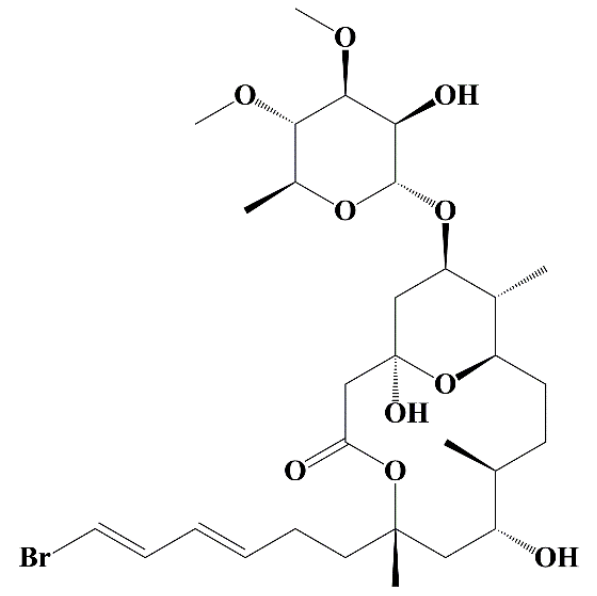

Lyngbyaloside B (82)

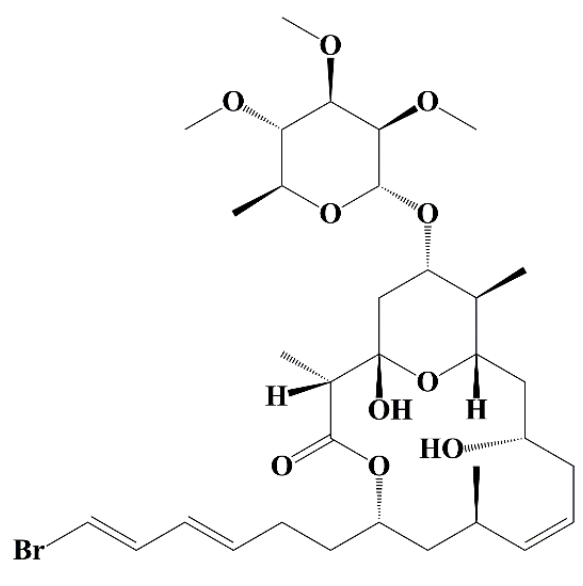

2-epi-lyngbyalosid (83)

Figure 12. Isolated marine cyanobacteria-derived macrolides (78-83). 


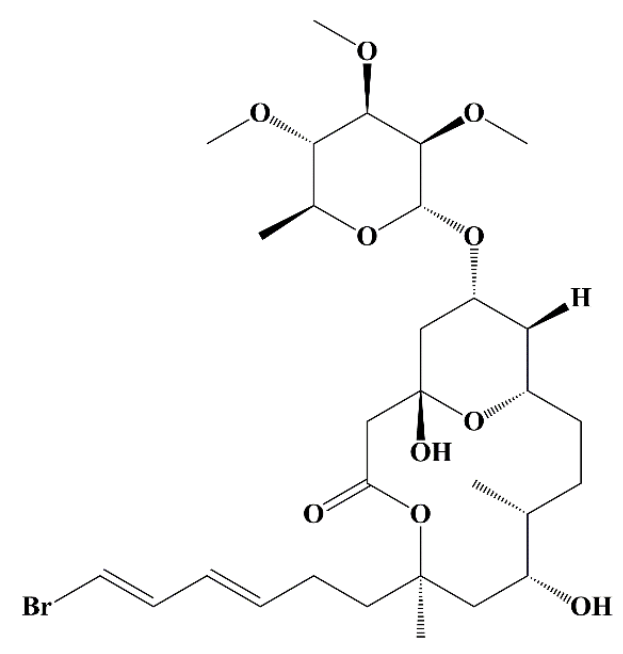

$18 E$-lyngbyaloside C (84)<smiles>C/C=C/C/C(C)=C\[C@H](C/C=C/C=C/C[C@@H](C)/C=C(\C)C(C[C@@H](O)C[C@@H](O)CC(=O)O)OC)OC</smiles>

Biselyngbyolide A (86)
Koshikalide (88)

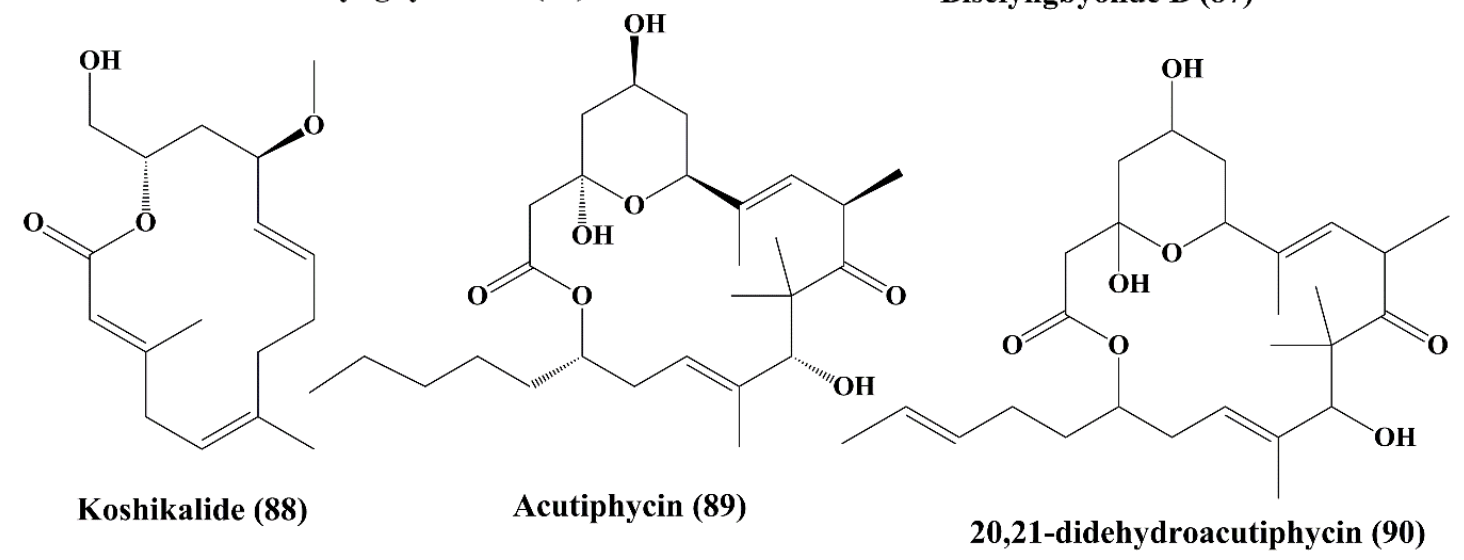

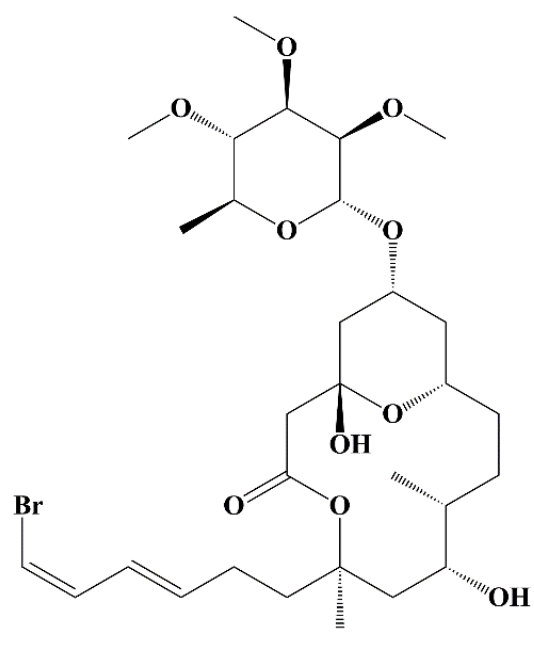

18Z-lyngbyaloside C (85)

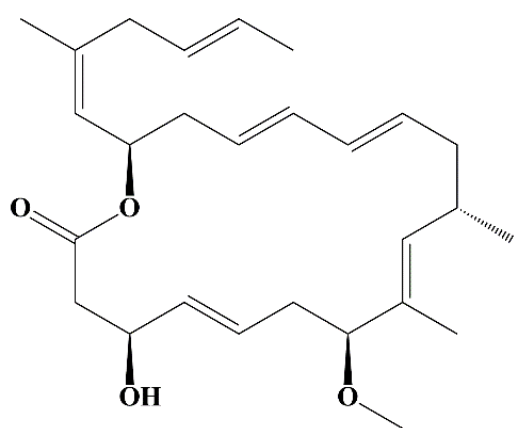

Biselyngbyolide B (87)

Figure 13. Isolated marine cyanobacteria-derived macrolides (84-90). 


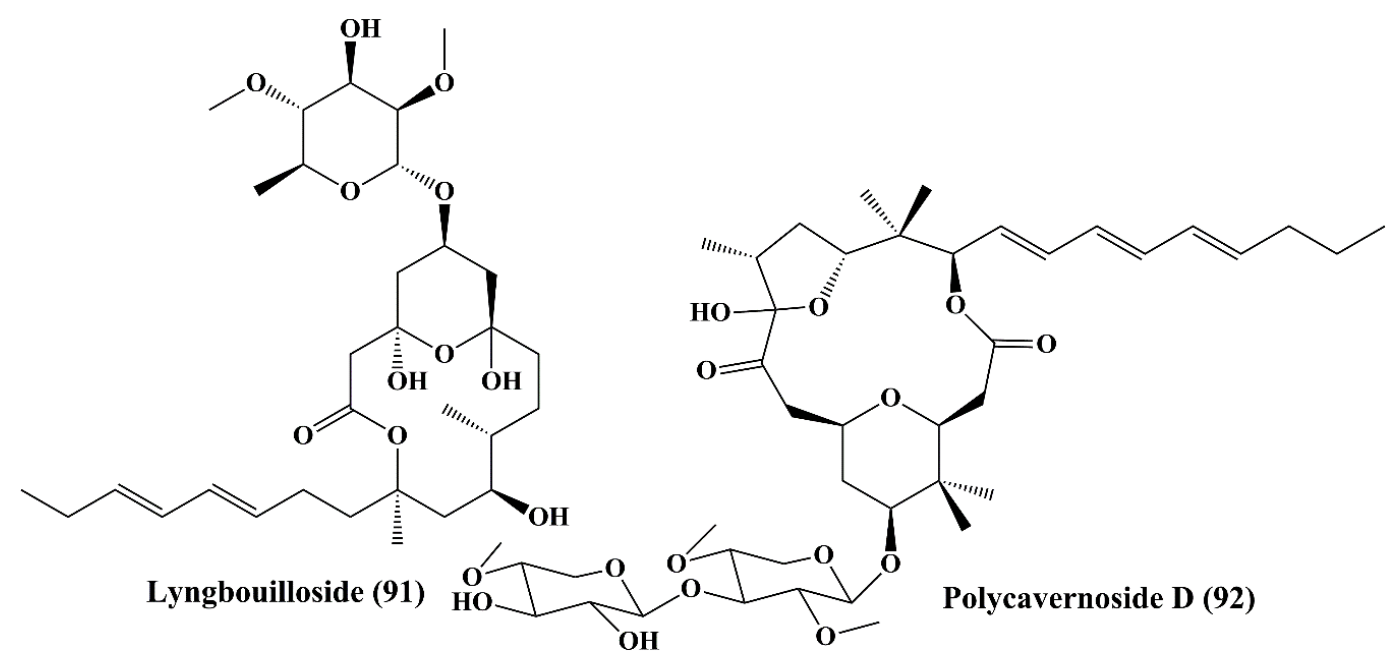

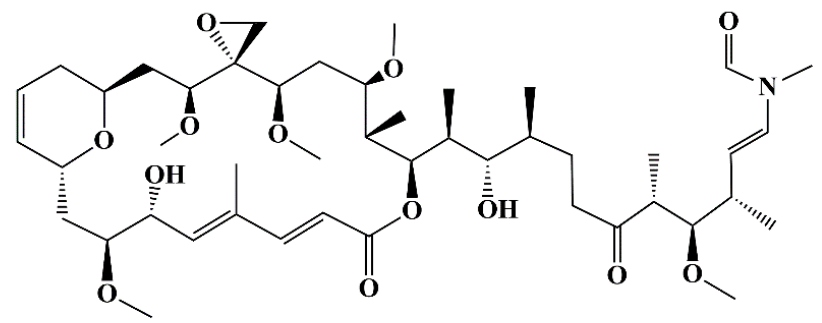

Tolytoxin (93)

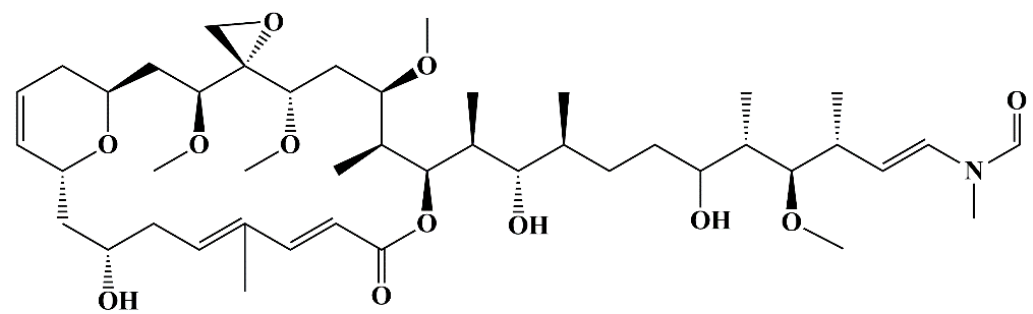

Scytophycin A (94)

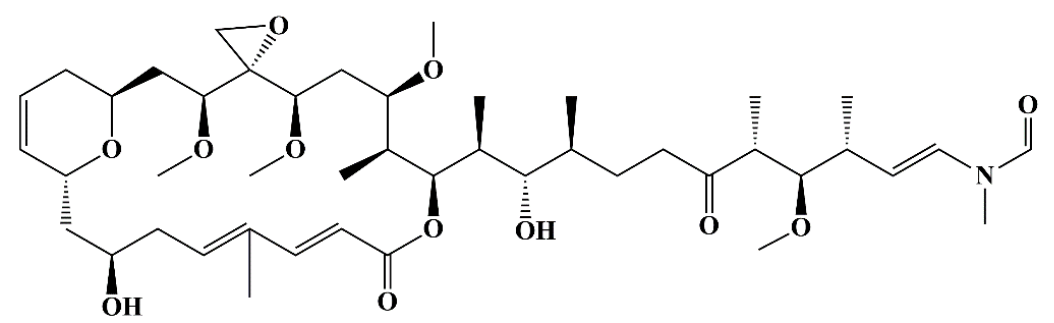

Scytophycin B (95)

Figure 14. Isolated marine cyanobacteria-derived macrolides and lactones (91-95).

\subsection{Lactones}

Tolytoxin (6-hydroxy-7-O-methyl-scytophycin B, 93) (Figure 14), a macrolide isolated from the lyophilized cells of Seytonema ocellaturn, exhibited cell growth inhibition of a panel of mammalian cells [154]. Scytophycin A-E (94-98) (Figures 14 and 15), were reported to be isolated from blue green alga Seytonema pseudohofmanni, exhibited cytotoxic effect against human carcinoma of nasopharynx cell (kB cells) [155]. Caylobolide A (99) (Figure 15) is a macrolactone obtained from cyanobacteria Lyngbya majuscula that has exhibited In vitro cytotoxicity against human colon tumor cells HCT 116 [156]. 
Caylobolide B (100) (Figure 15) is obtained from Phormidium sp., and this has exhibited cytotoxic activity against HT29 colorectal adenocarcinoma and HeLa cervical carcinoma cells [157].

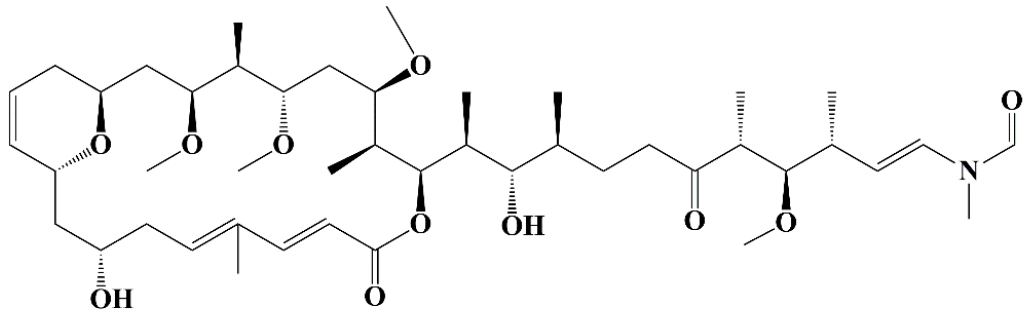

Scytophycin C (96)<smiles>COC(CC(C)C(OC(=O)/C=C/C(C)=C/CC(O)CC1C=CCC(CC(C)C(C)(O)C(C)OC)O1)C(C)[C@@H](O)C(C)CCC(=O)C(C)[C@@H](OC)[C@@H](C)/C=C/N(C)C=O)OC</smiles>

Scytophycin D (97)

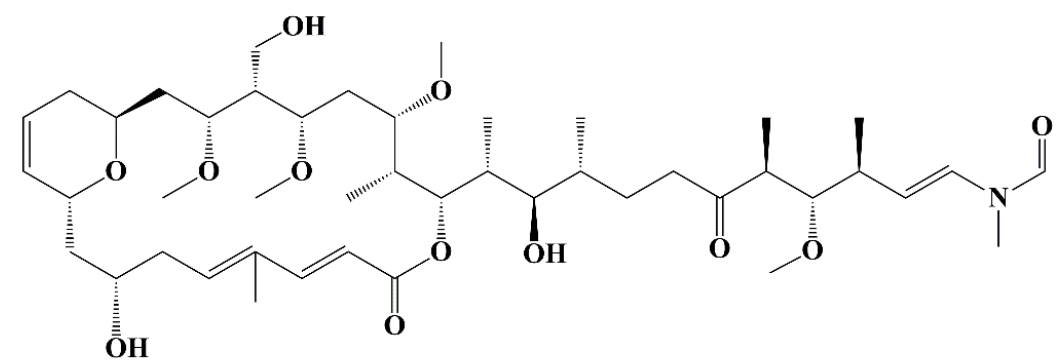

Scytophycin E (98)<smiles>CCCCC(C)C(CC(O)CCCC(O)C[C@@H](O)C[C@H](O)CCCC(O)CCCC(O)CCCC(O)CCCC(O)CCCC(O)CC(C)CC(=O)O)OC(O)CCCC(O)CO</smiles>

Caylobolide A (99)<smiles>CCCCC(C)C(CC(O)CCC[C@H](O)C[C@H](O)C[C@H](O)CCCC(O)CCCC(O)CCCC(O)CCCC(O)CC(O)CCCC(C)=CC(=O)O)OC</smiles>

Caylobolide B (100)

Figure 15. Isolated marine cyanobacteria-derived lactones (96-100). 


\subsection{Fatty Acid Amines}

Isomalyngamide A (101) (Figure 16) belongs to the class of fatty acid amines, which is isolated from the cyanobacteria Lyngbya majuscule and has inhibited the proliferation ofbreast cancer MCF-7 and MDA-MB-231 cells [158]. Isomalyngamide A-1 (102) (Figure 16) is extracted from cyanobacteria Lyngbya majuscule and Lyngbya sordida and has been shown to inhibit the proliferation of MDA-MB-231 cells [158]. Jamaicamides A (103), B (104), and C (105) (Figure 16) are fatty acid amines containing compound extracted from Lyngbya majuscule and Lyngbya sordida, showed cytotoxicity to both the H-460 human lung and neuro-2a mouse neuroblastoma cell lines [159].
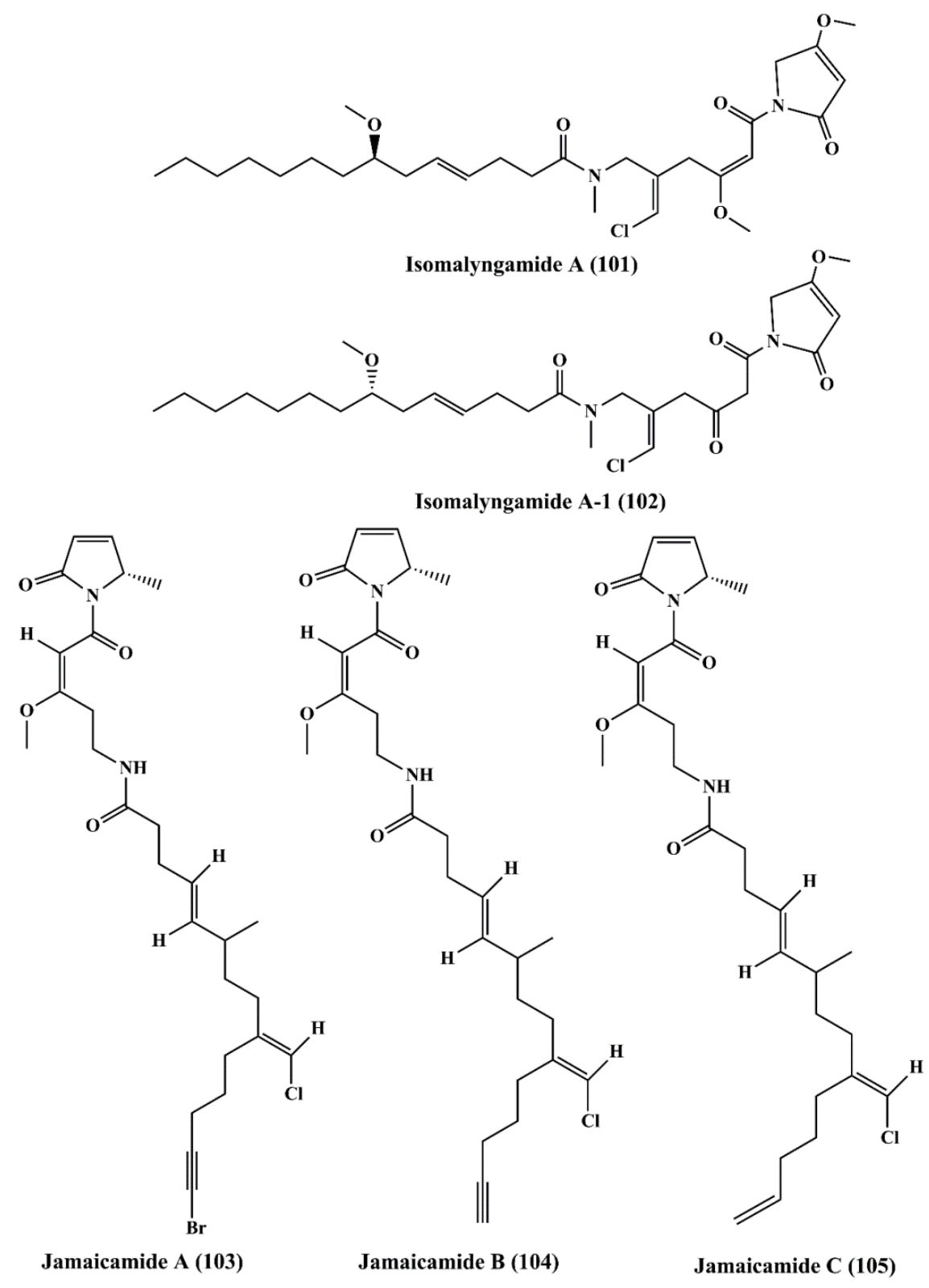

Figure 16. Isolated marine cyanobacteria-derived fatty acid amines (101-105).

\subsection{Pigment}

Scytonemin (106) (Figure 17) is a yellow-green pigment obtained from stigonema species of blue-green algae (cyanobacteria). It showed antiproliferative activity against Jurkat $\mathrm{T}$ cells by inducing apoptosis. The formation of mitotic spindle and the protein serine/threonine kinase activity was inhibited by scytonemin $[160,161]$. 


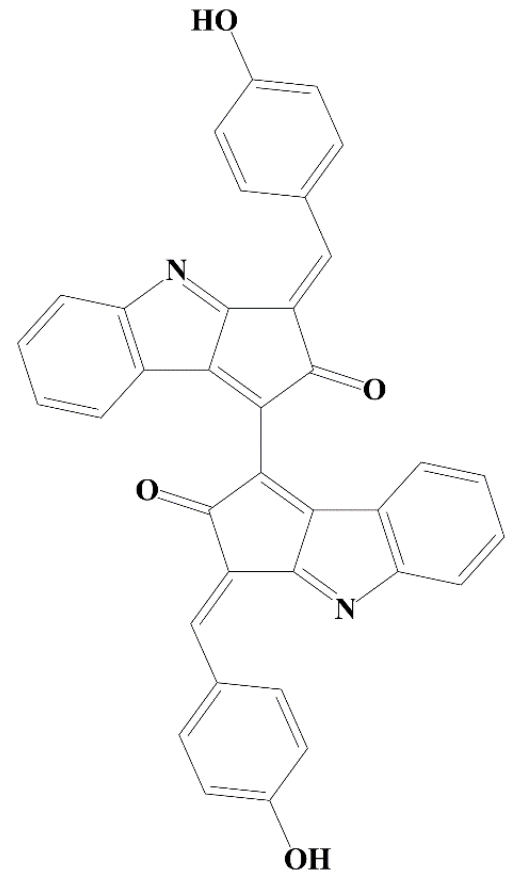

Scytonemin (106)

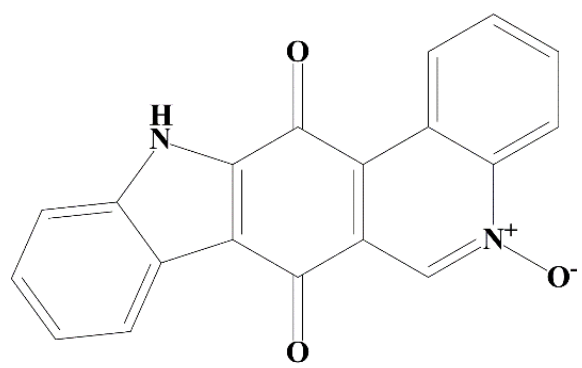

Calothrixin A (108)

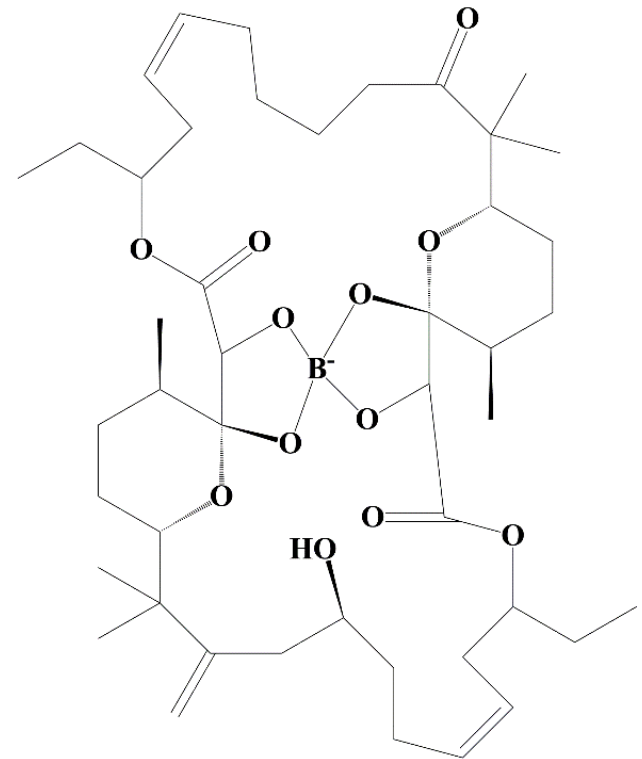

Borophycin (107)

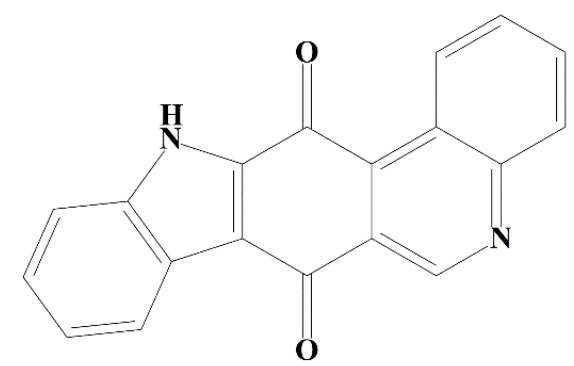

Calothrixin B (109)

Figure 17. Isolated marine cyanobacteria-derived pigment, boron containing metabolite, and phenanthridine alkaloids (106-109).

\subsection{Boron Containing Metabolite}

Borophycin (107) (Figure 17) is a boron-containing metabolite derived from marine blue-green algae (cyanobacterium) Nostoc spongiaeforme and N. linckia. It effectively showed anticancer activity against human cancer cell lines, namelyкB colorectal adenocarcinoma and LoVohuman epidermoid carcinoma $[48,162]$.

\subsection{Phenanthridine Alkaloids}

Calothrixins A (108) and B (109) (Figure 17) are phenanthridine alkaloids isolated from the marine cyanobacterium Calothrix sp. They possessed significant cytotoxicity and inhibited the proliferation of human carcinoma cell line (HeLa) [163,164]. It also inhibited the proliferation of CEM leukemia cells (human T-cell leukemia cells) by inducing cell cycle arrest at G1 and G2/M Phases [165].

\section{Microalgae Metabolites as Anticancer Drugs with Their Mechanisms of Action}

The following compounds have been reported from the microalgal species that have shown anticancer properties (Table 5). 
Table 2. Anticancer effects and mechanisms of action of various secondary metabolites of marine microalgae.

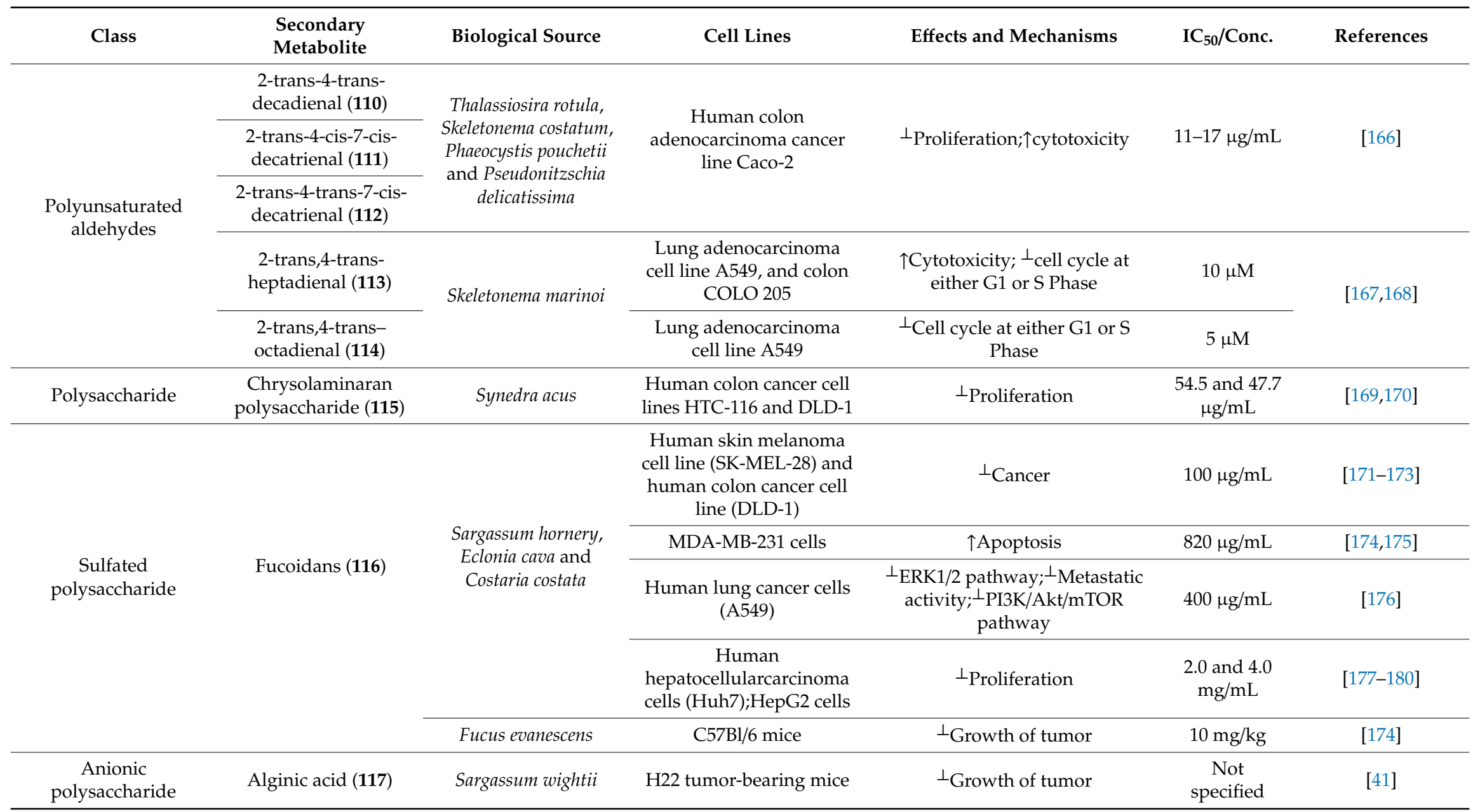


Table 3. Cont

\begin{tabular}{|c|c|c|c|c|c|c|}
\hline Class & $\begin{array}{l}\text { Secondary } \\
\text { Metabolite }\end{array}$ & Biological Source & Cell Lines & Effects and Mechanisms & $\mathrm{IC}_{50} /$ Conc. & References \\
\hline \multirow{5}{*}{ Polysaccharide } & \multirow{5}{*}{ Laminarin (118) } & \multirow{5}{*}{ Eisenia bicyclis } & $\begin{array}{c}\text { ES2 (ovarian clear cell } \\
\text { carcinoma cells); OV90 } \\
\text { (papillary serous } \\
\text { adenocarcinoma cells) cell } \\
\text { lines }\end{array}$ & $\begin{array}{l}{ }^{\perp} \text { Proliferation; } \uparrow \text { apoptosis; }{ }^{\perp} \text { cell } \\
\text { cycle at subG1 Phase }\end{array}$ & $2 \mathrm{mg} / \mathrm{mL}$ & {$[181,182]$} \\
\hline & & & $\begin{array}{c}\text { JB6 Cl41 (normal mouse } \\
\text { epidermal cells); } \\
\text { SK-MEL-28 (human } \\
\text { malignant melanoma) cells }\end{array}$ & ${ }^{\perp}$ Cancer & $\begin{array}{c}\text { Not } \\
\text { specified }\end{array}$ & {$[183,184]$} \\
\hline & & & $\begin{array}{l}\text { Human colon cancer cell } \\
\text { lines, such as HCT-116, } \\
\text { HT-29, and DLD-1 }\end{array}$ & $\uparrow$ Cytotoxicity & $200 \mu \mathrm{g} / \mathrm{mL}$ & {$[182,185-188]$} \\
\hline & & & $\begin{array}{l}\text { Human colon carcinoma } \\
\text { cells (LoVo) }\end{array}$ & $\uparrow$ Apoptosis & $\begin{array}{c}\text { Not } \\
\text { specified }\end{array}$ & [189] \\
\hline & & & $\begin{array}{c}\text { Human colon cancer cell } \\
\text { line (HT-29) }\end{array}$ & $\begin{array}{c}\uparrow \text { Apoptosis, } \perp_{\text {cell cycle at subG1 }} \\
\text { and G2-M Phase }\end{array}$ & $5 \mathrm{mg} / \mathrm{mL}$ & [190-192] \\
\hline \multirow{4}{*}{ Carotenoids } & \multirow{3}{*}{ Violaxanthin (119) } & \multirow{3}{*}{ Dunaliella tertiolecta } & MCF-7 cancer cell line & 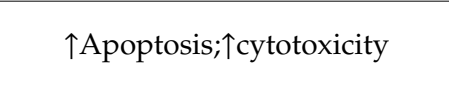 & $\begin{array}{l}20 \text { and } 40 \\
\mu \mathrm{g} / \mathrm{mL}\end{array}$ & [193-196] \\
\hline & & & $\begin{array}{l}\text { L1210 (human MDR1 } \\
\text { gene-transfected mouse } \\
\text { lymphoma cells); } \\
\text { MDA-MB-231 (human } \\
\text { breast cancer cells) }\end{array}$ & \multirow{2}{*}{$\begin{array}{c}\perp_{\mathrm{P} \text {-glycoprotein }}(\mathrm{P} \text {-gp) and } \\
\text { MRP1 }\end{array}$} & \multirow{2}{*}{$\begin{array}{c}\text { Not } \\
\text { specified }\end{array}$} & [197] \\
\hline & & & $\begin{array}{c}\text { Human MDR1 } \\
\text { gene-transfected mouse } \\
\text { lymphoma; } \\
\text { MCF-7 (human breast } \\
\text { cancer cell) }\end{array}$ & & & [198] \\
\hline & Neoxanthin (120) & Tetraselmis suecica & HeLa; A549 cancer cells & $\uparrow$ Cytotoxicity & $\begin{array}{c}\text { Not } \\
\text { specified }\end{array}$ & [199] \\
\hline
\end{tabular}


Table 4. Cont

\begin{tabular}{|c|c|c|c|c|c|c|}
\hline Class & $\begin{array}{l}\text { Secondary } \\
\text { Metabolite }\end{array}$ & Biological Source & Cell Lines & Effects and Mechanisms & $\mathrm{IC}_{50} /$ Conc. & References \\
\hline & Fucoxanthin (121) & Undaria pinnatifida & $\begin{array}{l}\text { Human leukemia cell line } \\
\text { (HL-60) }\end{array}$ & $\begin{array}{c}{ }^{\perp} \text { Proliferation; } \uparrow a p o p t o s i s ;{ }^{\perp} \text { cell } \\
\text { cycle at G0/G1 Phase or G2/M } \\
\text { Phase }\end{array}$ & $22.6 \mu \mathrm{M}$ & [200-205] \\
\hline & \multirow[t]{2}{*}{ Siphonaxanthin (122) } & \multirow{2}{*}{$\begin{array}{c}\text { Codium fragile, } \\
\text { Caulerpa lentillifera } \\
\text { and Umbraulva } \\
\text { japonica }\end{array}$} & $\begin{array}{c}\text { Human leukemia cell line } \\
\text { (HL-60) }\end{array}$ & $\begin{array}{c}\uparrow \text { Apoptosis; } \uparrow \text { chromatin } \\
\text { condensation; } \downarrow \text { Bcl-2; } \\
\uparrow \text { caspase-3; } \uparrow G A D D 5 \alpha ; \uparrow D R 5\end{array}$ & $10 \mu \mathrm{M}$ & [206] \\
\hline & & & $\begin{array}{c}\text { Human umbilical vein } \\
\text { endothelial cells (HUVECs) }\end{array}$ & 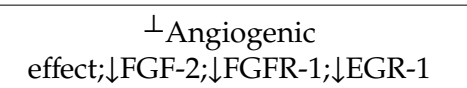 & $2.5 \mu \mathrm{M}$ & [207-209] \\
\hline & Zeaxanthin (123) & $\begin{array}{c}\text { Porphyridium } \\
\text { cruentum, Isochrysis } \\
\text { galbana, Phaeodactylum } \\
\text { tricornutum, } \\
\text { Tetraselmis suecica and } \\
\text { Nannochloropsis } \\
\text { gaditana }\end{array}$ & $\begin{array}{c}\text { Human colon } \\
\text { adenocarcinoma cell line } \\
\text { (HT-29) }\end{array}$ & $\uparrow$ Cytotoxicity & $10 \mu \mathrm{M}$ & {$[210,211]$} \\
\hline $\begin{array}{l}\text { Xanthophyll } \\
\text { carotenoids }\end{array}$ & Lutein (124) & $\begin{array}{c}\text { Porphyridium } \\
\text { cruentum, Isochrysis } \\
\text { galbana, Phaeodactylum } \\
\text { tricornutum, } \\
\text { Tetraselmis suecica and } \\
\text { Nannochloropsi } \\
\text { sgaditana }\end{array}$ & $\begin{array}{c}\text { Human colon } \\
\text { adenocarcinoma cell line } \\
\text { (HT-29) }\end{array}$ & $\uparrow$ Cytotoxicity & $\begin{array}{c}\text { Not } \\
\text { specified }\end{array}$ & [211] \\
\hline Sterol & Stigmasterol (125) & Navicula incerta & $\begin{array}{c}\text { Human liver cancer cell } \\
\text { line (HepG2) }\end{array}$ & 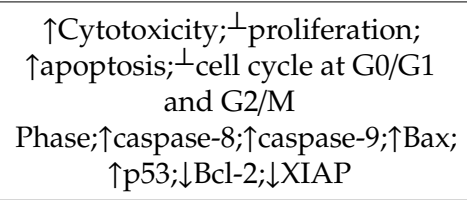 & $20 \mu \mathrm{M}$ & {$[213,214]$} \\
\hline Fatty alcohol ester & $\begin{array}{l}\text { Nonyl 8-acetoxy- } \\
\text { 6-methyloctanoate } \\
\text { (126) }\end{array}$ & $\begin{array}{l}\text { Phaeodactylum } \\
\text { tricornutum }\end{array}$ & $\begin{array}{c}\text { Human promyelocytic } \\
\text { leukemia cell line (HL-60), } \\
\text { a human lung carcinoma } \\
\text { cell line (A549) and a } \\
\text { mouse melanoma cell line } \\
\text { (B16F10). }\end{array}$ & $\begin{array}{c}\uparrow \text { Apoptosis; }{ }^{\perp} \text { cell cycle at the sub } \\
\text { G1 Phase }\end{array}$ & $\begin{array}{c}65.15 \mu \mathrm{M}, \\
50 \mu \mathrm{g} / \mathrm{mL}, \\
\text { not specified }\end{array}$ & [215] \\
\hline
\end{tabular}


Table 5. Cont.

\begin{tabular}{|c|c|c|c|c|c|c|}
\hline Class & $\begin{array}{l}\text { Secondary } \\
\text { Metabolite }\end{array}$ & Biological Source & Cell Lines & Effects and Mechanisms & $\mathrm{IC}_{50} /$ Conc. & References \\
\hline Epimeric carotenoids & $\begin{array}{c}\text { Dinochrome A and B } \\
(127,128)\end{array}$ & Peridinium bipes & $\begin{array}{l}\text { GOTO (neuroblastoma } \\
\text { cells); OST (osteosarcoma } \\
\text { cells) and HeLa cells }\end{array}$ & $\begin{array}{l}{ }^{\perp} \text { Proliferation; }{ }^{\perp} \text { TPA-stimulated } \\
\text { 32P-incorporation into the } \\
\text { phosholipids of HeLa cells }\end{array}$ & $\begin{array}{c}5 \mu \mathrm{g} / \mathrm{mL} \text { and } \\
25 \mu \mathrm{g} / \mathrm{mL}\end{array}$ & [216] \\
\hline \multirow{4}{*}{$\begin{array}{l}\text { Porphyrin } \\
\text { Phaeophytins }\end{array}$} & $\begin{array}{c}\text { Porphyrinolactone } \\
\text { (129) }\end{array}$ & \multirow{4}{*}{ Cladophora fascicularis } & \multirow{4}{*}{ HeLa carcinoma cell line } & \multirow{4}{*}{$\begin{array}{c}{ }^{\perp} \text { Proliferation; }{ }^{\perp} \text { activation of } \\
\text { NF- } \mathrm{kB}\end{array}$} & \multirow{4}{*}{$50 \mu \mathrm{M}$} & \multirow{4}{*}{ [217] } \\
\hline & $\begin{array}{l}\text { 20-chlorinated }\left(13^{2}-S\right)- \\
\text { hydroxyphaeophytin } \\
\text { A (130) }\end{array}$ & & & & & \\
\hline & $\begin{array}{c}(132-S)- \\
\text { hydroxyphaeophytin } \\
\text { A (131) and B (132) }\end{array}$ & & & & & \\
\hline & $\begin{array}{c}(132-\mathrm{R})- \\
\text { hydroxyphaeophytin } \\
\text { A (133) and B (134) }\end{array}$ & & & & & \\
\hline Glycolipid & $\begin{array}{c}\text { Nigricanosides A } \\
(\mathbf{1 3 5}) \text { and B (136) and } \\
\text { methyl esters of } \\
\text { nigricanosides A (137) } \\
\text { and B (138) }\end{array}$ & Avrainvillea nigricans & $\begin{array}{l}\text { Human breast cancer } \\
\text { MCF-7 cells and human } \\
\text { colon cancer HCT-116 cells }\end{array}$ & $\begin{array}{c}\perp^{\perp} \text { Proliferation, antimitotic } \\
\text { activity, } \uparrow \text { tubulin polymerization } \\
\text { within the cell }\end{array}$ & $\begin{array}{c}\text { Not } \\
\text { specified }\end{array}$ & [218] \\
\hline
\end{tabular}

Various symbols $\left(\uparrow, \downarrow\right.$ and $\left.{ }^{\perp}\right)$ indicate increase, decrease and inhibition in the obtained variables, respectively. 


\subsection{Polyunsaturated Aldehydes (PUAs)}

Polyunsaturated aldehydes (PUAs) are derived from the marine diatoms Thalassiosira rotula, Skeletonema costatum, Phaeocystis pouchetii, and Pseudo-nitzschia delicatissima [166]. The PUAs isolated from these diatoms are 2-trans-4-trans-decadienal (110), 2-trans-4-cis-7-cis-decatrienal (111), and 2-trans-4-trans-7-cis-decatrienal (112) (Figure 18) [167]. These compounds exhibited potent antiproliferative and cytotoxic activity on human colon adenocarcinoma cancer line Caco-2 [167]. Three more PUAs such as 2-trans-4-trans-heptadienal, 2-trans-4-trans-octadienal, and 2-trans-4-trans-7-octatrienal (octatrienal) were reported to be extracted from marine diatom Skeletonema marinoi, among which 2-trans-4-trans-octadienal (113), and 2-trans-4-trans-heptadienal (114) were reported to possess significant cytotoxicity against lung adenocarcinoma cell line A549 and colon (COLO 205) cancer cells [168]. These metabolites also induced apoptosis, which is evident from the chromatin condensation, loss of membrane integrity, and nuclear fragmentation. These PUAs induced cell cycle arrest of all the carcinoma cell lines at either the G1 or S Phase associated with upregulation of caspase-3 and apoptosis-inducing factor 1 (AIFM1) [168]. None of the PUAs showed any toxicity on the human non-tumorigenic lung epithelial cell line BEAS-2B [168].
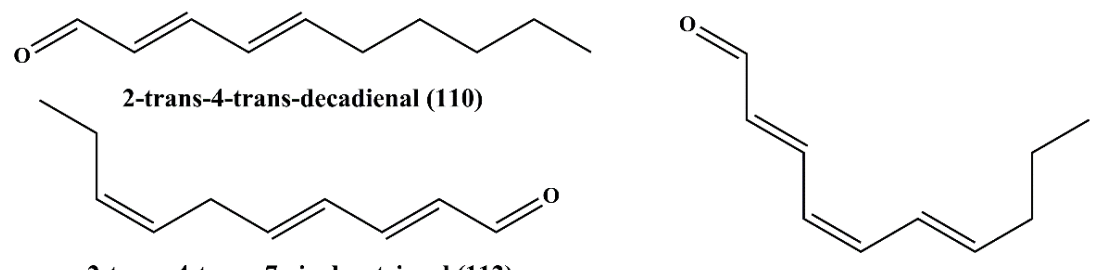

2-trans-4-trans-7-cis-decatrienal (112)

2-trans-4-cis-7-cis-decatrienal (111)<smiles>CCCC=CC=CC=O</smiles><smiles>CCC=CC=CC=O</smiles>

2-trans-4-trans-octadienal (113)

2-trans-4-trans-heptadienal (114)

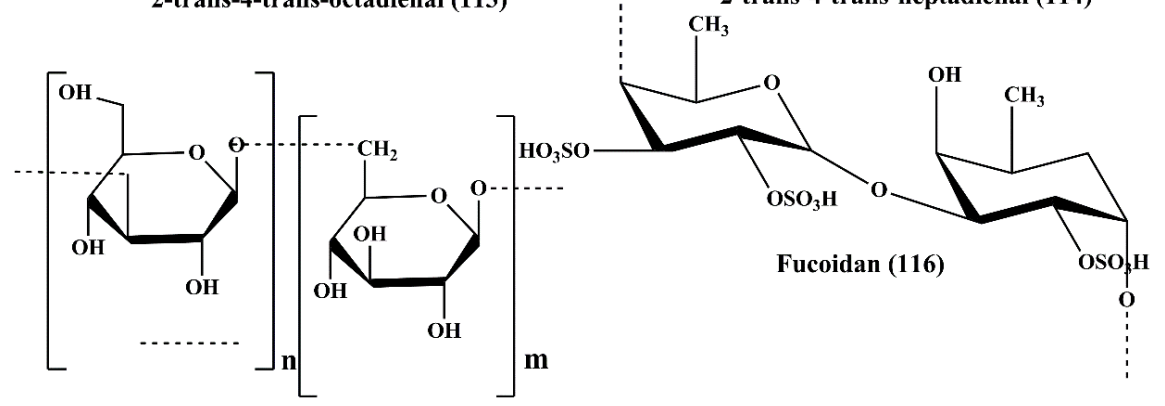

Chrysolaminaran monomer (115)

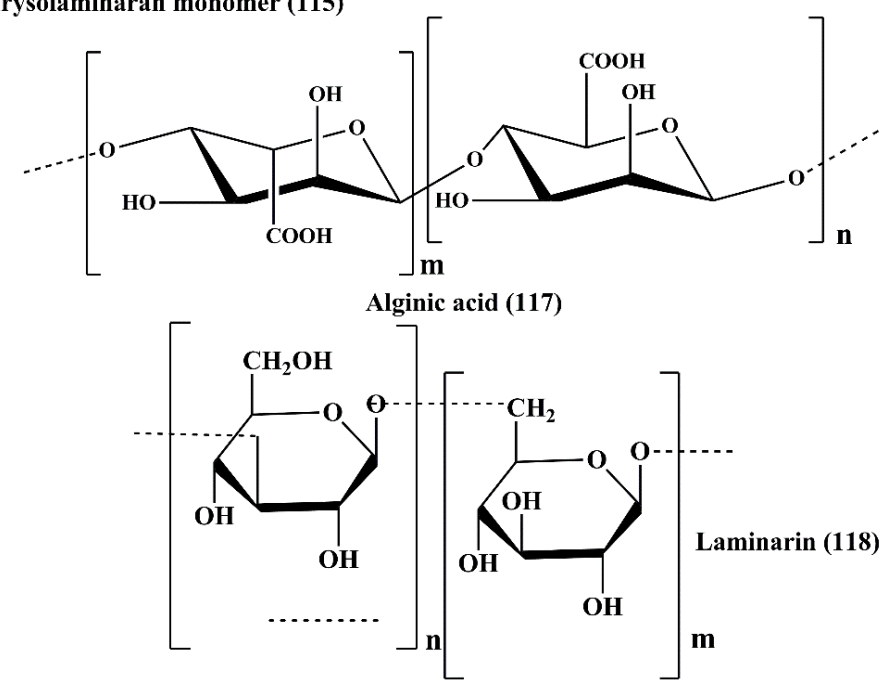

Figure 18. Chemical structure of polyunsaturated aldehydes and polysaccharides (110-118). 


\subsection{Polysaccharide}

Microalgae polysaccharides have shown bio-stimulant activity that has been proven to be effective for a number of industrial applications, although only a few studies have shown the potential to act as an anticancer agent.The potentiality of the polysaccharides varied with changes in molecular weight and sulfate content [169].

\subsubsection{Chrysolaminaran Polysaccharide}

Chrysolaminaran polysaccharide (115) (Figure 18) is a polysaccharide which is isolated from diatom Synedra acus. It belongs to chrysolaminaran family. It showed antitumor activity on human colon cancer cell lines HTC-116 and DLD-1 by inhibiting cancer cell proliferation [170].

\subsubsection{Sulfated Polysaccharide}

The sulfated polysaccharide was reported to be an important constituent of the brown seaweeds of Undaria pinnatifida and Saccharina japonica [171]. This has an antitumor function [171] and prevented the proliferation of human breast cancer (T-47D) and melanoma (SK-MEL-28) cell lines and prevents the colony development [172].

Fucoidans (116) (Figure 18), are sulfated polysaccharides isolated from the brown seaweeds of Sargassum hornery, Eclonia cava, and Costaria costata [173]. It showed antitumor activity against human skin melanoma cell line (SK-MEL-28) and human colon cancer cell line (DLD-1) [173]. It also has been documented that fucoidans are an active constituent of Fucus evanescens (a brown algae of the Okhotsk sea), exhibited in vivo antitumor and antimetastatic activity in C57B1/6 mice, a preclinical animal model [174]. Low molecular weight fucoidan induced apoptosis through alteration of mitochondrial membrane potential by the release of cytochrome c, and inhibitions of Bcl-2, Bcl-xl, Mcl-1 antiapoptotic protein and also activated apoptosis-inducing factors, caspase-3, caspase-7, caspase-9, in MDA-MB-231 cells [175]. ERK1/2 pathway inhibition in human lung cancer cells (A549) led to antimetastatic effect imposed by fucoidan. It also inhibited the phosphoinositide 3-kinases/protein kinase B/ mechanistic target of rapamycin (PI3K/Akt/mTOR) pathway, associated with the downregulation of the expression levels of matrix metalloproteinase-2 (MMP-2) in the A549 human lung carcinoma cell line [176]. Fucoidan inhibited the phosphorylation of EGF receptor. Additionally, it also inhibited the phosphorylation of ERK, JNK, c-fos, and c-jun and activator protein-1 (AP-1) [177]. Over-sulfated fucoidan blocked the angiogenesis process by suppressing mitogenic and chemotactic response of the vascular endothelial growth factor (VEGF) [178]. In another reported study, fucoidan inhibited the proliferation of human hepatocellular carcinoma cells (Huh7) by downregulating the expression levels of chemotaxin CXCL12 and its receptor CXCR4 [179]. It also reduced the expression levels of transforming growth factor (TGF) receptor I and transforming growth factor receptor II proteins and controlled the associated signaling molecules of TGF and regulated the SMAD2, SMAD3, and SMAD4 protein phosphorylation. This could potentially be another type of novel revolutionary mechanism by which the fucoidans exhibited antitumor activity in the breast carcinoma cells by the influence of epithelial-mesenchymal transition [180].

\subsubsection{Alginic Acid}

Alginic acid (117) (Figure 18), commonly known as algin, is an anionic polysaccharide obtained from the cell wall of brown algae or seaweeds Sargassum wightii. Nanoparticles containing alginic acid provided stimulating antitumor effect on $\mathrm{H} 22$ tumor-bearing mice [41]. This polysaccharide also binds with toxic substances and heavy metals that cause cancer present in the intestine and it exerted its activity by converting these toxic substances into non-toxic ones [181]. 


\subsubsection{Laminarin}

Laminarin (118) (Figure 18) is a polysaccharide obtained from brown algae Eisenia bicyclis [182]. It exhibited anticancer activity by inhibiting the proliferation and inducing apoptosis, and cell cycle arrest at the subG1 Phase in ovarian clear cell carcinoma cells (ES2), and papillary serous adenocarcinoma (OV90) cell lines. PI3K/MAPK intracellular signaling mechanism is inhibited in ovarian cancer cells, as well as the increased release of cytochrome c associated with an increase in DNA fragmentation and expression level of apoptosis linked proteins. It also induced MMP loss in both the carcinoma cells, along with autophagy through the inactivation of ULK1 and P62 phosphorylation [183]. Similarly, laminarin and its sulfated analog displayed potential in vitro anticancer activity against JB6 Cl41 (normal mouse epidermal cells), and SK-MEL-28 (human malignant melanoma) cells. Inhibition of proliferation and migration of these cancer cells is associated with inhibition of MMP-2 and MMP-9 proteinases and down-regulation of ERK1/2 signaling mechanism [184]. Similarly, it also inhibited the colony formation of human colon cancer cell lines, such as HCT-116, HT-29, and DLD-1, and displayed cytotoxicity against various carcinoma cell lines [182,185-188]. Ji and Ji [189] reported the anticancer activity of laminarin and its sulfated analog against LoVo cells. It is often associated with induction of apoptosis, upregulation of the expression levels of death receptor 4 (DR4) and DR5, TNF-related apoptosis-inducing ligand (TRAIL), Fas-associated protein with death domain(FADD), Bid, tBid and Bax, and downregulation of pro-caspase-8, pro-caspase-3, and Bcl-2 [190,191]. Additionally, activation of casapse-8, casapse-3, casapse-6, casapse-7, and casapse- 9 and increased release of cytochromec were observed following the treatment with laminarin and its analogs $[190,191]$. The involvement of the laminarin on the ErbB signaling mechanism indicatesanother mechanism of action behind its apoptosis induction in human colon cancer cell line (HT-29) associated with cell cycle arrest at subG1 and G2-M Phases [192].

\subsection{Carotenoids}

Carotenoids are tetraterpenoids, which are also classified as the pigments formed by plants, algae, bacteria, and fungi [193]. There are more than 1100 carotenoids that have been identified so far. The carotenoid's general configuration is a polyene chain of 9-11 double bonds. This correlates with numerous pharmacological features, including anticancer behavior. Various xanthophylls carotenoids were identified, such as violaxanthin, siphonaxanthin, fucoxanthin, neoxanthin, zeaxanthin, lutein, and lactucaxanthin, to be the major constituents in microalgae [193-195].

\subsubsection{Violaxanthin}

Violaxanthin (119) (Figure 19) is the active metabolite reported to be present in the dichloromethane extract of the green algae Dunaliella tertiolecta [196]. It induced early apoptosis associated with biochemical and morphological changes in MCF-7 cancer cell line, but it did not contribute to the fragmentation of DNA. Additionally, it also reversed the multidrug resistance (MDR) by inhibiting the P-glycoprotein (P-gp) and MRP1 in L1210 (human MDR1 gene-transfected mouse lymphoma cells) and MDA-MB-231 (human breast cancer cells) [197]. Similar observations were recorded where violaxanthin reversed the MDR in human MDR1 (gene-transfected mouse lymphoma) and MCF-7 (human breast cancer cell) [198]. 
<smiles>CC(C)=C/C=C/C=C(C)/C=C/C=C(C)/C=C/C=C(C)/C=C/C=C(C)/C=C/[C@]1(O)C(C)(C)C[C@H](C)CC1(C)C</smiles>

Violaxanthin (119)<smiles>CC1=C(/C=C/C(C)=C/C=C/C(C)=C/C=C/C(C)=C/C=C/C(C)=C/C=C/C2(C)C[C@@H](O)CC(C)(C)C2(C)C)C(C)(C)C[C@@H](O)C1</smiles><smiles>CC(=O)O[C@@H]1CC(C)(C)C(=C=CC(C)=CC=CC(C)=CC=CC=C(C)C=CC=C(C)C(=O)C[C@]2(O)C(C)(C)C[C@@H](O)CC2(C)C)[C@](C)(O)C1</smiles>

Fucoxanthin (121)<smiles>CC1=C[C@@H](C)CC(C)(C)[C@H]1/C=C/C(C)=C/C=C/C(C)=C/C=C/C=C(C)/C=C/C=C(\CO)C(=O)CC1=C(C)C[C@@H](O)CC1(C)C</smiles>

Figure 19. Chemical structures of marine microalgae carotenoids (119-122).

\subsubsection{Neoxanthin}

Neoxanthin (120) (Figure 19) is a xanthophyll carotenoid that possesses cytotoxic activity on HeLa and A549 cancer cells. It is even more cytotoxic than violaxanthin [199].

\subsubsection{Fucoxanthin}

Fucoxanthin (121) (Figure 19) is a pigment belonging to the xanthophylls family and found in brown algae Undaria pinnatifida as a major carotenoid. It shows antiproliferative activity against human leukemia cell line (HL-60) by inducing apoptosis [200]. Various studies revealed the anticancer nature in which it inhibited proliferation by inducing apoptosis and cell cycle arrest at the G0/G1 Phase or G2/M Phase through various molecules and pathways involving Bcl-2 protein, MAPK, NF- $\mathrm{kB}$, caspase-3, caspase-8, caspase-9, and GADD45 in which their expression levels were regulated by fucoxanthin [201]. Among various carotenoids, fucoxanthin has been thoroughly researched as an anticancer agent and it has been established as having a significant anticancer activity [200,202-205].

\subsubsection{Siphonaxanthin}

Siphonoxanthin (122) (Figure 19) is a keto-carotenoid present as an active metabolite in green algae Codium fragile, Caulerpa lentillifera, and Umbraulva japonica. Siphonaxanthin demonstrated the anticancer effect on the human leukemia cell line (HL-60) by inducing apoptosis and an increase in chromatin 
condensation, in association with the decreased expression level of Bcl-2 and increased caspase 3 activation. The expression level of GADD5 $\alpha$ and DR5 were also upregulated [206]. The antiangiogenic effect was also displayed by siphonaxanthinin human umbilical vein endothelial (HUVEC) cells and aortic rings of rats [207]. It reduced the mRNA expression level of fibroblast growth factor 2 (FGF-2), fibroblast growth factor receptor (FGFR-1), and early growth response 1 (EGR-1) [208,209].

\subsubsection{Zeaxanthin and Lutein}

Zeaxanthin (123) (Figure 20) is a carotenoid alcohol present in many microalgae, such as Porphyridium cruentum, Isochrysis galbana, Phaeodactylum tricornutum, Tetraselmis suecica and Nannochloropsis gaditana [210]. It exhibited potent cytotoxicity against human colon adenocarcinoma cell line (HT-29) but it did not induce any cytotoxicity against human normal colon epithelial cell line (CCD 841 CoTr) [211]. Lutein (124) is a xanthophyll carotenoid, which exhibited similar anticancer profile as zeaxanthin [211,212].

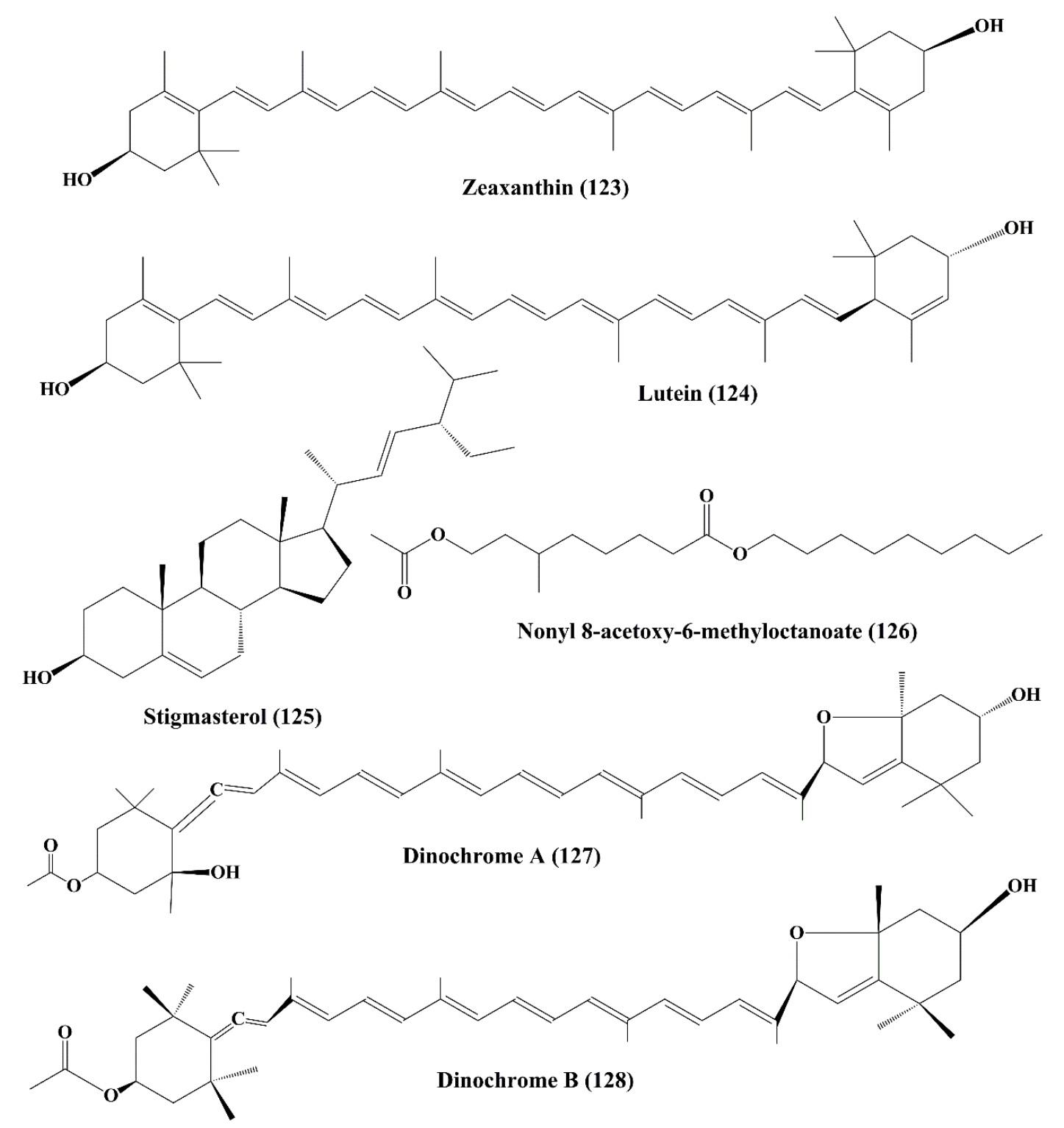

Figure 20. Chemical structure of marine microalgae metabolites (123-128). 


\subsection{Stigmasterol}

Stigmasterol (125) (Figure 20) is a sterol extracted from a microalga benthic diatom Navicula incerta. It showed significant anticancer activity by inhibiting the proliferation of the human liver cancer cell line (HepG2) by inducing apoptosis through mitochondrial membrane potential and cause morphological changes and damage of DNA $[213,214]$. The up-regulation of the expression of caspase-8, caspase-9, Bax, and p53 was induced by stigmasterol whereas antiapoptotic proteins, such as Bcl-2, and X-linked inhibitor of apoptosis protein (XIAP), was down-regulated. The result showed that the cell cycle arrest takes place at $G_{0} / G_{1}$ and $G_{2} / M$ Phases due to cell component defects.

\subsection{Nonyl 8-Acetoxy-6-Methyloctanoate}

Nonyl 8-acetoxy-6-methyloctanoate (126) (Figure 20) is a fatty alcohol ester isolated from a marine diatom Phaeodactylum tricornutum. The anticancer activity of the secondary metabolite was established on the human promyelocytic leukemia cell line (HL-60), a human lung carcinoma cell line (A549), and a mouse melanoma cell line (B16F10). It induced damage of DNA and increased the apoptotic activity and triggered cell cycle arrest at the sub G1 Phase. It activated the pro-apoptotic protein Bax, and suppress the antiapoptotic protein Bcl-xL, and also increases the expression levels of both caspase-3 and p53 proteins [215].

\subsection{Dinochrome $A$ and $B$}

Dinochrome A (127) and B (128) (Figure 20) are epimeric carotenoids isolated from marine red tide Peridinium bipes. They possess strong anticarcinogenic activity by inhibiting the proliferation of GOTO (neuroblastoma cells), OST (osteosarcoma cells) and HeLa cells [216].

\subsection{Phaeophytins}

Phaeophytins are porphyrin-containing organic heterocyclic molecules. Several phaeophytins, such as porphyrinolactone (129), 20-chlorinated (132-S)-hydroxyphaeophytin A (130), (132S)-hydroxyphaeophytin A (131) and B (132), and (132-R)-hydroxyphaeophytin A (133) and B (134) (Figure 21) were isolated from a marine green algae Cladophora fascicularis. The antiproliferative activity was characterized by inhibition of the activation of NF- $\mathrm{kB}$ in the HeLa carcinoma cell line by inhibiting the TNF- $\alpha$-induced NF- $\kappa$ B translocation from the cytoplasm into the nucleus [217]. 


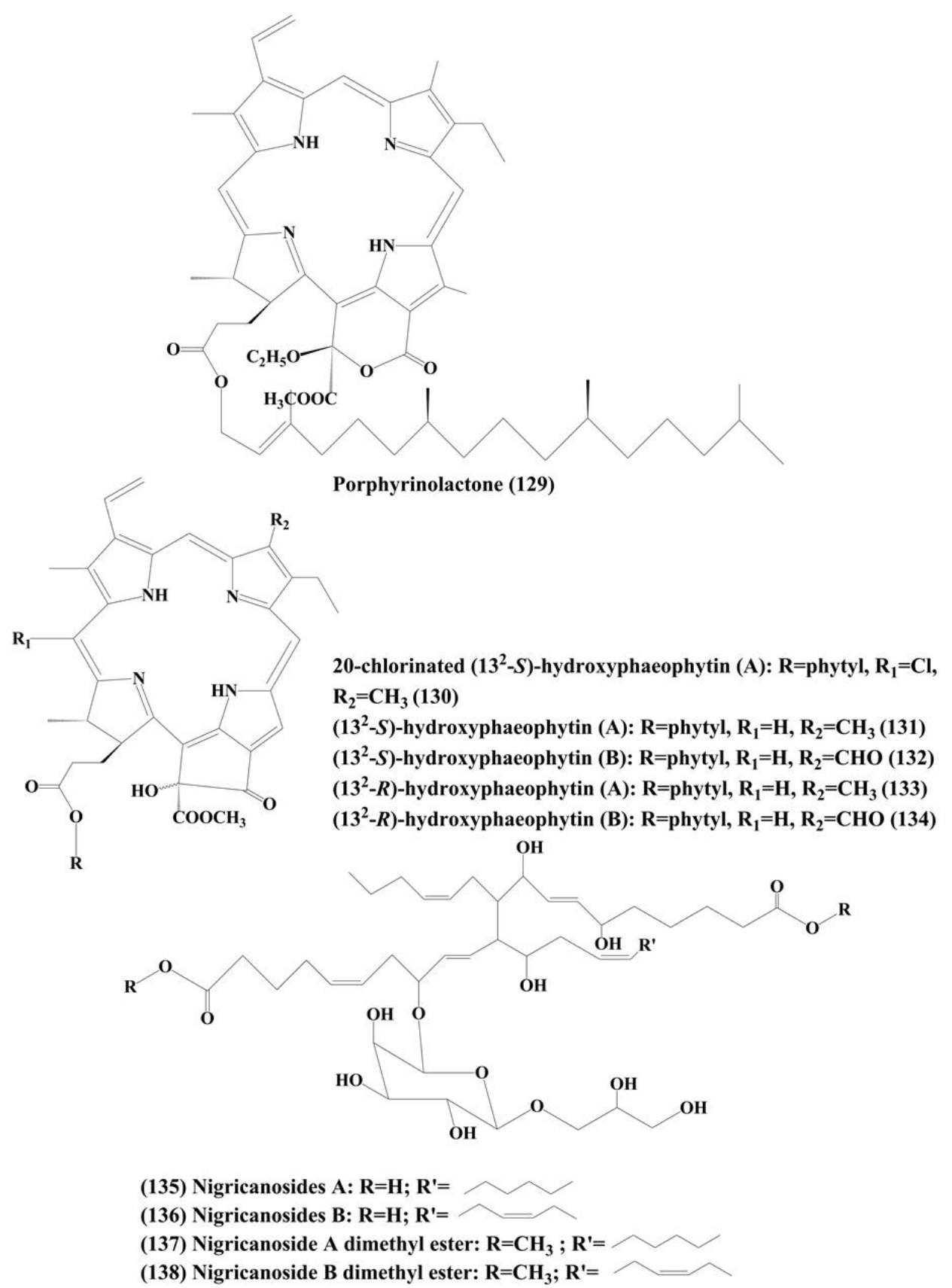

Figure 21. Structure of marine microalgae metabolites (129-138).

6.8. Nigricanosides A (135) and B (136) and Methyl Esters of Nigricanosides A (137) and B (138)

These are glycolipids (Figure 21) extracted from a green algae Avrainvillea nigricans. These metabolites inhibited the proliferation of human breast cancer MCF-7 cells and human colon cancer HCT-116 cells and they also possess antimitotic activity which triggers tubulin polymerization within the cells [218].

\section{Conclusions, Current Challenges and Future Perspectives}

This review describes the most recently extracted or generated molecules from marine organisms, such as cyanobacteria and microalgae, with potential for cancer therapy. Marine resources certainly have valuable and undiscovered biochemical versatility and demonstrate a greater opportunity for the development of new anticancer agents. While a variety of compounds have been identified to suppress 
cell growth in a broad spectrum of cancer cell types, the mechanism of action still remains unclear. A handful of marine molecules have demonstrated possible cytotoxic actions toward specific cancer by inhibition of cell proliferation, its antimitotic behavior (antitubulin impacts), induced apoptosis and inhibition of movement, invasion, or metastatic potential of cancer cells.

While these metabolites have shown potential for cancer treatment, there are several challenges associated with the development of these drugs that need consideration. Oceans certainly provide a large supply of valuable species, but the researchers still cannot access any of these regions. For years, the selection of entities in readily accessible places was preferred. Therefore, the problem is that marine research is not always easily accessible where researchers and the oceanographer need to have strong working ties. Genetic engineering is undergoing development in order to enhance drug production through the conversion of genetic data from the target compound into the host cells. It is an important field for regulation of the isolation and expression of aquatic genes, helping us produce lead compounds from the aquatic ecosystem in a more controlled way. Secondary metabolites are hard to produce independently from cultures, since their development is directly or indirectly dependent on host. Therefore, several of the main genes stay silent while these things are attempted to evolve In vitro. Another big concern is that the development of a specific molecule requires sufficient resources. There is still little research available on the toxicity studies of these marine metabolites in normal cells; this has to be addressed.

Marine cyanobacteria and microalgae tend to be an effective source of anticancer drugs. Nevertheless, more studies are required to understand the basic targets and pathways behind the cytotoxicity of these compounds in cancer cells.

Author Contributions: Conceptualization, A.M.; literature search and collection, S.B. (Sankhadip Bose), S.B. (Sabyasachi Banerjee), J.K.P., G.D., R.G.K., J.M. and S.K.M.; writing-original draft preparation, A.M., S.B. (Sankhadip Bose) and S.B. (Sabyasachi Banerjee); writing-review and editing, K.L.K., C.F. and A.B.; supervision, A.M.; project administration, A.B. All authors have read and agreed to the published version of the manuscript.

Funding: This research received no external funding.

Conflicts of Interest: The authors declare no conflict of interest.

\section{References}

1. World Health Organization. WHO Report on Cancer: Setting Priorities, Investing Wisely and Providing Care for All; World Health Organization: Geneva, Switzerland, 2020.

2. Jemal, A.; Bray, F.; Center, M.M.; Ferlay, J.; Ward, E.; Forman, D. Global cancer statistics. CA Cancer J. Clin. 2011, 61, 69-90. [CrossRef] [PubMed]

3. Newman, D.J.; Cragg, G.M. Natural Products as Sources of New Drugs over the 30 Years from 1981 to 2010. J. Nat. Prod. 2012, 75, 311-335. [CrossRef] [PubMed]

4. Sithranga-Boopathy, N.; Kathiresan, K. Anticancer drugs from marine flora: An overview. J. Oncol. 2010, 2010, 214186. [CrossRef] [PubMed]

5. Banerjee, S.; Bose, S.; Mandal, S.C.; Dawn, S.; Sahoo, U.; Ramadan, M.A.; Mandal, S.K. Pharmacological Property of Pentacyclic Triterpenoids. Egypt J. Chem. 2019, 62, 13-35. [CrossRef]

6. Grothaus, P.G.; Cragg, G.M.; Newman, D.J. Plant natural products in anticancer drug discovery. Curr. Org. Chem. 2010, 14, 1781-1791. [CrossRef]

7. Demain, A.L.; Vaishnav, P. Natural products for cancer chemotherapy. Microb. Biotechnol. 2011, 4, 687-699. [CrossRef]

8. Cragg, G.M.; Kingston, D.G.I.; Newman, D.J. Anticancer Agents from Natural Products, 2nd ed.; CRC/Taylor \& Francis: Boca Raton, FL, USA, 2012.

9. Basmadjian, C.; Zhao, Q.; Djehal, A.; Bentouhami, E.; Nebigil, C.G.; Johnson, R.A.; Serova, M.; De Gramont, A.; Faivre, S.; Raymond, E.; et al. Cancer wars: Natural products strike back. Front. Chem. 2014, 2, 20. [CrossRef] 
10. Cragg, G.M.; Newman, D.J. Plants as a source of anti-cancer agents. J. Ethnopharmacol. 2005, 100, 72-79. [CrossRef]

11. Wang, W.; Wang, S.X.; Guan, H.S. The antiviral activities and mechanisms of marine polysaccharides: An overview. Mar. Drugs 2012, 10, 2795-2816. [CrossRef]

12. Khalifa, S.A.M.; Elias, N.; Farag, M.A.; Chen, L.; Saeed, A.; Hegazy, M.F.; Moustafa, M.S.; Abd El-Wahed, A.; Al-Mousawi, S.M.; Musharraf, S.G.; et al. Marine natural products: A source of novel anticancer drugs. Mar. Drugs 2019, 17, 491. [CrossRef]

13. Faulkner, D.J. Marine pharmacology. Antonie Leeuwenhoek 2000, 77, 135-145. [CrossRef] [PubMed]

14. Schwartsmann, G.; Brondani, A.; Berlinck, R.G.S.; Jimeno, J. Marine organisms and other novel natural sources of new cancer drugs. Ann. Oncol. 2000, 11, 235-243. [CrossRef] [PubMed]

15. White, M.C.; Holman, D.M.; Boehm, J.E.; Peipins, L.A.; Grossman, M.; Henley, S.J. Age and cancerrisk: A potentially modifiable relationship. Am. J. Prev. Med. 2014, 46, S7-S15. [CrossRef] [PubMed]

16. Newman, D.; Cragg, G. Marine-sourced anti-cancer and cancer pain control agents in clinical and late preclinical development. Mar. Drugs 2014, 12, 255-278. [CrossRef] [PubMed]

17. Gerwick, W.H.; Moore, B.S. Lessons from the past and charting the future of marine natural products drug discovery and chemical biology. Chem. Biol. 2012, 19, 85-98. [CrossRef] [PubMed]

18. Montaser, R.; Luesch, H. Marine natural products: A new wave of drugs? Future Med. Chem. 2011, 3, 1475-1489. [CrossRef] [PubMed]

19. Townsend, M.; Davies, K.; Hanley, N.; Hewitt, J.E.; Lundquist, C.J.; Lohrer, A.M. The challenge of implementing the marine ecosystem services concept. Front. Mar. Sci. 2018, 5, 359. [CrossRef]

20. Snelgrove, P.V.R. Getting to the bottom of marine biodiversity: Sedimentary habitats: Ocean bottom are the most widespread habitats on earth and support high biodiversity and key ecosystem services. BioScience 1999, 49, 129-138. [CrossRef]

21. Lauritano, C.; Andersen, J.H.; Hansen, E.; Albrigtsen, M.; Escalera, L.; Esposito, F.; Helland, K.; Hanssen, K.Ø.; Romano, G.; Ianora, A. Bioactivity screening of microalgae for antioxidant, anti-inflammatory, anticancer, anti-diabetes and antibacterial activities. Front. Mar. Sci. 2016, 3, 1-12. [CrossRef]

22. Ruiz-Torres, V.; Encinar, J.A.; Herranz-López, M.; Pérez-Sánchez, A.; Galiano, V.; Barrajón-Catalán, E.; Micol, V. An Updated Review on Marine Anticancer Compounds: The Use of Virtual Screening for the Discovery of Small-Molecule Cancer Drugs. Molecules 2017, 22, 1037. [CrossRef]

23. Deshmukh, S.K.; Prakash, V.; Ranjan, N. Marine Fungi: A Source of Potential Anticancer Compounds. Front. Microbiol. 2018, 8, 2536. [CrossRef] [PubMed]

24. Vasconcelos, A.A.; Pomin, V.H. Marine Carbohydrate-Based Compounds with Medicinal Properties. Mar. Drugs 2018, 16, 233. [CrossRef] [PubMed]

25. Mahapatra, G.P.; Raman, S.; Nayak, S.; Gouda, S.; Das, G.; Patra, J.K. Metagenomics approaches in discovery and development of new bioactive compounds from marine actinomycetes. Curr. Microbiol. 2019. [CrossRef] [PubMed]

26. Malve, H. Exploring the ocean for new drug developments: Marine pharmacology. J. Pharm. Bioallied Sci. 2016, 8, 83-91. [CrossRef]

27. Costa, M.; Costa-Rodrigues, J.; Fernandes, M.H.; Barros, P.; Vasconcelos, V.; Martins, R. Marine cyanobacteria compounds with anticancer properties: A review on the implication of apoptosis. Mar. Drugs 2012, 10, 2181-2207. [CrossRef]

28. Boopathy, N.S.; Kathiresan, K. Anticancer agents derived from marine algae. In Functional Ingredients from Algae for Foods and Nutraceuticals; Dominguez, H., Ed.; Woodhead Publishing Series in Food Science, Technology and Nutrition; Elsevier: Sawston, UK; Cambridge, UK, 2013; Chapter 9; pp. 307-337.

29. Bajpai, V.K.; Shukla, S.; Kang, S.M.; Hwang, S.K.; Song, X.; Huh, Y.S.; Han, Y.K. Developments of cyanobacteria for nano-marine drugs: Relevance of nanoformulations in cancer therapies. Mar. Drugs 2018, 16, 179. [CrossRef]

30. Raja, R.; Hemaiswarya, S.; Ganesan, V.; Carvalho, I.S. Recent developments in therapeutic applications of cyanobacteria. Crit. Rev. Microbiol. 2016, 42, 394-405. [CrossRef]

31. Kang, K.H.; Kim, S.K. Beneficial effect of peptides from microalgae on anticancer. Curr. Protein Pept. Sci. 2013, 14, 212-217. [CrossRef] 
32. Blunt, J.W.; Carroll, A.R.; Copp, B.R.; Davis, R.A.; Keyzers, R.A.; Prinsep, M.R. Marine natural products. Nat. Prod. Rep. 2018, 35, 8-53. [CrossRef]

33. Mondal, A.; Gandhi, A.; Fimognari, C.; Atanasov, A.G.; Bishayee, A. Alkaloids for cancer prevention and therapy: Current progress and future perspectives. Eur. J. Pharmacol. 2019, 858, 172472. [CrossRef]

34. Aniszewski, T. Alkaloids—Secrets of Life: Alkaloids Chemistry, Biological Significance, Applications and Ecological Role; Elsevier: Amsterdam, The Netherlands, 2007; p. 334.

35. Güven, K.C.; Coban, B.; Sezik, E.; Erdugan, H.; Kaleağasığlu, F. Alkaloids of Marine Macroalgae. In Natural Products; Ramawat, K., Mérillon, J.M., Eds.; Springer: Berlin/Heidelberg, Germany, 2013; pp. 25-37.

36. Choi, E.J.; Nam, S.J.; Paul, L.; Beatty, D.; Kauffman, C.A.; Jensen, P.R.; Fenical, W. Previously uncultured marine bacteria linked to novel alkaloid production. Chem. Biol. 2015, 22, 12709. [CrossRef] [PubMed]

37. Ramesh, C.; Vinithkumar, N.V.; Kirubagaran, R. Marine pigmented bacteria: A prospective source of antibacterial compounds. J. Nat. Sci. Biol. Med. 2019, 10, 104-113. [CrossRef]

38. Picott, K.J.; Deichert, J.A.; deKemp, E.M.; Schatte, G.; Sauriol, F.; Ross, A.C. Isolation and characterization of tambjamine MYP1, a macrocyclic tambjamine analogue from marine bacterium Pseudoalteromonas citrea. Med. Chem. Comm. 2019, 10, 478-483. [CrossRef]

39. El-Hack, M.E.A.; Abdelnour, S.; Alagawany, M.; Abdo, M.; Sakr, M.A.; Khafaga, A.F.; Mahgoub, S.A.; Elnesr, S.S.; Gebriel, M.G. Microalgae in modern cancer therapy: Current knowledge. Biomed. Pharmacother. 2019, 111, 42-50. [CrossRef] [PubMed]

40. Demay, J.; Bernard, C.; Reinhardt, A.; Marie, B. Natural Products from Cyanobacteria: Focus on Beneficial Activities. Mar. Drugs 2019, 17, 320. [CrossRef] [PubMed]

41. IUPAC. Compendium of Chemical Terminology, 2nd ed.; McNaught, A.D., Wilkinson, A., Eds.; Blackwell Scientific Publications: Oxford, UK, 1997; ISBN 0-9678550-9-8. [CrossRef]

42. Sadaka, C.; Ellsworth, E.; Hansen, P.; Ewin, R.; Damborg, P.; Watts, J. Review on abyssomicins: Inhibitors of the chorismate pathway and folate biosynthesis. Molecules 2018, 23, 1371-1396. [CrossRef]

43. Davidson, B.S. New dimensions in natural products research: Cultured marine microorganisms. Curr. Opin. Biotechnol. 1995, 6, 284-291. [CrossRef]

44. Kandi, S.; Godishala, V.; Rao, P.; Ramana, K.V. Biomedical significance of terpenes: An insight. Biomed. Biotechnol. 2015, 3, 8-10.

45. Kitts, D.D.; Weiler, K. Bioactive proteins and peptides from food sources. Applications of bioprocesses used in isolation and recovery. Curr. Pharm. Des. 2003, 9, 1309-1323. [CrossRef]

46. Sarmadi, B.; Ismail, A.; Hamid, M. Antioxidant and angiotensin converting enzyme (ACE) inhibitory activities of cocoa (Theobroma cacao L.) autolysates. Food Res. Int. 2011, 44, 290-296. [CrossRef]

47. Ghanbari, R. Review on the bioactive peptides from marine sources: Indication for health effects. Int. J. Pept. Res. Ther. 2018, 25, 1187-1199. [CrossRef]

48. Slizyte, R.; Mozuraityte, R.; Martinez-Alvarez, O. Functional, bioactive and antioxidative properties of hydrolysates obtained from cod (Gadusmorhua) backbones. Proc. Biochem. 2009, 44, 668-677. [CrossRef]

49. Shukla, S. Therapeutic importance of peptides from marine source: A mini review. Ind. J. Geo Mar. Sci. 2016, 45, 1422-1431.

50. Aneiros, A.; Garateix, A. Bioactive peptides from marine sources: Pharmacological properties and isolation procedures. J. Chromatogr. B 2004, 803, 41-53. [CrossRef] [PubMed]

51. Cheung, R.C.F.; Ng, T.B.; Wong, J.H. Marine Peptides: Bioactivities and Applications. Mar. Drugs 2015, 13, 4006-4043. [CrossRef] [PubMed]

52. Ma, D.; Zou, B.; Cai, G.; Hu, X.; Liu, J.O. Total synthesis of the cyclodepsipeptideapratoxin A and its analogues and assessment of their biological activities. Chem. Eur. J. 2006, 12, 7615-7626. [CrossRef] [PubMed]

53. Bhakuni, D.; Rawat, D. Bioactive marine nucleosides. In Bioactive Marine Natural Products; Springer: Dordrecht, The Netherlands, 2005; pp. 208-234.

54. Huang, R.M.; Chen, Y.N.; Zeng, Z.; Gao, C.H.; Su, X.; Peng, Y. Marine nucleosides: Structure, bioactivity, synthesis and biosynthesis. Mar. Drugs 2014, 12, 5817-5838. [CrossRef]

55. Isono, K. Nucleoside antibiotics-Structure, biologicalactivity, and biosynthesis. J. Antibiot. 1988, 41, 1711-1739. [CrossRef]

56. Isono, K. Current progress on nucleoside antibiotics. Pharmacol. Ther. 1991, 52, 269-286. [CrossRef] 
57. Faulkner, D.J. Marine natural products. Nat. Prod. Rep. 1993, 10, 497-539. [CrossRef]

58. Sable, R.; Parajuli, P.; Jois, S. Peptides, Peptidomimetics, and Polypeptides from Marine Sources: A Wealth of Natural Sources for Pharmaceutical Applications. Mar. Drugs 2017, 15, 124. [CrossRef] [PubMed]

59. Newman, D.J.; Cragg, G.M. Advanced preclinical and clinical trials of natural products and related compounds from marine sources. Curr. Med. Chem. 2004, 11, 1693-1731. [CrossRef] [PubMed]

60. Machella, N.; Regoli, F.; Cambria, A.; Santella, R.M. Oxidative damage to DNA: An immunohistochemical approach for detection of 7,8-dihydro-8-oxodeoxyguanosine in marine organisms. Mar. Environ. Res. 2004, 58, 725-729. [CrossRef]

61. Schwartsmann, G.; Da Rocha, A.B.; Mattei, J.; Lopes, R. Marine-derived anticancer agents in clinical trials. Expert Opin Investig. Drugs 2003, 12, 1367-1383. [CrossRef] [PubMed]

62. Helbert, W. Marine polysaccharide sulfatases. Front. Mar. Sci. 2017, 4, 6. [CrossRef]

63. Jiao, G.; Yu, G.; Zhang, J.; Ewart, H.S. Chemical structures and bioactivities of sulfated polysaccharides from marine algae. Mar. Drugs 2011, 9, 196-223. [CrossRef]

64. Vázquez, J.A.; Rodríguez-Amado, I.; Montemayor, M.I.; Fraguas, J.; González Mdel, P.; Murado, M.A. Chondroitin sulfate, hyaluronic acid and chitin/chitosan production using marine waste sources: Characteristics, applications and eco-friendly processes: A review. Mar. Drugs 2013, 11, 747-774. [CrossRef]

65. Poli, A.; Anzelmo, G.; Nicolaus, B. Bacterial exopolysaccharides from extreme marine habitats: Production, characterization and biological activities. Mar. Drugs 2010, 8, 1779-1802. [CrossRef]

66. Pomin, V.H. Marine medicinal glycomics. Front. Cell Infect. Microbiol. 2014, 4, 1-13. [CrossRef]

67. Kang, H.K.; Seo, C.H.; Park, Y. The effects of marine carbohydrates and glycosylated compounds on human health. Int. J. Mol. Sci. 2015, 16, 6018-6056. [CrossRef]

68. Thomas, N.V.; Kim, S.K. Beneficial effects of marine algal compounds in cosmeticals. Mar. Drugs 2013, 11, 146-164. [CrossRef] [PubMed]

69. Boisson-Vidal, C.; Zemani, F.; Caligiuri, G.; Galy-Fauroux, I.; Colliec-Jouault, S.; Helley, D.; Fischer, A.M. Neoangiogenesis induced by progenitor endothelial cells: Effect of fucoidan from marine algae. Cardiovasc. Hematol. Agents Med. Chem. 2007, 5, 67-77. [CrossRef] [PubMed]

70. Aisa, Y.; Miyakawa, Y.; Nakazato, T.; Shibata, H.; Saito, K.; Ikeda, Y.; Kizaki, M. Fucoidan induces apoptosis of human HS-sultan cells accompanied by activation of caspase-3 and down-regulation of ERK pathways. Am. J. Hematol. 2005, 78, 7-14. [CrossRef] [PubMed]

71. Nobili, S.; Lippi, D.; Witort, E.; Donnini, M.; Bausi, L.; Mini, E.; Capaccioli, S. Natural compounds for cancer treatment and prevention. Pharmacol. Res. 2009, 59, 365-378. [CrossRef] [PubMed]

72. Thacker, R.W.; Paul, V.J. Morphological, chemical, and genetic diversity of tropical marine cyanobacteria Lyngbya spp. and Symploca spp. (Oscillatoriales). Appl. Environ. Microbiol. 2004, 70, 3305-3312. [CrossRef]

73. Bai, R.; Pettit, G.R.; Hamel, E. Dolastatin 10, a powerful cytostatic peptide derived from a marine animal. Inhibition of tubulin polymerization mediated through the vinca alkaloid binding domain. Biochem. Pharmacol. 1990, 39, 1941-1949. [CrossRef]

74. Madden, T.; Tran, H.T.; Beck, D.; Huie, R.; Newman, R.A.; Pusztai, L.; Wright, J.J.; Abbruzzese, J.L. Novel marine-derived anticancer agents: A phase I clinical, pharmacological, and pharmacodynamic study of dolastatin 10 (NSC 376128) in patients with advanced solid tumors. Clin. Cancer Res. 2000, 6, 1293-1301.

75. Pereira, R.B.; Evdokimov, N.M.; Lefranc, F.; Valentão, P.; Kornienko, A.; Pereira, D.M.; Andrade, P.B.; Gomes, N.G.M. Marine-Derived Anticancer Agents: Clinical Benefits, Innovative Mechanisms, and New Targets. Mar. Drugs 2019, 17, 329. [CrossRef]

76. Kobayashi, M.; Natsume, T.; Tamaoki, S.; Watanabe, J.; Asano, H.; Mikami, T.; Miyasaka, K.; Miyazaki, K.; Gondo, M.; Sakakibara, K.; et al. Antitumor activity of TZT-1027, a novel dolastatin 10 derivative. Jpn. J. Cancer Res. 1997, 88, 316-327. [CrossRef]

77. Otani, M.; Natsume, T.; Watanabe, J.I.; Kobayashi, M.; Murakoshi, M.; Mikami, T.; Nakayama, T. TZT-1027, an antimicrotubule agent, attacks tumor vasculature and induces tumor cell death. Jpn. J. Cancer Res. 2000, 91, 837-844. [CrossRef]

78. Mayer, A.M.S.; Glaser, K.B.; Cuevas, C.; Jacobs, R.S.; Kem, W.; Little, R.D.; McIntosh, J.M.; Newman, D.J.; Potts, B.C.; Shuster, D.E. The odyssey of marine pharmaceuticals: A current pipeline perspective. Trends Pharmacol. Sci. 2010, 31, 255-265. [CrossRef] [PubMed] 
79. Hammond, L.A.; Ruvuna, F.; Cunningham, C.C.; Ebbinghaus, S.; Rubin, E.; Hersh, A.M.E.; Eder, J.P.; Weiss, J.; Rowinsky, E.K. Phase (Ph) I evaluation of the dolastatin analogue synthadotin (SYN-D; ILX651): Pooled data analysis of three alternate schedules in patients (pts) with advanced solid tumors. J. Clin. Oncol. 2004, 22, 3068. [CrossRef]

80. Ebbinghaus, S.; Hersh, E.; Cunningham, C.C.; O’Day, S.; McDermott, D.; Richards, J.S.D.A.; Eckardt, J.; Haider, O.L.; Hammond, L.A. Phase II study of synthadotin (SYN-D; ILX651) administered daily for 5 consecutive days once every 3 weeks $(\mathrm{qd} \times 5 \mathrm{q} 3 \mathrm{w})$ in patients (Pts) with inoperable locally advanced or metastatic melanoma. J. Clin. Oncol. 2004, 22, 7530. [CrossRef]

81. Gulder, T.A.; Moore, B.S. Salinosporamide natural products: Potent $20 \mathrm{~S}$ proteasome inhibitors as promising cancer chemotherapeutics. Angew. Chem. Int. Ed. Engl. 2010, 49, 9346-9367. [CrossRef] [PubMed]

82. Chauhan, D.; Catley, L.; Li, G.; Podar, K.; Hideshima, T.; Velankar, M.; Mitsiades, C.; Mitsiades, N.; Yasui, H.; Letai, A.; et al. A novel orally active proteasome inhibitor induces apoptosis in multiple myeloma cells with mechanisms distinct from Bortezomib. Cancer Cell 2005, 8, 407-419. [CrossRef] [PubMed]

83. Harrison, S.J.; Mainwaring, P.; Price, T.; Millward, M.J.; Padrik, P.; Underhill, C.R.; Cannell, P.K.; Reich, S.D.; Trikha, M.; Spencer, A. Phase I clinical trial of marizomib (NPI-0052) in patients with advanced malignancies including multiple myeloma: Study NPI-0052-102 final results. Clin. Cancer Res. 2016, 22, 4559-4566. [CrossRef]

84. Itoh, T.; Kinoshita, M.; Aoki, S.; Kobayashi, M. Komodoquinone A, a novel neuritogenic anthracycline, from marine Streptomyces sp. KS3. J. Nat. Prod. 2003, 66, 1373-1377. [CrossRef]

85. Maskey, R.P.; Li, F.; Qin, S.; Fiebig, H.H.; Laatsch, H. Chandrananimycins A approximately C: Production of novel anticancer antibiotics from a marine Actinomadura sp. isolate M048 by variation of medium composition and growth conditions. J. Antibiot. (Tokyo) 2003, 56, 622-629. [CrossRef]

86. Andrianasolo, E.H.; Gross, H.; Goeger, D.; Musafija-Girt, M.; McPhail, K.; Leal, R.M.; Mooberry, S.L.; Gerwick, W.H. Isolation of swinholide A and related glycosylated derivatives from two field collections of marine cyanobacteria. Org. Lett. 2005, 7, 1375-1378. [CrossRef]

87. Mooberry, S.L.; Leal, R.M.; Tinley, T.L.; Luesch, H.; Moore, R.E.; Corbett, T.H. The molecular pharmacology of symplostatin 1: A new antimitotic dolastatin 10 analog. Int. J. Cancer 2003, 104, 512-521. [CrossRef]

88. Kwan, J.C.; Rocca, J.R.; Abboud, K.A.; Paul, V.J.; Luesch, H. Total Structure Determination of Grassypeptolide, a New Marine Cyanobacterial Cytotoxin. Org. Lett. 2008, 10, 789-792. [CrossRef] [PubMed]

89. Kwan, J.C.; Ratnayake, R.; Abboud, K.A.; Paul, V.J.; Luesch, H. Grassypeptolides A-C, cytotoxic bis-thiazoline containing marine cyclodepsipeptides. J. Org. Chem. 2010, 75, 8012-8023. [CrossRef] [PubMed]

90. Gerwick, W.H.; Proteau, P.J.; Nagle, D.G.; Hamel, E.; Blokhin, A.; Slate, D. Structure of curacin A, a novel antimitotic, antiproliferative, and brine shrimp toxic natural product from the marine cyanobacterium Lyngbya majuscule. J. Org. Chem. 1994, 59, 1243-1245. [CrossRef]

91. Yoo, H.D.; Nagle, D.G.; Geralds, R.S.; Gerwick, W.H.; Kim, T.S.; Nambu, M.; White, J.D. Absolute configuration of curacin A, a novel antimitotic agent from the tropical marine cyanobacterium Lyngbyamajuscula. Tetrahedron Lett. 1995, 36, 1189-1192.

92. Catassi, A.; Cesario, A.; Arzani, D.; Menichini, P.; Alama, A.; Bruzzo, C.; Imperatori, A.; Rotolo, N.; Granone, P.; Russo, P. Characterization of apoptosis induced by marine natural products in non small cell lung cancer A549 cells. Cell Mol. Life Sci. 2006, 63, 2377-2386. [CrossRef]

93. Blokhin, A.V.; Yoo, H.D.; Geralds, R.S.; Nagle, D.G.; Gerwick, W.H.; Hamel, E. Characterization of the interaction of the marine cyanobacterial natural product curacin A with the colchicine site of tubulin and initial structure-activity studies with analogues. Mol. Pharmacol. 1995, 48, 523-531. [PubMed]

94. Verdier-Pinard, P.; Lai, J.Y.; Yoo, H.D.; Yu, J.; Marquez, B.; Nagle, D.G.; Nambu, M.; White, J.D.; Falck, J.R.; Gerwick, W.H.; et al. Structure-activity analysis of the interaction of curacin A, the potent colchicine site antimitotic agent, with tubulin and effects of analogs on the growth of MCF-7 breast cancer cells. Mol. Pharmacol. 1998, 53, 62-76. [CrossRef]

95. Wipf, P.; Reeves, J.; Day, B. Chemistry and Biology of Curacin A. Curr. Pharm. Des. 2004, 10, 1417-1437. [CrossRef]

96. Williams, P.G.; Yoshida, W.Y.; Moore, R.E.; Paul, V.J. The isolation and structure elucidation of Tasiamide B, a 4-amino-3-hydroxy-5-phenylpentanoic acid containing peptide from the marine cyanobacterium Symploca sp. J. Nat. Prod. 2003, 66, 1006-1009. [CrossRef] 
97. Luesch, H.; Yoshida, W.Y.; Moore, R.E.; Paul, V.J. New apratoxins of marine cyanobacterial origin from Guam and Palau. Bioorg. Med. Chem. 2002, 10, 1973-1978. [CrossRef]

98. Paatero, A.O.; Kellosalo, J.; Dunyak, B.M.; Almaliti, J.; Gestwicki, J.E.; Gerwick, W.H.; Taunton, J.; Paavilainen, V.O. Apratoxin kkills cells by direct blockade of the Sec61 protein translocation channel. Cell Chem. Biol. 2016, 23, 561-566. [CrossRef] [PubMed]

99. Matthew, S.; Schupp, P.J.; Luesch, H. Apratoxin E, a cytotoxic peptolide from a Guamanian collection of the marine cyanobacterium Lyngbya bouillonii. J. Nat. Prod. 2008, 71, 1113-1116. [CrossRef] [PubMed]

100. Tidgewell, K.; Engene, N.; Byrum, T.; Media, J.; Doi, T.; Valeriote, F.A.; Gerwick, W.H. Evolved diversification of a modular natural product pathway: Apratoxins F and G, two cytotoxic cyclic depsipeptides from a Palmyra collection of Lyngbya bouillonii. Chem. Biochem. 2010, 11, 1458-1466. [CrossRef] [PubMed]

101. Han, B.; Gross, H.; Goeger, D.E.; Mooberry, S.L.; Gerwick, W.H. Aurilides B and C, Cancer cell toxins from a Papua New Guinea collection of the marine cyanobacterium Lyngb yamajuscula. J. Nat. Prod. 2006, 69, 572-575. [CrossRef]

102. Sato, S.; Murata, A.; Orihara, T.; Shirakawa, T.; Suenaga, K.; Kigoshi, H.; Uesugi, M. Marine natural product aurilide activates the OPA1-mediated apoptosis by binding to prohibitin. Chem. Biol. 2011, 18, 131-139. [CrossRef]

103. Medina, R.A.; Goeger, D.E.; Hills, P.; Mooberry, S.L.; Huang, N.; Romero, L.I.; Ortega-Barría, E.; Gerwick, W.H.; McPhail, K.L. Coibamide A, a potent antiproliferative cyclic depsipeptide from the Panamanian marine cyanobacterium Leptolyngbya sp. J. Am. Chem. Soc. 2008, 130, 6324-6325. [CrossRef]

104. Serrill, J.D.; Wan, X.; Hau, A.M.; Jang, H.S.; Coleman, D.J.; Indra, A.K.; Alani, A.W.; McPhail, K.L.; Ishmael, J.E. Coibamide A, a natural lariat depsipeptide, inhibits VEGFA/VEGFR2 expression and suppresses tumor growth in glioblastoma xenografts. Investig. New Drugs 2016, 34, 24-40. [CrossRef]

105. Hau, A.M.; Greenwood, J.A.; Löhr, C.V.; Serrill, J.D.; Proteau, P.J.; Ganley, I.G.; McPhail, K.L.; Ishmael, J.E. Coibamide A induces mTOR-independent autophagy and cell death in human glioblastoma cells. PLoS ONE 2013, 8, e65250. [CrossRef]

106. Zhang, F.; Xu, X.; Li, T.; Liu, Z. Shellfish toxins targeting voltage-gated sodium channels. Mar. Drugs 2013, 11, 4698-4723. [CrossRef]

107. Davies-Coleman, M.T.; Dzeha, T.M.; Gray, C.A.; Hess, S.; Pannell, L.K.; Hendricks, D.T.; Arendse, C.E. Isolation of homodolastatin 16, a new cyclic depsipeptide from a Kenyancollection of Lyngbya majuscula. J. Nat. Prod. 2003, 66, 712-715. [CrossRef]

108. Taori, K.; Paul, V.J.; Luesch, H. Structure and activity of largazole, a potent antiproliferative agent from the Floridian marine cyanobacterium Symploca sp. J. Am. Chem. Soc. 2008, 130, 1806-1807. [CrossRef] [PubMed]

109. Liu, Y.; Salvador, L.A.; Byeon, S.; Ying, Y.; Kwan, J.C.; Law, B.K.; Hong, J.; Luesch, H. Anticolon cancer activity of largazole, a marine-derived tunable histone deacetylase inhibitor. J. Pharmacol. Exp. Ther. 2010, 335, 351-361. [CrossRef] [PubMed]

110. Kang, H.K.; Choi, M.C.; Seo, C.H.; Park, Y. Therapeutic properties and biological benefits of marine-derived anticancer peptides. Int. J. Mol. Sci. 2018, 19, 919. [CrossRef] [PubMed]

111. Han, B.N.; McPhail, K.L.; Gross, H.; Goeger, D.E.; Mooberry, S.L.; Gerwick, W.H. Isolation and structure of five lyngbyabellin derivatives from a Papua New Guinea collection of the marine cyanobacterium Lyngbya majuscula. Tetrahedron 2005, 61, 11723-11729. [CrossRef]

112. Choi, H.; Mevers, E.; Byrum, T.; Valeriote, F.A.; Gerwick, W.H. Lyngbyabellins K-N from Two Palmyra Atoll Collections of the marine cyanobacterium Moorea bouillonii. Eur. J. Org. Chem. 2012, 2012, 5141-5150. [CrossRef]

113. Pettit, G.R.; Hogan, F.; Xu, J.P.; Tan, R.; Nogawa, T.; Cichacz, Z.; Pettit, R.K.; Du, J.; Ye, Q.H.; Cragg, G.M.; et al. Antineoplastic agents. 536. New sources of naturally occurring cancer cellgrowth inhibitors from marine organisms, terrestrial plants, and microorganisms. J. Nat. Prod. 2008, 71, 438-444. [CrossRef]

114. Williams, P.G.; Yoshida, W.Y.; Moore, R.E.; Paul, V.J. Isolation and structure determination of obyanamide, a novel cytotoxic cyclic depsipeptide from the marine cyanobacterium Lyngbya confervoides. J. Nat. Prod. 2002, 65, 29-31. [CrossRef] 
115. Williams, P.G.; Yoshida, W.Y.; Quon, M.K.; Moore, R.E.; Paul, V.J. The structure of palau'amide, a potent cytotoxin from a species of the marine cyanobacterium Lyngbya. J. Nat. Prod. 2003, 66, 1545-1549. [CrossRef]

116. Taniguchi, M.; Nunnery, J.K.; Engene, N.; Esquenazi, E.; Byrum, T.; Dorrestein, P.C.; Gerwick, W.H. Palmyramide A, a cyclic depsipeptide from a Palmyra Atoll collection of the marine cyanobacterium Lyngbya majuscula. J. Nat. Prod. 2010, 73, 393-398. [CrossRef]

117. Montaser, R.; Paul, V.J.; Luesch, H. Pitipeptolides C-F, antimycobacterial cyclodepsipeptides from the marine cyanobacterium Lyngbya majuscula from Guam. Phytochemistry 2011, 72, 2068-2074. [CrossRef]

118. Luesch, H.; Pangilinan, R.; Yoshida, W.Y.; Moore, R.E.; Paul, V.J. Pitipeptolides A and B, new cyclodepsipeptides from the marine cyanobacterium Lyngbya majuscula. J. Nat. Prod. 2001, 64, 304-307. [CrossRef] [PubMed]

119. Montaser, R.; Abboud, K.A.; Paul, V.J.; Luesch, H. Pitiprolamide, a proline-rich dolastatin 16 analogue from the marine cyanobacterium Lyngbya majuscula from Guam. J. Nat. Prod. 2011, 74, 109-112. [CrossRef] [PubMed]

120. Williams, P.G.; Yoshida, W.Y.; Moore, R.E.; Paul, V.J. Tasipeptins A and B: New cytotoxicdepsipeptides from the marine cyanobacterium Symploca sp. J. Nat. Prod. 2003, 66, 620-624. [CrossRef] [PubMed]

121. Williams, P.G.; Yoshida, W.Y.; Quon, M.K.; Moore, R.E.; Paul, V.J. Ulongapeptin, a cytotoxiccyclicdepsipeptide from a Palauan marine cyanobacterium Lyngbya sp. J. Nat. Prod. 2003, 66, 651-654. [CrossRef] [PubMed]

122. Salvador, L.A.; Biggs, J.S.; Paul, V.J.; Luesch, H. Veraguamides A-G, cyclic hexadepsipeptides from a dolastatin 16-producing cyanobacterium Symploca cf. hydnoides from Guam. J. Nat. Prod. 2011, 74, 917-927. [CrossRef] [PubMed]

123. Mevers, E.; Liu, W.T.; Engene, N.; Mohimani, H.; Byrum, T.; Pevzner, P.A.; Dorrestein, P.C.; Spadafora, C.; Gerwick, W.H. Cytotoxic veraguamides, alkynyl bromide-containing cyclicdepsipeptides from the marine cyanobacterium cf. Oscillatoria margaritifera. J. Nat. Prod. 2011, 74, 928-936. [CrossRef]

124. Han, B.; Goeger, D.; Maier, C.S.; Gerwick, W.H. The wewakpeptins, cyclic depsipeptides from aPapua New Guinea collection of the marine cyanobacterium Lyngbya semiplena. J. Org. Chem. 2005, 70, 3133-3139. [CrossRef]

125. Golakoti, T.; Yoshida, W.Y.; Chaganty, S.; Moore, R.E. Isolation and structure determination of nostocyclopeptides A1 and A2 from the terrestrial cyanobacterium Nostoc sp. ATCC53789. J. Nat. Prod. 2001, 64, 54-59. [CrossRef]

126. Williams, P.G.; Yoshida, W.Y.; Moore, R.E.; Paul, V.J. Tasiamide, a cytotoxic peptide from the marine cyanobacterium Symploca sp. J Nat. Prod. 2002, 65, 1336-1339. [CrossRef]

127. Simmons, T.L.; McPhail, K.L.; Ortega-Barria, E.; Mooberry, S.L.; Gerwick, W.H. Belamide A, a new antimitotic tetrapeptide from a Panamanian marine cyanobacterium. Tetrahedron Lett. 2006, 47, 3387-3390. [CrossRef]

128. Teruya, T.; Sasaki, H.; Fukazawa, H.; Suenaga, K. Bisebromoamide, a potent cytotoxic peptide from the marine cyanobacterium Lyngbya sp.: Isolation, stereostructure, and biological activity. Org. Lett. 2009, 11, 5062-5065. [CrossRef] [PubMed]

129. Sasaki, H.; Teruya, T.; Fukazawa, H.; Suenaga, K. Revised structure and structure-activity relationship of bisebromoamide and structure of norbisebromoamide from the marine cyanobacterium Lyngbya sp. Tetrahedron 2011, 67, 990-994. [CrossRef]

130. Jimenez, J.I.; Scheuer, P.J. New lipopeptides from the Caribbean cyanobacterium Lyngbyamajuscula. J. Nat. Prod. 2001, 64, 200-203. [CrossRef] [PubMed]

131. Morgan, J.B.; Liu, Y.; Coothankandaswamy, V.; Mahdi, F.; Jekabsons, M.B.; Gerwick, W.H.; Valeriote, F.A.; Zhou, Y.D.; Nagle, D.G. Kalkitoxin inhibits angiogenesis, disrupts cellular hypoxic signaling, and blocks mitochondrial electron transport in tumor cells. Mar. Drugs 2015, 13, 1552-1568. [CrossRef]

132. Wrasidlo, W.; Mielgo, A.; Torres, V.A.; Barbero, S.; Stoletov, K.; Suyama, T.L.; Klemke, R.L.; Gerwick, W.H.; Carson, D.A.; Stupack, D.G. The marine lipopeptide somocystinamide a triggers apoptosis via caspase 8. Proc. Natl. Acad. Sci. USA 2008, 105, 2313-2318. [CrossRef]

133. Malloy, K.L.; Villa, F.A.; Engene, N.; Matainaho, T.; Gerwick, L.; Gerwick, W.H. Malyngamide 2, an oxidized lipopeptide with nitric oxide inhibiting activity from a Papua New Guinea marine cyanobacterium. J. Nat. Prod. 2011, 74, 95-98. [CrossRef]

134. Gross, H.; McPhail, K.L.; Goeger, D.E.; Valeriote, F.A.; Gerwick, W.H. Two cytotoxic stereo isomers of malyngamide C, 8-epi-malyngamide $\mathrm{C}$ and 8-O-acetyl-8-epi-malyngamide $\mathrm{C}$, from the marine cyanobacterium Lyngbya majuscula. Phytochemistry 2010, 71, 1729-1735. [CrossRef] 
135. Horgen, F.D.; Kazmierski, E.B.; Westenburg, H.E.; Yoshida, W.Y.; Scheuer, P.J. Malevamide D: Isolation and structure determination of an isodolastatin $\mathrm{H}$ analogue from the marine cyanobacterium Symploca hydnoides. J. Nat. Prod. 2002, 65, 487-491. [CrossRef]

136. Gutiérrez, M.; Tidgewell, K.; Capson, T.L.; Engene, N.; Almanza, A.; Schemies, J.; Jung, M.; Gerwick, W.H. Malyngolide Dimer, a bioactive symmetric cyclodepside from the Panamanian marine cyanobacterium Lyngbya majuscula. J. Nat. Prod. 2010, 73, 709-711. [CrossRef]

137. Foster, B.J.; Fortuna, M.; Wiegand, R.A.; Valeriote, F.A. Cryptophycin 1 cellular levels and effects in vitro using L1210 cells. Investig. New Drugs 1998, 16, 199-204. [CrossRef]

138. Kerksiek, K.; Mejillano, M.R.; Schwartz, R.E.; Georg, G.I.; Himes, R.H. Interaction of cryptophycin 1 with tubulin and microtubules. FEBS Lett. 1995, 377, 59-61. [CrossRef]

139. Weiss, C.; Figueras, E.; Borbely, A.N.; Sewald, N. Cryptophycins: Cytotoxic cyclodepsipeptides with potential for tumor targeting. J. Pept. Sci. 2017, 23, 514-531. [CrossRef]

140. Mooberry, S.L.; Busquets, L.; Tien, G. Induction of apoptosis by cryptophycin 1, a new antimicrotubule agent. Int. J. Cancer 1997, 73, 440-448. [CrossRef]

141. Field, J.J.; Kanakkanthara, A.; Miller, J.H. Microtubule-targeting agents are clinically successful due to both mitotic and interphase impairment of microtubule function. Bioorg. Med. Chem. 2014, 22, 5050-5059. [CrossRef] [PubMed]

142. Tripathi, A.; Puddick, J.; Prinsep, M.R.; Rottmann, M.; Tan, L.T. Lagunamides A and B: Cytotoxic and antimalarial cyclodepsipeptides from the marine cyanobacterium Lyngbya majuscula. J. Nat. Prod. 2010, 73, 1810-1814. [CrossRef]

143. Tripathi, A.; Puddick, J.; Prinsep, M.R.; Rottmann, M.; Chan, K.P.; Chen, D.Y.K.; Tan, L.T. Lagunamide C, a cytotoxic cyclodepsipeptide from the marine cyanobacterium Lyngbya majuscula. Phytochemistry 2011, 72, 2369-2375. [CrossRef]

144. Teruya, T.; Sasaki, H.; Kitamura, K.; Nakayama, T.; Suenaga, K. Biselyngbyaside, a macrolideglycoside from the marine cyanobacterium Lyngbya sp. Org. Lett. 2009, 11, 2421-2424. [CrossRef]

145. Morita, M.; Ohno, O.; Teruya, T.; Yamori, T.; Inuzuka, T.; Suenaga, K. Isolation and structures of biselyngbyasides B, C, and D from the marine cyanobacterium Lyngbya sp., and the biological activities of biselyngbyasides. Tetrahedron 2012, 68, 5984-5990. [CrossRef]

146. Watanabe, A.; Ohno, O.; Morita, M.; Inuzuka, T.; Suenaga, K. Structures and biological activities of novel biselyngbyaside analogs isolated from the marine cyanobacterium Lyngbya sp. Bull. Chem. Soc. Jpn. 2015, 88, 1256-1264. [CrossRef]

147. Luesch, H.; Yoshida, W.Y.; Harrigan, G.G.; Doom, J.P.; Moore, R.E.; Paul, V.J. Lyngbyaloside B, a new glycoside macrolide from a Palauan marine cyanobacterium, Lyngbya sp. J. Nat. Prod. 2002, 65, 1945-1948. [CrossRef]

148. Matthew, S.; Salvador, L.A.; Schupp, P.J.; Paul, V.J.; Luesch, H. Cytotoxic halogenated macrolides and modified peptides from the apratoxin-producing marine cyanobacterium Lyngbya bouillonii from Guam. J. Nat. Prod. 2010, 73, 1544-1552. [CrossRef] [PubMed]

149. Ohno, O.; Watanabe, A.; Morita, M.; Suenaga, K. Biselyngbyolide B, a novel ER stress-inducer isolated from the marine cyanobacterium Lyngbya sp. Chem. Lett. 2014, 43, 287-289. [CrossRef]

150. Iwasaki, A.; Teruya, T.; Suenaga, K. Isolation and structure of koshikalide, a 14-membered macrolide from the marine cyanobacterium Lyngbya sp. Tetrahedron Lett. 2010, 51, 959-960. [CrossRef]

151. Barchi, J.J.; Moore, R.E.; Patterson, G.M.L. Acutiphycin and 20,21-didehydroacutiphycin, new antineoplastic agents from the cyanophyte Oscillatoria acutissima. J. Am. Chem. Soc. 1984, 106, 8193-8197. [CrossRef]

152. Tan, L.T.; Márquez, B.L.; Gerwick, W.H. Lyngbouilloside, a novel glycosidic macrolide from the marine cyanobacterium Lyngbya bouillonii. J. Nat. Prod. 2002, 65, 925-928. [CrossRef] [PubMed]

153. Navarro, G.; Cummings, S.; Lee, J.; Moss, N.; Glukhov, E.; Valeriote, F.A.; Gerwick, L.; Gerwick, W.H. Isolation of polycavernoside D from a marine cyanobacterium. Environ. Sci. Technol. Lett. 2015, 2, 166-170. [CrossRef]

154. Patterson, G.M.L.; Carmeli, S. Biological effects of tolytoxin (6-hydroxy-7-O-methyl-scytophycin b), a potent bioactive metabolite from cyanobacteria. Arch. Microbiol. 1992, 157, 406-410. [CrossRef] 
155. Carmeli, S.; Moore, R.E.; Patterson, G.M.L. Tolytoxin and new scytophycins from three species of Scytonema. J. Nat. Prod. 1990, 53, 1533-1542. [CrossRef]

156. MacMillan, J.B.; Molinski, T.F. Caylobolide A, a unique 36-membered macrolactone from a Bahamian Lyngbyamajuscula. Org. Lett. 2002, 4, 1535-1538. [CrossRef]

157. Salvador, L.A.; Paul, V.J.; Luesch, H. Caylobolide B, a macrolactone from symplostatin1-producing marine cyanobacteria Phormidium sp., from Florida. J. Nat. Prod. 2010, 73, 1606-1609. [CrossRef]

158. Chang, T.T.; More, S.V.; Lu, I.H.; Hsu, J.C.; Chen, T.J.; Jen, Y.C.; Lu, C.K.; Li, W.S. Isomalyngamide A, A-1 and their analogs suppress cancer cell migration in vitro. Eur. J. Med. Chem. 2011, 46, 3810-3819. [CrossRef] [PubMed]

159. Edwards, D.J.; Marquez, B.L.; Nogle, L.M.; McPhail, K.; Goeger, D.E.; Roberts, M.A.; Gerwick, W.H. Structure and biosynthesis of the jamaicamides, new mixed polyketide-peptide neurotoxins from the marine cyanobacterium Lyngbyamajuscula. Chem. Biol. 2004, 11, 817-833. [CrossRef] [PubMed]

160. Stevenson, C.S.; Capper, E.A.; Roshak, A.K.; Marquez, B.; Grace, K.; Gerwick, W.H.; Jacobs, R.S.; Marshall, L.A. Scytonemin-A marine natural product inhibitor of kinases key in hyperproliferative inflammatory diseases. Inflam. Res. 2002, 51, 112-114. [CrossRef] [PubMed]

161. Stevenson, C.S.; Capper, E.A.; Roshak, A.K.; Marquez, B.; Eichman, C.; Jackson, J.R.; Mattern, M.; Gerwick, W.H.; Jacobs, R.S.; Marshall, L.A. The identification and characterization of the marine natural product scytonemin as a novel antiproliferative pharmacophore. J. Pharmacol. Exp. Ther. 2002, 303, 858-866. [CrossRef]

162. Banker, R.; Carmeli, S. Tenuecyclamides A-D, cyclic hexapeptides from the cyanobacterium Nostoc spongiaeforme var.tenue. J. Nat. Prod. 1998, 61, 1248-1251. [CrossRef]

163. Rickards, R.W.; Rothschild, J.M.; Willis, A.C.; de Chazal, N.M.; Kirk, J.; Kirk, K.; Saliba, K.J.; Smith, G.D. Calothrixins $\mathrm{A}$ and $\mathrm{B}$, novel pentacyclic metabolites from Calothrix cyanobacteria with potent activity against malaria parasites and human cancer cells. Tetrahedron 1999, 55, 13513-13520. [CrossRef]

164. Xu, S.; Nijampatnam, B.; Dutta, S.; Velu, S.E. Cyanobacterial metabolite calothrixins: Recent advances in synthesis and biological evaluation. Mar. Drugs 2016, 14, 17. [CrossRef]

165. Khan, Q.A.; Lu, J.; Hecht, S.M. Calothrixins, a new class of human DNA topoisomerase Ipoisons. J. Nat. Prod. 2009, 72, 438-442. [CrossRef]

166. Lavrentyev, P.J.; Franzè, G.; Pierson, J.J.; Stoecker, D.K. The effect of dissolved polyunsaturated aldehydes on microzooplankton growth rates in the Chesapeake Bay and Atlantic coastal waters. Mar. Drugs 2015, 13, 2834-2856. [CrossRef]

167. Miralto, A.; Barone, G.; Romano, G.; Poulet, S.A.; Ianora, A.; Russo, G.L.; Buttino, I.; Mazzarella, G.; Laabir, M.; Cabrini, M.; et al. The insidious effect of diatoms on copepod reproduction. Nature 1999, 402, 173-176. [CrossRef]

168. Sansone, C.; Braca, A.; Ercolesi, E.; Romano, G.; Palumbo, A.; Casotti, R.; Francone, M.; Ianora, A. Diatom-derived polyunsaturated aldehydes activate cell death in human cancer cell lines but not normal cells. PLoS ONE 2014, 9, e101220. [CrossRef] [PubMed]

169. Chanda, M.; Merghoub, N.; EL Arroussi, H. Microalgae polysaccharides: The new sustainable bioactive products for the development of plant bio-stimulants? World J. Microbiol. Biotechnol. 2019, 35, 177. [CrossRef] [PubMed]

170. Kusaikin, M.I.; Ermakova, S.P.; Shevchenko, N.M.; Isakov, V.V.; Gorshkov, A.G.; Vereshchagin, A.L.; Grachev, M.A.; Zvyagintseva, T.N. Structural characteristics and antitumor activity of a new chrysolaminaran from the diatom alga Synedra acus. Chem. Nat. Compd. 2010, 46, 1-4. [CrossRef]

171. Synytsya, A.; Kim, W.J.; Kim, S.M.; Pohl, R.; Synytsya, A.; Kvasnička, F.; Čopíková, J.; Park, Y.I. Structure and antitumour activity of fucoidan isolated from sporophyll of Korean brown seaweed Undaria pinnatifida. Carbohydr. Polym. 2010, 81, 41-48. [CrossRef]

172. Vishchuk, O.S.; Ermakova, S.P.; Zvyagintseva, T.N. Sulfated polysaccharides from brown seaweeds Saccharina japonica and Undaria pinnatifida: Isolation, structural characteristics, and antitumor activity. Carbohydr. Res. 2011, 346, 2769-2776. [CrossRef] [PubMed]

173. Ermakova, S.; Sokolova, R.; Kim, S.M.; Um, B.H.; Isakov, V.; Zvyagintseva, T. Fucoidans from brown seaweeds Sargassum hornery, Eclonia cava, Costaria costata: Structural characteristics and anticancer activity. Appl. Biochem. Biotechnol. 2011, 164, 841-850. [CrossRef] 
174. Alekseyenko, T.V.; Zhanayeva, S.Y.; Venediktova, A.A.; Zvyagintseva, T.N.; Kuznetsova, T.A.; Besednova, N.N.; Korolenko, T.A. Antitumor and antimetastatic activity of fucoidan, a sulfated polysaccharide isolated from the Okhotsk sea Fucus evanescens brown alga. Bull. Exp. Biol. Med. 2007, 143, 730-732. [CrossRef]

175. Zhang, Z.; Teruya, K.; Eto, H.; Shirahata, S. Induction of apoptosis by low-molecular-weight fucoidan through calcium-and caspase-dependent mitochondrial pathways in MDA-MB-231 breast cancer cells. Biosci. Biotechnol. Biochem. 2013, 77, 235-242. [CrossRef]

176. Lee, H.; Kim, J.S.; Kim, E. Fucoidan from seaweed Fucusvesiculosus inhibits migration and invasion of human lung cancer cell via PI3K-Akt-mTOR pathways. PLoS ONE 2012, 7, e50624. [CrossRef]

177. Lee, N.Y.; Ermakova, S.P.; Zvyagintseva, T.N.; Kang, K.W.; Dong, Z.; Choi, H.S. Inhibitory effects of fucoidan on activation of epidermal growth factor receptor and cell transformation in JB6 Cl41 cells. Food Chem. Toxicol. 2008, 46, 1793-1800. [CrossRef]

178. Koyanagi, S.; Tanigawa, N.; Nakagawa, H.; Soeda, S.; Shimeno, H. Oversulfation of fucoidan enhances its anti-angiogenic and antitumor activities. Biochem. Pharmacol. 2003, 65, 173-179. [CrossRef]

179. Nagamine, T.; Hayakawa, K.; Kusakabe, T.; Takada, H.; Nakazato, K.; Hisanaga, E.; Iha, M. Inhibitory effect of fucoidan on Huh7 hepatoma cells through downregulation of CXCL12. Nutr. Cancer 2009, 61, 340-347. [CrossRef]

180. Hsu, H.Y.; Lin, T.Y.; Hwang, P.A.; Chen, R.H.; Tsao, S.M.; Hsu, J. Fucoidan induces changes in the epithelial-mesenchymal transition and decreases metastasis by enhancing ubiquitin dependent TGF $\beta$ receptor degradation in breast cancer. Carcinogenesis 2013, 34, 874-884. [CrossRef]

181. Fedorov, S.N.; Ermakova, S.P.; Zvyagintseva, T.N.; Stonik, V.A. Anticancer and cancer preventive properties of marine polysaccharides: Some results and prospects. Mar. Drugs 2013, 11, 4876-4901. [CrossRef]

182. Menshova, R.V.; Ermakova, S.P.; Anastyuk, S.D.; Isakov, V.V.; Dubrovskaya, Y.V.; Kusaykin, M.I.; Um, B.H.; Zvyagintseva, T.N. Structure, enzymatic transformation and anticancer activity of branched high molecular weight laminaran from brown alga Eisenia bicyclis. Carbohydr. Polym. 2014, 99, 101-109. [CrossRef] [PubMed]

183. Bae, H.; Song, G.; Lee, J.Y.; Hong, T.; Chang, M.J.; Lim, W. Laminarin-derived from brown algae suppresses the growth of ovarian cancer cells via mitochondrial dysfunction and ER stress. Mar. Drugs 2020, 18, 152. [CrossRef]

184. Malyarenko, O.S.; Usoltseva, R.V.; Zvyagintseva, T.N.; Ermakova, S.P. Laminaran from brown alga Dictyota dichotoma and its sulfated derivative as radioprotectors and radiosensitizers in melanoma therapy. Carbohydr. Polym. 2019, 206, 539-547. [CrossRef] [PubMed]

185. Menshova, R.V.; Anastyuk, S.D.; Ermakova, S.P.; Shevchenko, N.M.; Isakov, V.I.; Zvyagintseva, T.N. Structure and anticancer activity in vitro of sulfated galactofucan from brown alga Alaria angusta. Carbohydr. Polym. 2015, 132, 118-125. [CrossRef]

186. Usoltseva, R.V.; Anastyuk, S.D.; Shevchenko, N.M.; Zvyagintseva, T.N.; Ermakova, S.P. The comparison of structure and anticancer activity in vitro of polysaccharides from brown algae Alaria marginata and A. angusta. Carbohydr. Polym. 2016, 153, 258-265. [CrossRef]

187. Usoltseva, R.V.; Shevchenko, N.M.; Malyarenko, O.S.; Ishina, I.A.; Ivannikova, S.I.; Ermakova, S.P. Structure and anticancer activity of native and modified polysaccharides from brown alga Dictyota dichotoma. Carbohydr. Polym. 2018, 180, 21-28. [CrossRef]

188. Usoltseva, R.V.; Anastyuk, S.D.; Shevchenko, N.M.; Surits, V.V.; Silchenko, A.S.; Isakov, V.V.; Zvyagintseva, T.N.; Thinh, P.D.; Ermakova, S.P. Polysaccharides from brown algae Sargassum duplicatum: The structure and anticancer activity In vitro. Carbohydr. Polym. 2017, 175, 547-556. [CrossRef] [PubMed]

189. Ji, C.F.; Ji, Y.B. Laminarin-induced apoptosis in human colon cancer LoVo cells. Oncol. Lett. 2014, 7, 1728-1732. [CrossRef] [PubMed]

190. Ji, Y.B.; Ji, C.F.; Zhang, H. Laminarin induces apoptosis of human colon cancer LoVocells through a mitochondrial pathway. Molecules 2012, 17, 9947-9960. [CrossRef] [PubMed]

191. Ji, C.F.; Ji, Y.B.; Meng, D.Y. Sulfated modification and anti-tumor activity of laminarin. Exp. Ther. Med. 2013, 6, 1259-1264. [CrossRef] [PubMed]

192. Park, H.K.; Kim, I.H.; Kim, J.; Nam, T.J. Induction of apoptosis and the regulation of ErbB signaling by laminarin in HT-29 human colon cancer cells. Int. J. Mol. Med. 2013, 32, 291-295. [CrossRef]

193. Henríquez, V.; Escobar, C.; Galarza, J.; Gimpel, J. Carotenoids in Microalgae. In Carotenoids in Nature; Stange, C., Ed.; Springer: Cham, Switzerland, 2016; Volume 79. 
194. De Jesus Raposo, M.F.; de Morais, R.M.S.C.; de Morais, A.M.M.B. Health applications of bioactive compounds from marine microalgae. Life Sci. 2013, 93, 479-486. [CrossRef]

195. Sathasivam, R.; Radhakrishnan, R.; Hashem, A.; Abd_Allah, E.F. Microalgae metabolites: A rich source for food and medicine. Saudi J. Biol. Sci. 2019, 26, 709-722. [CrossRef]

196. Pasquet, V.; Morisset, P.; Ihammouine, S.; Chepied, A.; Aumailley, L.; Berard, J.B.; Serive, B.; Kaas, R.; Lanneluc, I.; Thiery, V.; et al. Antiproliferative activity of violaxanthin isolated from bioguided fractionation of Dunaliella tertiolecta extracts. Mar. Drugs 2011, 9, 819-831. [CrossRef]

197. Molnár, J.; Engi, H.; Hohmann, J.; Molnar, P.; Deli, J.; Wesolowska, O.; Michalak, K.; Wang, Q. Reversal of multidrug resistance by natural substances from plants. Curr. Top. Med. Chem. 2010, 10, 1757-1768.

198. Gyémánt, N.; Tanaka, M.; Molnár, P.; Deli, J.; Mándoky, L.; Molnár, J. Reversal of multidrug resistance of cancer cells in vitro: Modification of drug resistance by selected carotenoids. Anticancer Res. 2006, 26, 367-374.

199. Saini, R.K.; Moon, S.H.; Gansukh, E.; Keum, Y.S. An efficient one-step scheme for the purification of major xanthophyll carotenoids from lettuce, and assessment of their comparative anticancer potential. Food Chem. 2018, 266, 56-65. [CrossRef] [PubMed]

200. Hosokawa, M.; Wanezaki, S.; Miyauchi, K.; Kurihara, H.; Kohno, H.; Kawabata, J.; Odashima, S.; Takahashi, K. Apoptosis-inducing effect of fucoxanthin on human leukemia cell line HL-60. Food Sci. Technol. Res. 1999, 5, 243-246. [CrossRef]

201. Kumar, S.R.; Hosokawa, M.; Miyashita, K. Fucoxanthin: A marine carotenoid exerting anti-cancer effects by affecting multiple mechanisms. Mar. Drugs 2013, 11, 5130-5147. [CrossRef]

202. Kotake-nara, E.; Kushiro, M.; Zhang, H.; Sugawara, T.; Miyashita, K.; Nagao, A. Carotenoids affect proliferation of human prostate cancer cells. J. Nutr. 2001, 131, 3303-3306. [CrossRef] [PubMed]

203. Kadekaru, T.; Toyama, H.; Yasumoto, T. Safety evaluation of Fucoxanthin purified from Undaria pinnatifida. J. Jpn. Soc. Food Sci. 2008, 55, 304-308. [CrossRef]

204. Ishikawa, C.; Tafuku, S.; Kadekaru, T.; Sawada, S.; Tomita, M.; Okudaira, T.; Nakazato, T.; Toda, T.; Uchihara, J.N.; Taira, N.; et al. Antiadult T-cell leukemia effects of brown algae fucoxanthin and its deacetylated product, fucoxanthinol. Int. J. Cancer 2008, 123, 2702-2712. [CrossRef]

205. Kong, Z.; Kao, N.; Hu, J.; Wu, C. Fucoxanthin richbrown algae extract decreases inflammation and attenuates colitis-associated colon cancer in mice. J. Food Nutr. Res. 2016, 4, 137-147.

206. Ganesan, P.; Noda, K.; Manabe, Y.; Ohkubo, T.; Tanaka, Y.; Maoka, T.; Sugawara, T.; Hirata, T. Siphonaxanthin, a marine algal carotenoids from green algae, effectively induces apoptosis in human leukemia (HL-60) cells. Biochim. Biophys. Acta 2011, 1810, 497-503. [CrossRef]

207. Ganesan, P.; Matsubara, K.; Ohkubo, T.; Tanaka, Y.; Noda, K.; Sugawara, T.; Hirata, T. Anti-angiogenic effect of siphonaxanthin from green alga, Codium fragile. Phytomedicine 2010, 17, 1140-1144. [CrossRef]

208. Ganesan, P.; Matsubara, K.; Sugawara, T.; Hirata, T. Marine algal carotenoids inhibit angiogenesis by down-regulating FGF-2-mediated intracellular signals in vascular endothelial cells. Mol. Cell Biochem. 2013, 380, 1-9. [CrossRef]

209. Sugawara, T.; Ganesan, P.; Li, Z.; Manabe, Y.; Hirata, T. Siphonaxanthin, a green algal carotenoid, as a novel functional compound. Mar. Drugs 2014, 12, 3660-3668. [CrossRef] [PubMed]

210. Di Lena, G.; Casini, I.; Lucarini, M.; Lombardi-Boccia, G. Carotenoid profiling of five microalgae species from large-scale production. Food Res. Int. 2019, 120, 810-818. [CrossRef] [PubMed]

211. Grudzinski, W.; Piet, M.; Luchowski, R.; Reszczynska, E.; Welc, R.; Paduch, R.; Gruszecki, W.I. Different molecular organization of two carotenoids, lutein and zeaxanthin, in human colon epithelial cells and colon adenocarcinoma cells. Spectrochim. Acta Part A Mol. Biomol. Spectrosc. 2018, 188, 57-63. [CrossRef] [PubMed]

212. Galasso, C.; Gentile, A.; Orefice, I.; Ianora, A.; Bruno, A.; Noonan, D.M.; Sansone, C.; Albini, A.; Brunet, C. Microalgal derivatives as potential nutraceutical and food supplements for human health: A focus on cancer prevention and interception. Nutrients 2019, 11, 1226. [CrossRef]

213. Kim, Y.S.; Li, X.F.; Kang, K.H.; Ryu, B.; Kim, S.K. Stigmasterol isolated from marine microalgae Navicula incerta induces apoptosis in human hepatoma HepG2 cells. BMB Rep. 2014, 47, 433-438. [CrossRef]

214. Hussein, H.A.; Abdullah, M.A. Anticancer compounds derived from marine diatoms. Mar. Drugs 2020, 18, 356. [CrossRef] [PubMed] 
215. Samarakoon, K.W.; Ko, J.Y.; Lee, J.H.; Kwon, O.N.; Kim, S.W.; Jeon, Y.J. Apoptotic anticancer activity of a novel fatty alcohol ester isolated from cultured marine diatom, Phaeodactylum tricornutum. J. Funct. Foods 2014, 6, 231-240. [CrossRef]

216. Maoka, T.; Tsushima, M.; Nishino, H. Isolation and characterization of dinochrome A and B, anti-carcinogenic active carotenoids from the fresh water red tide Peridinium bipes. Chem. Pharm. Bull. 2002, 50, 1630-1633. [CrossRef]

217. Huang, X.; Li, M.; Xu, B.; Zhu, X.; Deng, Z.; Lin, W. Proteasome and NF-kB inhibiting phaeophytins from the green alga Cladophora fascicularis. Molecules 2007, 12, 582-592. [CrossRef]

218. Williams, D.E.; Sturgeon, C.M.; Roberge, M.; Andersen, R.J. Nigricanosides A and B, antimitotic glycolipids isolated from the green alga Avrainvillea nigricans collected in Dominica. J. Am. Chem. Soc. 2007, 129, 5822-5823. [CrossRef]

(C) 2020 by the authors. Licensee MDPI, Basel, Switzerland. This article is an open access article distributed under the terms and conditions of the Creative Commons Attribution (CC BY) license (http://creativecommons.org/licenses/by/4.0/). 